Article

\title{
Small AntiMicrobial Peptide with In Vivo Activity Against Sepsis
}

\author{
Héloise Boullet ${ }^{1}$, Fayçal Bentot ${ }^{1}$, Arnaud Hequet ${ }^{2}$, Carine Ganem-Elbaz ${ }^{2}$, Chérine Bechara ${ }^{1}$, \\ Emeline Pacreau ${ }^{3}$, Pierre Launay ${ }^{3}{ }^{(}$, Sandrine Sagan ${ }^{1}{ }^{1}$, Claude Jolivalt ${ }^{2}$, Claire Lacombe ${ }^{1,4}$, \\ Roba Moumné ${ }^{1}$ and Philippe Karoyan $1,5,6, *$ (D)
}

1 Sorbonne Université, École Normale Supérieure, PSL University, CNRS, Laboratoire des Biomolécules, LBM, 75005 Paris, France; hel.boullet@gmail.com (H.B.); faycal.bentot@gmail.com (F.B.);

cherine.bechara@umontpellier.fr (C.B.); sandrine.sagan@sorbonne-universite.fr (S.S.);

claire.lacombe.s@gmail.com (C.L.); roba.moumne@sorbonne-universite.fr (R.M.)

2 Laboratoire Charles Friedel, UMR7223, École Nationale Supérieure de Chimie de Paris, 11 rue Pierre et Marie Curie, 75005 Paris, France; arhequet@gmail.com (A.H.); carine.ganem-elbaz@curie.fr (C.G.-E.); claude.jolivalt@sorbonne-universite.fr (C.J.)

3 Inserm U1149, Labex Inflammex, Bichat Medical School, 75005 Paris, France; emeline.pacreau@inserm.fr (E.P.); pierre.launay@inserm.fr (P.L.)

4 Faculté des Sciences et Technologie, Univ Paris Est-Créteil Val de Marne, 94000 Créteil, France

5 Kayvisa, AG, Industriestrasse, 44, $6300 \mathrm{Zug}$, Switzerland

6 Kaybiotix, GmbH, Zugerstrasse 32, 6340 Baar, Switzerland

* Correspondence: philippe.karoyan@sorbonne-universite.fr; Tel.: +33-44274469

Academic Editors: Henry Mosberg, Tomi Sawyer and Carrie Haskell-Luevano Received: 30 March 2019; Accepted: 17 April 2019; Published: 1 May 2019

\begin{abstract}
Antimicrobial peptides (AMPs) are considered as potential therapeutic sources of future antibiotics because of their broad-spectrum activities and alternative mechanisms of action compared to conventional antibiotics. Although AMPs present considerable advantages over conventional antibiotics, their clinical and commercial development still have some limitations, because of their potential toxicity, susceptibility to proteases, and high cost of production. To overcome these drawbacks, the use of peptides mimics is anticipated to avoid the proteolysis, while the identification of minimalist peptide sequences retaining antimicrobial activities could bring a solution for the cost issue. We describe here new polycationic $\beta$-amino acids combining these two properties, that we used to design small dipeptides that appeared to be active against Gram-positive and Gram-negative bacteria, selective against prokaryotic versus mammalian cells, and highly stable in human plasma. Moreover, the in vivo data activity obtained in septic mice reveals that the bacterial killing effect allows the control of the infection and increases the survival rate of cecal ligature and puncture (CLP)-treated mice.
\end{abstract}

Keywords: polycationic $\beta$-amino acids; small antimicrobial peptides; sepsis

\section{Introduction}

If the discovery of antibiotics is one of the major medical breakthroughs of the last century, bacterial resistance has consecutively emerged as a main medical problem [1]. Indeed, the number of infections caused by bacterial strains resistant to conventional antibiotics is rising and despite the success of genomics in identifying new essential bacterial genes, there is a lack of sustainable leads in antibacterial drug discovery to address these increasing multidrug-resistant (MDR) microorganisms [2]. The search for novel antibiotics with original mechanism of action is of particular interest. In this context, Antimicrobial Peptides (AMPs) are considered as an inspirational source for future antibiotics $[3,4]$. Indeed, although their mechanism of action is still a matter of basic research, it is generally admitted 
that most of them act directly on the bacterial membrane (membranolytic) and thus likely escape the mechanisms of bacterial resistance [5]. Although AMPs present considerable advantages as new generation antibiotics, their development as therapeutics is still limited by peptide drawbacks, such as their potential toxicity, susceptibility to proteases, and high manufacturing costs. To overcome these limitations, different strategies have been investigated: The use of unnatural amino acids is anticipated to enhance their proteolytic stability [6], while the identification of small antimicrobial peptides (SAMP) [7] with sequence length ranging from 2 to 10 amino acids is suggested as an interesting solution for the cost issue. Small non peptidic scaffolds that mimic their mechanism of action have also been recently reported $[8,9]$.

AMPs are usually amphipathic sequences and contain several basic residues, i.e., lysine and arginine, as well as a hydrophobic core, which are critical for their activity. The lysine and arginine side-chains are positively charged at physiological $\mathrm{pH}$ and direct these amphiphilic peptides to the anionic surface of bacterial cell membranes, allowing the interaction of hydrophobic residues with the hydrocarbon core of the lipid bilayer. In the aim of identifying minimalist sequence that act like AMP, the use of building blocks bearing multi-cationic groups at physiological $\mathrm{pH}$ could be an interesting strategy. Aussedat et al. have previously reported a small achiral tetravalent template, the " $\alpha$-bis-arginine", which contains twice the side chain of arginine, and thus increases the charge density of the peptide sequence [10]. Although a promising tool, the steric hindrance of the $\alpha$-bis-arginine quaternary center adjacent to the amine and acid functions rendered its peptidic coupling difficult in SPPS or LPPS (Solid and Liquid Phase Peptide Syntheses). The use of additional non-bulky spacers such as glycine or $\beta$-alanine residues was necessary to incorporate this $\alpha$-amino acid into peptides. Consequently, even if the number of charged residues could be reduced through the use of this multi-charged amino acid, the overall size of the peptide cannot be shortened. We report here new residues that combine the advantage of the $\alpha$-bis-arginine but can be easily oligomerized leading to small peptides with potential therapeutic applications: the $\beta^{2,2}$ - and $\beta^{3,3}$-homo-bis-arginine derivatives, homologated respectively on the carboxylate or on the amino side (Figure 1). We postulated that the additional methylene group of $\beta$-amino acids (in green in Figure 1) would limit the steric hindrance around the quaternary center (in red in Figure 1) and facilitate their incorporation into peptides. Oligomers of $\beta$-amino acids represent one of the most studied class of foldamers. Since the pioneer work of Seebach et al. [11], only few studies dealing with $\beta^{2,2}$ - or $\beta^{3,3}$-amino acids have been reported in the literature [12-14]. Noticeably, while the use of lipophilic $\beta^{2,2}$-amino acids has proven valuable for the design of both antibacterial [15] and anticancer peptides [16,17], geminally disubstituted residues with basic side-chains have not been reported so far.

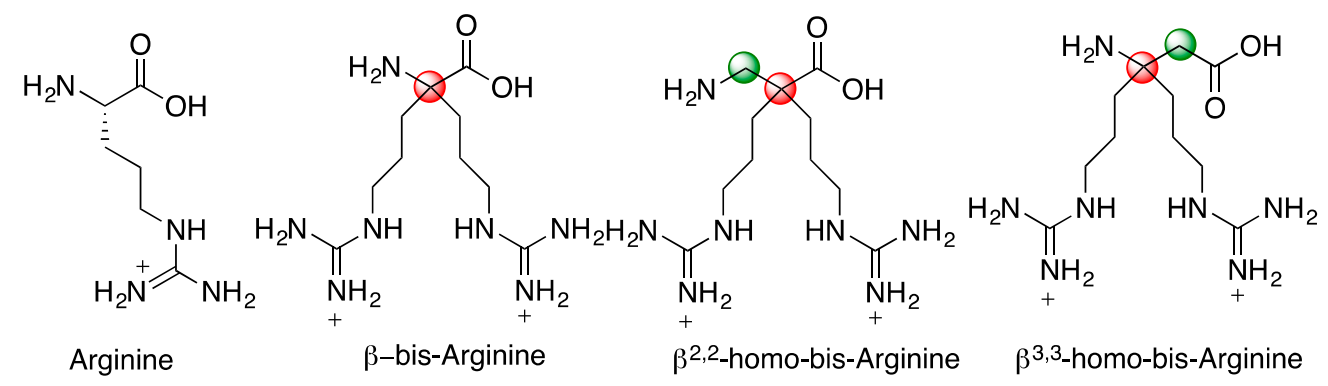

Figure 1. Bis-disubstituted-arginine analogues.

We report here the syntheses of $\beta^{2,2}$ - and $\beta^{3,3}$-bis-homo-ornithine/arginine, and their use to design small cationic peptides. These peptides were evaluated as antimicrobial agents against Gram-positive and Gram-negative bacteria, and their cytotoxicity against eukaryotic cells as well as their stability in human serum were assessed. This work led to the selection of a dipeptide as a lead for in vivo studies for the treatment of sepsis in mice. Remarkably, the in vivo results revealed that the bacterial killing effect of this cationic dipeptide allows the control of the infection and sustains the immune response in the remediation of sepsis. 


\section{Results}

\subsection{Amino Acids Syntheses}

The $\beta^{2,2}$ - (1 and 2 ) and $\beta^{3,3}$-bis-homo-ornithine derivatives (3) required for the synthesis of the cationic dipeptides were prepared suitably protected for dipeptide syntheses (Figure 2).

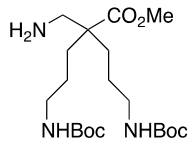

1

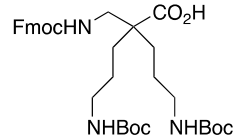

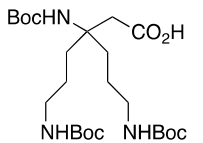

Figure 2. $\beta^{2,2}$ - and $\beta^{3,3}$-bis-homo-ornithine derivatives suitably protected for peptide syntheses.

The $\beta^{2,2}$-homo-bis-ornithine methyl ester 1 and the Fmoc-protected $\beta^{2,2}$-homo-bis-ornithine 2 were both obtained from methyl cyanoacetate, respectively, in three and four steps (Scheme 1).

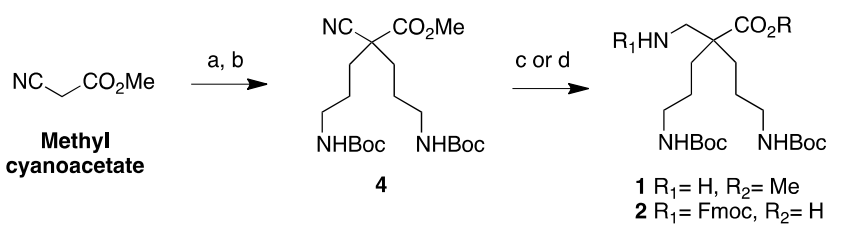

Scheme 1. $\beta^{2,2}$-homo-bis-ornithine derivatives 1 and 2 syntheses. (a) $\mathrm{CH}_{2}=\mathrm{CHCN}, \mathrm{LiClO}_{4}, \mathrm{NEt}_{3}(93 \%$ );

(b) $\mathrm{H}_{2}, \mathrm{PtO}_{2}, \mathrm{Boc}_{2} \mathrm{O}, \mathrm{MeOH}(21 \%)$; (c) $\mathrm{H}_{2}, \mathrm{Ni}$ Raney, $\mathrm{MeOH}(\mathbf{1}, 98 \%)$; (d) $1 / \mathrm{H}_{2}, \mathrm{Ni}$ Raney, $\mathrm{NaOH}(2 \mathrm{M})$,

$\mathrm{THF} / \mathrm{EtOH} 2 / \mathrm{FmocOSu}, \mathrm{K}_{2} \mathrm{CO}_{3}, \mathrm{H}_{2} \mathrm{O}$, dioxane (2, 72\%).

The double Michael addition on acrylonitrile [18] followed by selective reduction of the nitrile groups in $\gamma$-position over $\mathrm{PtO}_{2}$ and simultaneous Boc-protection of the resulting amines gave the key intermediate 4 with moderate yields (21\%). Improvement of this yield could be realized using a large excess of Raney Nickel (50\% Yields) but was not relevant for safety reason and large-scale synthesis. Reduction of the $\alpha$-nitrile by Raney nickel catalyzed hydrogenation in methanol led to the amine-free, acid-protected $\beta^{2,2}$-homo-bis-ornithine derivative 1 that could be directly used in peptide coupling on the amine side. The $N$-protected, acid-free counterpart 2 was obtained when the reduction of 4 was performed in the presence of sodium hydroxide, followed by a Fmoc-protection. Boc-protected $\beta^{3,3}$-homo-bis-ornithine derivative 3 was obtained starting from tert-butyl benzyl malonate (Scheme 2).

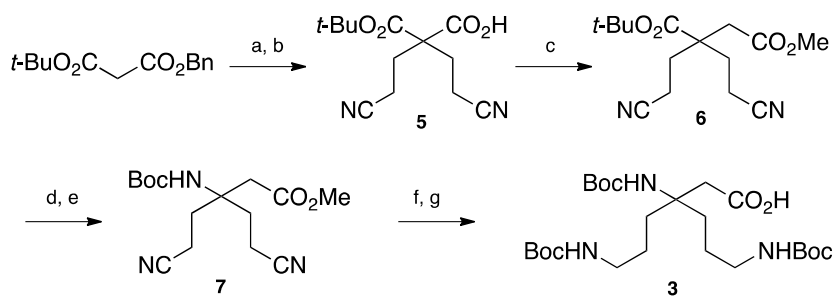

Scheme 2. $\beta^{3,3}$-homo-bis-ornithine derivatives 3 synthesis. (a) $\mathrm{CH}_{2}=\mathrm{CHCN} \mathrm{LiClO}_{4}, \mathrm{NEt}_{3}(88 \%$ ); (b) $\mathrm{NH}_{4}{ }^{+} \mathrm{HCO}_{2}{ }^{-}, \mathrm{Pd} / \mathrm{C}, \mathrm{MeOH}$ (83\%); (c) 1/1-chloro- $N, N$,2-trimethyl-1-propenylamine, DCM 2/TMSCHN 2 , DIEA, CH3CN 3/Ag $2 \mathrm{O}, \mathrm{DMF} / \mathrm{MeOH}$, reflux (21\%); (d) TFA/TIS/DCM (86\%); (e) $1 / \mathrm{ClCO}_{2} \mathrm{Et}, \mathrm{NEt}_{3}$, acetone, $0{ }^{\circ} \mathrm{C} 2 / \mathrm{NaN}_{3}, \mathrm{H}_{2} \mathrm{O}$ 3/toluene, tert-BuOH, reflux (35\%); (f) $1 / \mathrm{PtO}_{2}, \mathrm{H}_{2}, \mathrm{CHCl}_{3} / \mathrm{MeOH} 2 / \mathrm{K}_{2} \mathrm{CO}_{3}$, $\mathrm{Boc}_{2} \mathrm{O}, \mathrm{H}_{2} \mathrm{O} / \mathrm{THF}(62 \%)$; (g) $\mathrm{LiOH}, \mathrm{CH}_{3} \mathrm{CN} / \mathrm{H}_{2} \mathrm{O}$ (98\%).

The double Michael addition on acrylonitrile followed by selective benzyl ester hydrogenolysis using ammonium formate on palladium charcoal gave compound 5. Arndt-Eistert homologation catalyzed by silver oxide led to compound 6 with $21 \%$ yields over the three steps. After deprotection of the $t$-Bu ester, the acid group was converted to Boc-protected amine via a Curtius rearrangement. Reduction of the nitrile groups in $\gamma$-position was then achieved by platinum oxide catalyzed 
hydrogenation. Finally, protection of the amino groups as Boc-carbamate and saponification of the methyl ester gave access to compound 3 readily usable for peptide coupling on the acid side.

\subsection{Peptides Design and Syntheses}

With these compounds in hand, we have designed antimicrobial dipeptides inspired by the work of Svendsen and co-workers, who defined the minimal set of functional motifs required to develop short AMPs as two cationic charges and two bulky hydrophobic aromatic units [19,20]. Based on this minimalist pharmacophore model, they indeed developed promising antibacterial tripeptides composed of a central 2,5,7-tri-tertbutyltryptophan (Tbt) flanked by two arginine residues. These peptides have anti-infectious properties and have reached phase-II clinical studies [21-23]. Several other groups have then reported the successful implementation of this pharmacophore model [24-26]. Starting from the peptide reported by Svendsen et al., the two arginine residues were replaced by one dicationic amino acid, leading to dipeptides 8-13 containing a tryptophan derivative (Trp or Tbt) and a dicationic $\beta^{2,2}$ - or $\beta^{3,3}$-amino acid: Trp- $\beta^{2,2}-h$-bis-Orn-OMe (8), Tbt- $\beta^{2,2}-h$-bis-Orn-OMe (9), Gdm-Trp- $\beta^{2,2}-h$-bis-Arg-OMe (10), Tbt- $\beta^{2,2}-h$-bis-Arg-OMe (11), Gdm-Tbt- $\beta^{2,2}-h$-bis-Arg-OMe (12), and $\beta^{3,3}$-h-bis-Arg-Tbt-OMe (13) (Figure 3). In order to investigate the effect of the positive charge segregation on the antimicrobial activity of the compound [27], we also synthesized peptide 14 (Gdm- $\beta^{2,2}-h$-bis-Arg-Tbt-OMe), in which the sequence of dipeptide $\mathbf{1 1}$ is reversed.

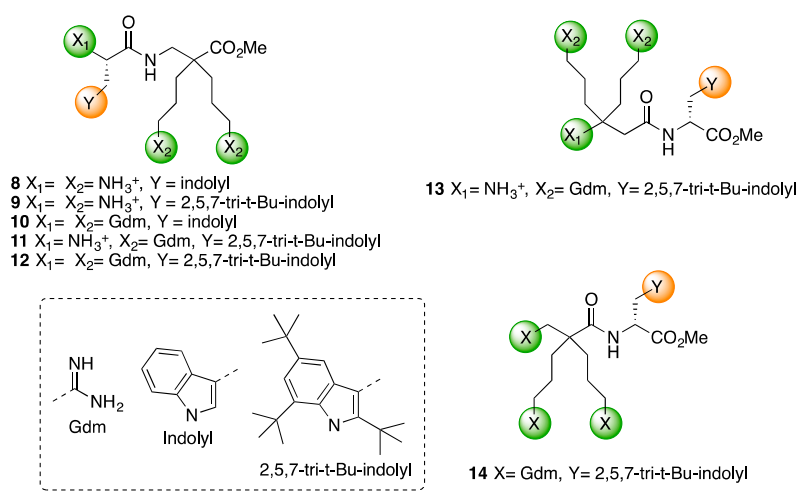

Figure 3. Structure of polycationic dipeptides 8-14.

To evaluate the ease of coupling of these new beta derivatives against their alpha counterparts, both liquid and solid phase peptide syntheses were tested. Compounds 8-12 were prepared by coupling the corresponding tryptophan derivatives (Boc-Trp-OH or Fmoc-Tbt-OH) with the $\beta^{2,2}-h$-bisornithine methyl ester $\mathbf{1}$ in solution, using HBTU as a coupling agent, in the presence of DIEA, in DMF (Scheme 3).

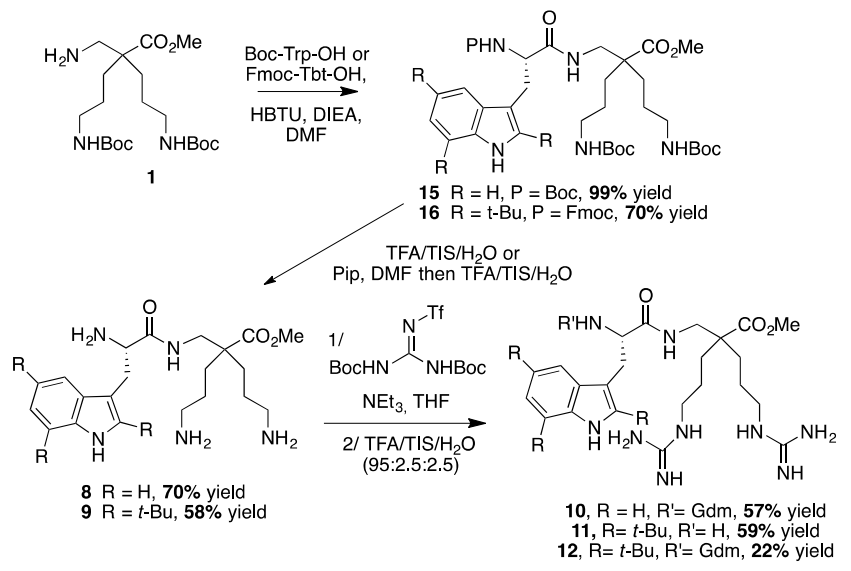

Scheme 3. Synthesis of peptides $\mathbf{8}-\mathbf{1 2}$ by LPPS. 
The fully protected dipeptides $\mathbf{1 5}$ and $\mathbf{1 6}$ were obtained from Boc-Trp-OH and Fmoc-Tbt-OH, in respectively $99 \%$ and $70 \%$ yields. Noticeably, the $\alpha$-bis-ornithine derivative coupling failed in the same conditions. Deprotection of the amines gave access to the corresponding $\beta^{2,2}-h$-bis-Ornitine derivatives $\mathbf{8}$ and 9. Introduction of the guanidinium group $(\mathrm{Gdm})$ on these two compounds followed by Boc-deprotection using a TFA cocktail led to the $\beta^{2,2}-h$-bis-Arg derivatives. While a unique tri-guanylated compound was obtained for the tryptophan containing dipeptide 10, two products were isolated for the Tbt-derived compound in respectively $59 \%$ and $22 \%$ yields: One with the guanidinium groups on the side chains of the amino acids (11) only, and one with an additional guanidinium group on the $\beta$-amine (12).

The synthesis of peptides $\mathbf{1 3}$ and $\mathbf{1 4}$ was achieved by SPPS, starting from a HMBA resin-bound Tbt (Scheme 4).

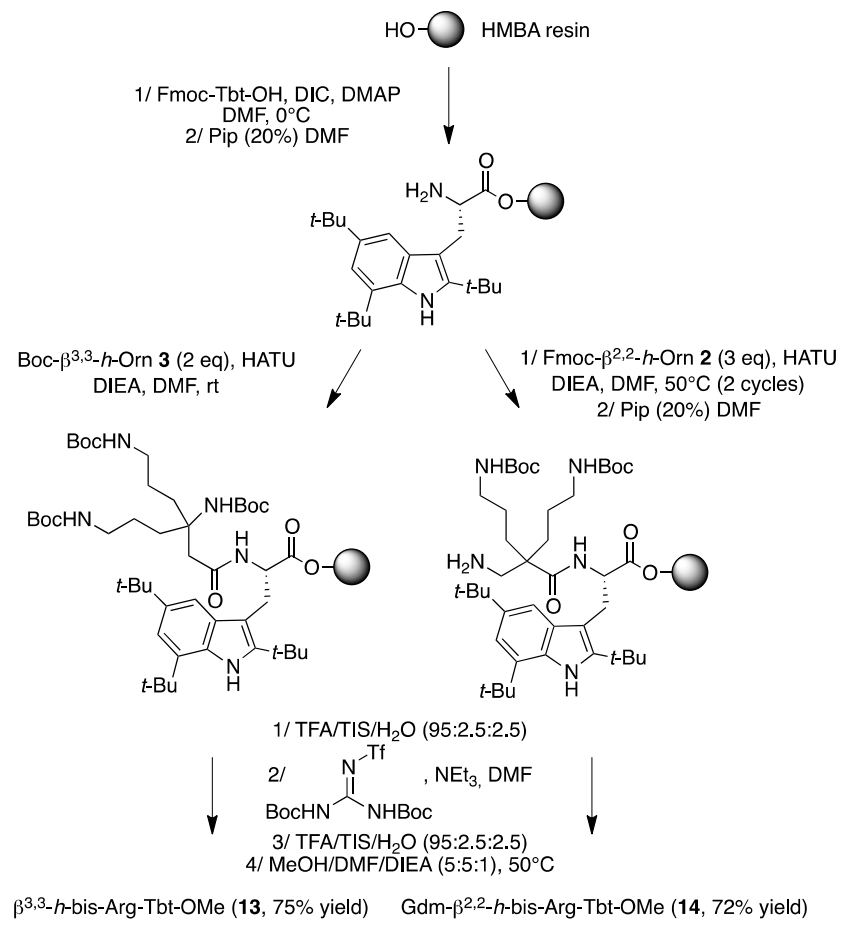

Scheme 4. Synthesis of peptides 13 and 14 by SPPS.

In both cases coupling of Fmoc- $\beta^{2,2}-h$-bis-Orn-OH 2 and Boc- $\beta^{3,3}-h$-bis-Orn-OH 3 was achieved through HATU activation, in the presence of DIEA, in DMF. However, because of the steric hindrance of its carboxyl group, heating at $50{ }^{\circ} \mathrm{C}$ as well as a second coupling round were necessary to ensure the complete conversion of $\mathbf{2}$. As anticipated, the improved reactivity of the carboxyl group of this residue with its $\beta^{3,3}$-counterpart confirms that an additional methylene near the quaternary center is an effective strategy to facilitate the incorporation of the bis-ornithine derivative into a peptide sequence. After piperidine-mediated Fmoc-deprotection and/or removal of the acid labile protective groups by treatment with a trifluoroacetic acid (TFA)-triisopropylsilane (TIS)- $\mathrm{H}_{2} \mathrm{O}$ cocktail, introduction of the guanidine moiety was performed using an excess of 1,3-di-Boc-2-(trifluoromethylsulfonyl)guanidine in DMF, in the presence of triethylamine, followed by removal of the Boc-protective groups. Cleavage of peptides $\mathbf{1 3}$ and $\mathbf{1 4}$ from the resin was achieved by treatment with methanol in the presence of DIEA and DMF giving direct access to the methyl ester protected dipeptide. Compound $\mathbf{1 4}$ was obtained as a tri-guanylated derivative. On the contrary, as expected, the steric hindrance of the quaternary $\beta$-amino group of compound 13 prevents any reaction on the backbone amine. In addition, NMR analysis confirmed that peptide $\mathbf{1 3}$ was only guanylated on the amine side-chains. Several studies have reported that the N-terminal capping of cationic peptides with a fatty acid moiety enhances their antimicrobial activity $[28,29]$. Thus, in order to further improve the potency of $\mathbf{1 1}$, an additional 
hydrophobic group was incorporated, first on the N-terminal end of the sequence. (Figure 4, peptides 17-19).

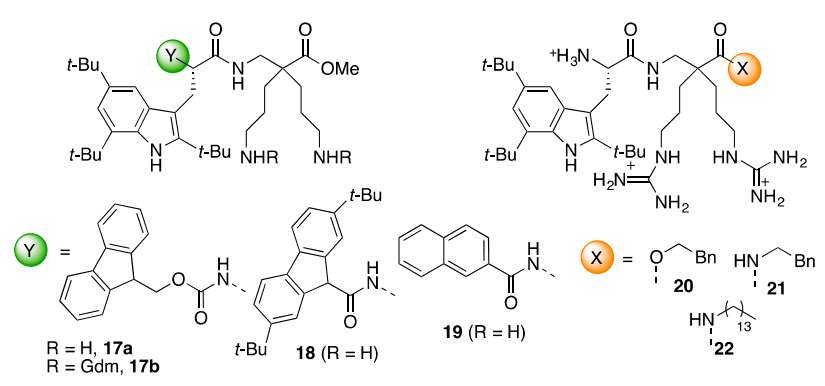

Figure 4. Pharmacomodulation of antimicrobial peptide.

We also evaluated whether such a capping effect could be also observed in this series of peptides. The biological activities of Fmoc-protected derivatives Fmoc-Tbt- $\beta^{2,2}$ - $h$-bis-Orn-OMe 17a and Fmoc-Tbt- $\beta^{2,2}-h$-bis-Arg-OMe 17b were synthesized in addition to the ones of the two compounds 18 and 19 capped through a more robust amide bond at their N-terminal end. All peptides were purified to $>95 \%$ homogeneity by preparative RP-HPLC and the mass of each purified peptide was checked by MALDI MS (see Supporting Information).

Finally, in order to study the influence Trp- and Tbt derivatives, we compared the retention time in RP-HPLC of selected peptides (Figure 5).

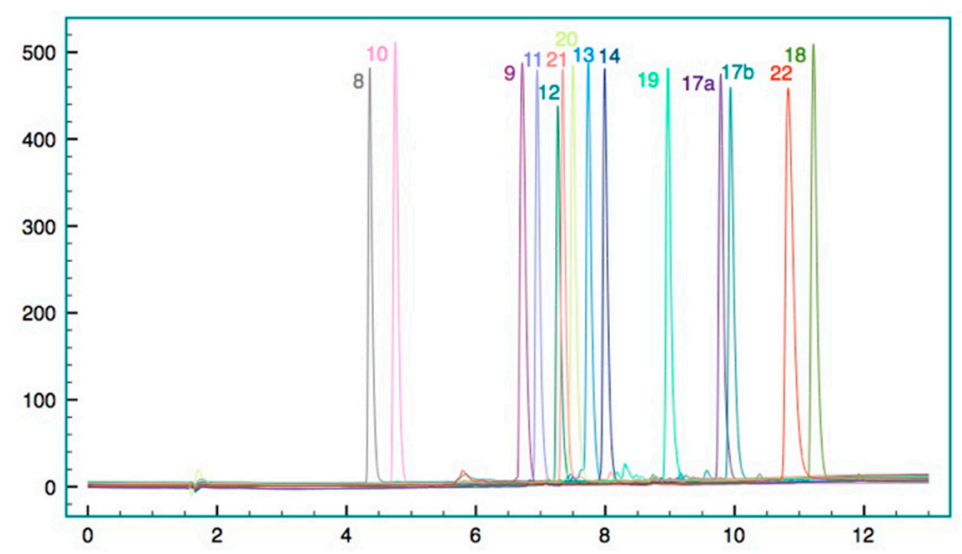

Figure 5. Superimposition of the analytical HPLC of peptides 8 to 22 on a C18 column, using as eluting gradient $\mathrm{H}_{2} \mathrm{O}$ containing $0.1 \%$ TFA with $5 \%$ to $100 \%$ with $\mathrm{MeCN}$ containing $0.1 \%$ TFA.

\subsection{Biological Activities}

\subsubsection{Antimicrobial, Hemolytic, and Cytotoxic Activities and Serum Stability}

The antibacterial activities of the peptides were then investigated in the conditions reported by Svendsen, by determining the Minimal Inhibitory Concentration (MIC, $\mu \mathrm{g} / \mathrm{mL})$ on six strains of bacteria; three Gram-positive, Staphylococcus aureus ATCC25923, Enterococcus faecalis ATCC29212, and the methicillin resistant Staphylococcus aureus SA-1199B, and three Gram-negative, Escherichia coli ATCC25922, Pseudomonas aeruginosa ATCC27853, and Acinetobacter baumannii ATCC19606 [14] (Table 1). The tri-peptide Arg-Tbt-Arg- $\mathrm{NH}_{2}$ reported by Svendsen (called here peptide A), and the dipeptide Tbt-Arg-OMe (called here peptide B), were used as positive controls of our experimental conditions.

The hemolytic and cytotoxic activities against human cells of all active peptides were assessed (Table 1, Figures 6 and 7 and Supporting Information). 
Table 1. Biological activity, hemolytic activities, and cytotoxicity.

\begin{tabular}{|c|c|c|c|c|c|c|c|c|c|c|}
\hline & \multicolumn{6}{|c|}{ MIC in $\mu \mathrm{g} / \mathrm{mL}(\mu \mathrm{M})$} & \multicolumn{2}{|c|}{ \% Hemolysis } & \multicolumn{2}{|c|}{$\%$ Cytotoxicity } \\
\hline & $\begin{array}{c}\text { S. aureus } \\
\text { ATCC25923 }\end{array}$ & $\begin{array}{c}\text { S. aureus } \\
\text { 1199B }\end{array}$ & $\begin{array}{c}\text { E. faecalis } \\
\text { ATCC29212 }\end{array}$ & $\begin{array}{c}\text { E. coli } \\
\text { ATCC25922 }\end{array}$ & $\begin{array}{l}\text { P. aeruginosa } \\
\text { ATCC } 27853\end{array}$ & $\begin{array}{l}\text { A. baumannii } \\
\text { ATCC19606 }\end{array}$ & $10 \mu \mathrm{M}$ & $50 \mu \mathrm{M}$ & $10 \mu \mathrm{M}$ & $50 \mu \mathrm{M}$ \\
\hline $\mathrm{A}$ & $8(12)$ & $16(23)$ & $32(47)$ & $>64(>93)$ & $32(47)$ & $>64(>93)$ & ND & ND & ND & ND \\
\hline $\mathrm{B}$ & $8(15)$ & $16(30)$ & $16(30)$ & $>64(>120)$ & $>64(>120)$ & $>64(>120)$ & ND & ND & ND & ND \\
\hline 8 & $>64(>16)$ & $>64(16)$ & $>64(>16)$ & $>64(>16)$ & $>64(>16)$ & $>64(>16)$ & ND & ND & ND & ND \\
\hline 9 & $8(14)$ & $>64(112)$ & $>64(112)$ & $>64(112)$ & $>64(112)$ & $>64(112)$ & ND & ND & ND & ND \\
\hline 10 & $64(120)$ & $>64(120)$ & $>64(120)$ & $>64(120)$ & $>64(120)$ & $>64(120)$ & ND & ND & ND & ND \\
\hline 11 & $2(3)$ & $16(24)$ & $16(24)$ & $8(12)$ & $4(6)$ & $64(97)$ & $<1$ & 20 & $<1$ & $<1$ \\
\hline 12 & $2(3)$ & $8(12)$ & $8(12)$ & $2(3)$ & $2(3)$ & $64(92)$ & $<1$ & 30 & $<1$ & $<1$ \\
\hline 13 & $2(3)$ & $2(3)$ & $4(6)$ & $8(12)$ & $8(12)$ & $>64(97)$ & $<1$ & 10 & $<1$ & $<1$ \\
\hline 14 & $8(12)$ & $8(12)$ & $8(12)$ & $32(46)$ & $>64(92)$ & $64(92)$ & $<1$ & 20 & $<1$ & $<1$ \\
\hline $17 \mathrm{a}$ & $4(5)$ & $2(2.5)$ & $2(2.5)$ & $>64(80)$ & $>64(80)$ & $4(5)$ & 80 & ND & 45 & 85 \\
\hline $17 \mathrm{~b}$ & $4(4)$ & $2(2)$ & $2(2)$ & $>64$ (73) & $>64(73)$ & $4(4)$ & 70 & ND & 10 & 80 \\
\hline 18 & $8(9)$ & $8(9)$ & $8(9)$ & $>64(73)$ & $>64(73)$ & $64(73)$ & 20 & ND & 50 & 80 \\
\hline 19 & $2(3)$ & $2(3)$ & $2(3)$ & $8(11)$ & $16(22)$ & $32(44)$ & 25 & ND & 55 & 80 \\
\hline 20 & $1(1.5)$ & $2(3)$ & $2(3)$ & $2(3)$ & $8(11)$ & $8(11)$ & 2 & 30 & $<1$ & 55 \\
\hline 21 & $2(3)$ & $4(6)$ & $8(11)$ & $8(11)$ & $>64(88)$ & $8(11)$ & 5 & 30 & $<1$ & $<1$ \\
\hline 22 & $32(48)$ & $>64(96)$ & $>64(96)$ & $>64(96)$ & $>64(96)$ & $>64(96)$ & ND & ND & ND & ND \\
\hline
\end{tabular}

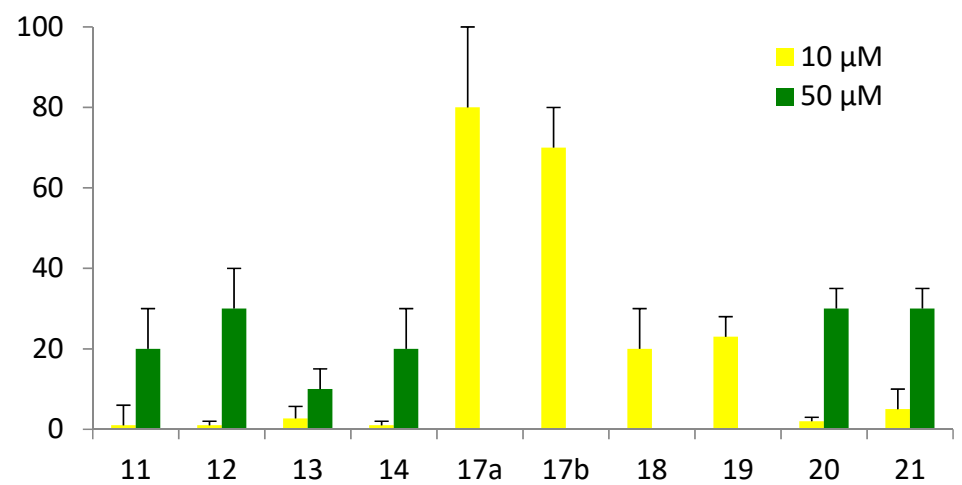

Figure 6. Percentage of hemolysis (see Supporting Information). The given results correspond to a percentage calculated as follows: \%age $=$ absorbance obtained with the peptide - absorbance obtained with the negative control (=buffer alone)/absorbance obtained with the positive control (=triton). ${ }^{*}$ The haemolytic activities of peptides $\mathbf{1 7 a}, \mathbf{1 7 b}, \mathbf{1 8}$, and 19 were not measured at $50 \mu \mathrm{M}$ because of their poor solubility at such concentration.

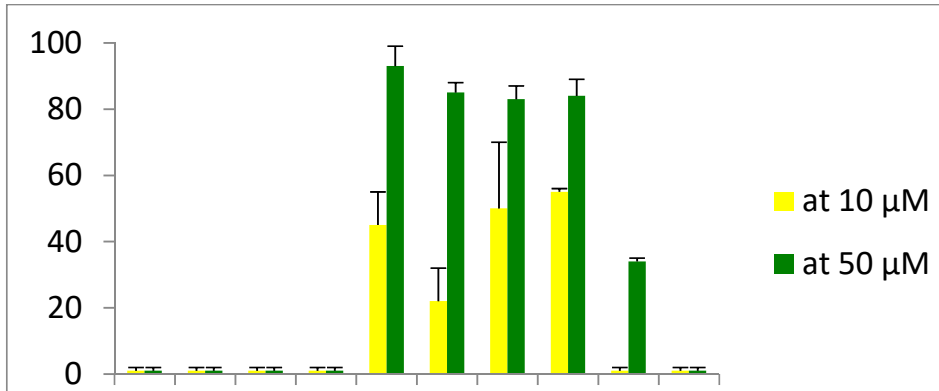

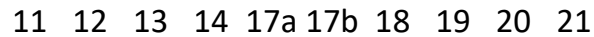

Figure 7. Percentage of cell death (see Supporting Information). 


\subsubsection{Interaction with Membrane Model}

Although the mechanism of action of AMPs is still an active field of research, it is generally admitted that a common primary mode of action involves the disruption of cellular membrane. In order to get some insights into the mechanism of action, biophysical studies were conducted with membrane model. We used the intrinsic fluorescent properties of the tryptophan residue, as initial analysis of the bactericidal mechanism [30]. Depending on its environment in peptides, the wavelength of the fluorescence light emitted by the aromatic tryptophan residues varies. In a polar environment (water), $\lambda \max$ is circa $357 \mathrm{~nm}$, whereas in a non-polar one, $\lambda \max$ shifts to shorter wavelengths (blue-shift). Moreover, the emission intensity increases when the tryptophan residue enters into a hydrophobic environment [31]. We therefore recorded the fluorescence of the most active peptide $\mathbf{1 1}$ and compared it to the inactive one $\mathbf{1 0}$ (Figure 8).

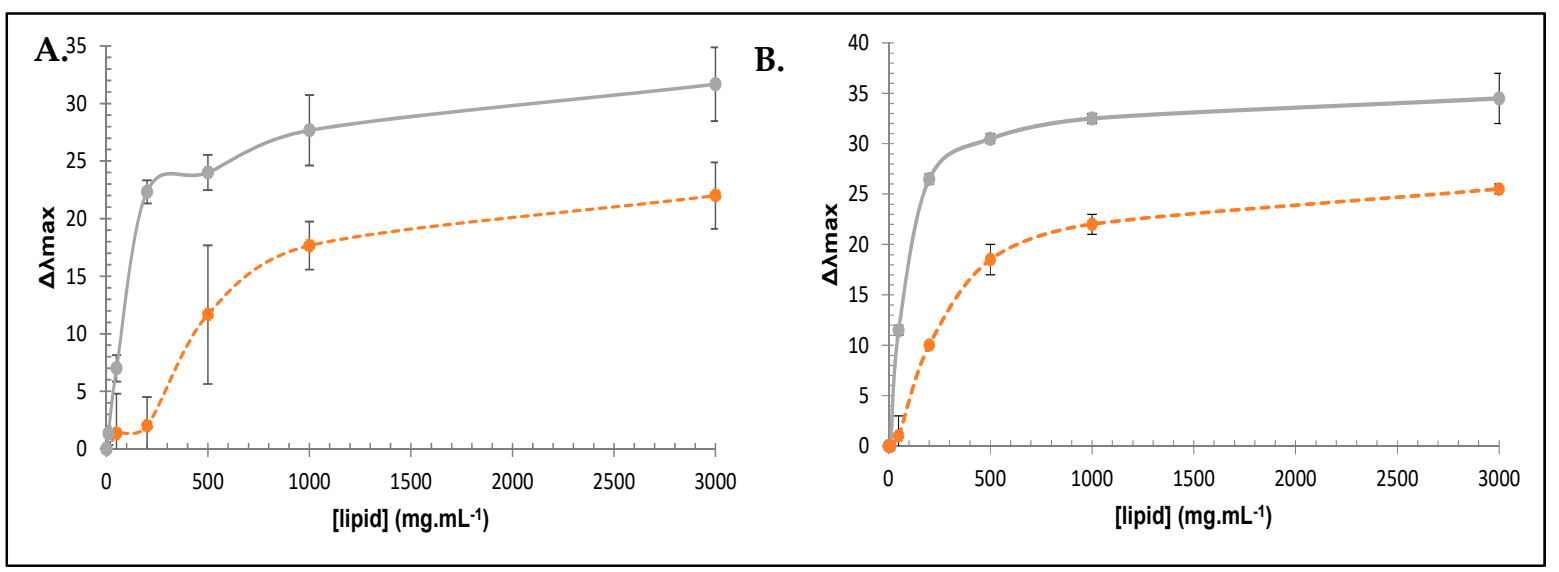

Figure 8. Lipid-induced changes in tryptophan fluorescence of peptide $\mathbf{1 1}$ (full line) and $\mathbf{1 0}$ (dashed line). Blue-shift for tryptophan in the wavelength of maximal emission in the presence of large unilamellar vesicles (LUVs) produced from S. aureus ATCC25923' phospholipids (A) and from E. coli K12 (B) (see Supporting Information).

\subsubsection{In Vivo Experiment Studies}

In vivo experiment studies were conducted on septic mice. Sepsis is a life-threatening condition described as a syndrome of infection complicated by acute organ dysfunction. It is still a leading cause of death in intensive care units despite early antibiotic strategies to control bacterial infection [32]. Therefore, the rapidity and efficacy of antibacterial strategies are highly connected to the outcome of this acute disease and patient survival. After acute cecal ligature and puncture (CLP), peptide $\mathbf{1 1}$ or PBS (negative control) were injected to mice and survival was observed (Figure 9).

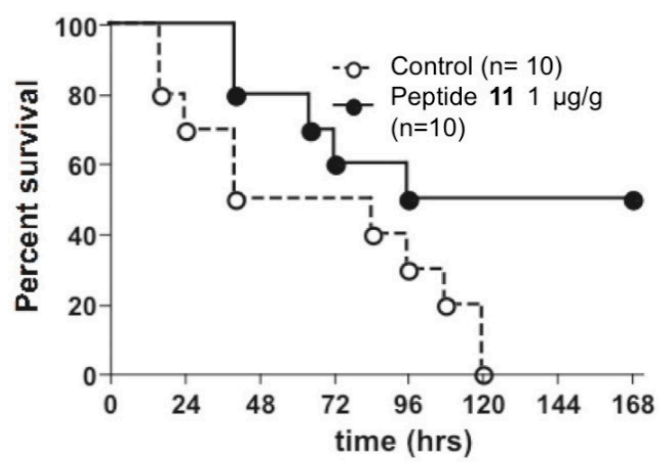

Figure 9. Survival after acute cecal ligature and puncture (CLP) in PBS-injected mice (open circle; $\mathrm{n}=$ 10) and peptide 11-injected mice (closed circle; $n=10$ ). Kaplan-Meier curves and log-rank test were used to analyze the mortality rate; $\mathrm{P}=0.0299$. 


\section{Discussion}

We have designed small AMPs based on new polycationic $\beta$-amino acids, $\beta^{2,2}$ - and $\beta^{3,3}$-homobis-ornithine derivatives. These moieties mimic the cationic side chains of two lysine residues or two arginine residues and thus allow shortening the cationic AMP size. Their combination with the supertryptophan residue (2,5,7-tri-tertbutyltryptophane) reported by Svendsen and co-workers allows obtaining highly active antimicrobial dipeptides. They exhibit activity in the range of 2 to $16 \mu \mathrm{g} / \mathrm{mL}$ (Table 1), values that are promising for compounds to enter into clinical trials. Among the different peptides tested, several $\beta^{2,2}$ - and $\beta^{3,3}$-bis cationic derivatives (peptides 11-14) were potent killing agents against the different strains, with MIC values comparable to or lower than that of the positive controls, and no significant difference was observed between the compound derived from the $\beta^{2,2}-(\mathbf{1 1})$ and $\beta^{3,3}$-h-bis-Arg (13). Noticeably, the $\beta^{2,2}$-amino acid derivatives are easier to synthesize.

Some structure activity relationships can be drawn from these results. First, the importance of the guanidinium groups for the antimicrobial activity is highlighted, since peptide $\mathbf{9}$, containing the $\beta^{2,2}-h$-bis-Orn, shows little antimicrobial activity against all strains (except $S$. aureus) compared to the $\beta^{2,2}-h$-bis-Arg analog 11. This net difference in the antimicrobial activity of arginine- and lysine-containing compounds agrees with the literature and is believed to result from the stronger ability of the guanidinium group to form bidentate hydrogen bonds with the phosphate moiety of phospholipid polar heads, in addition to electrostatic interactions [33]. Oppositely, the absence of difference in the antimicrobial activity of peptides $\mathbf{1 1}$ and $\mathbf{1 2}$ indicates that the additional guanidinium group on the $\beta$-amine has little influence, suggesting that the cationic group on the $\mathrm{N}$-terminal end is not involved in the pharmacophore of the peptide.

Another important point is the positive influence of the $t$-Bu group on the tryptophan moiety, similar to the peptide reported by Svendsen et al. Indeed, in comparison to $\mathbf{1 1}$ or 12, peptide $\mathbf{1 0}$ presents no activity on the tested strains. This lack of activity can be related to the lower lipophilicity of tryptophan compared to the Tbt derivatives 11 and 12, confirmed by its lower retention time in RP-HPLC (Figure 5) together with its lower capacity to interact with membrane. Indeed, the larger size of Tbt compared to Trp (around 2.5-fold) could allow a deeper penetration of this hydrophobic residue into the phospholipid bilayer and an effective disruption of the membrane that is not allowed by the smaller indole moiety. In order to evaluate this hypothesis, we recorded the fluorescence of the active peptide 11, and compared it to the inactive peptide 10. The tryptophan fluorescence spectra of both peptides in aqueous buffer had a maximum emission at $355 \mathrm{~nm}$. Addition of increasing concentration of large unilamellar vesicles (LUVs), prepared from phospholipids directly extracted from S. epidermidis, showed large blue-shift (near $35 \mathrm{~nm}$ ) in the emission maxima of peptide 11, characteristic of the embedding of Trp side chain into the hydrophobic medium of the negatively charged phospholipid (Figure 2). For peptide 10, the blue-shift was $10 \mathrm{~nm}$ smaller with apparent binding constant $\mathrm{K}_{\mathrm{L}}$ (lipid concentration that induced $50 \%$ of maximal blue-shift) about 3 times lower for peptide $\mathbf{1 1}(90 \pm$ $2 \mathrm{mg} \cdot \mathrm{mL}^{-1} \mathrm{~s}$ and $100 \pm 1.5 \mathrm{mg} \cdot \mathrm{mL}^{-1}$, respectively with $S$. aureus LUVs and E. coli LUVs) than for peptide $10\left(280 \pm 1.5 \mathrm{mg} \cdot \mathrm{mL}^{-1}\right.$ and $500 \pm 6 \mathrm{mg} \cdot \mathrm{mL}^{-1}$ with $S$. aureus LUVs and E. coli LUVs). These preliminary biophysical studies on the interaction of $\mathbf{1 1}$ with model membrane suggested that this compound indeed could act as an antimicrobial peptide, by destabilizing the bacterial membrane. We are aware that deeper investigations might be performed in order to assess the mechanism by which this membrane permeabilization occurs.

Interestingly, the sequence of the dipeptides seemed to have an influence on the bacterial activity. Indeed, even though the reverse peptide $\mathbf{1 4}$ had a similar activity against Gram-positive bacteria as the one of peptide 12, its potency against some of the Gram-negative strains was significantly lower. This decreased activity was accompanied by a higher hydrophobicity according to its longer retention time on reversed-phase HPLC (Figure 5). We anticipate that since the chemical composition of these peptides is similar, these different behaviors are likely related to a different spatial arrangement of the cationic and hydrophobic side-chains, giving a different amphiphilicity to peptide $\mathbf{1 4}$ vs. $\mathbf{1 2}$. Indeed, AMPs usually adopt facially amphiphilic conformations in which cationic hydrophilic and 
hydrophobic side chains segregate onto opposite regions of the molecular surface. The importance of this overall topology and not the precise sequence, secondary structure, or chirality of the peptides has been highlighted as key features for their cell-killing activity [34]. Seminal works from Seebach [11] and more recently from Balaram $[13,35]$ suggest that achiral $\beta^{2,2}$-amino acids are $\beta$-turn inducers. In order to get some insight into the solution structure of these peptides, ${ }^{1} \mathrm{H}$ NMR studies were conducted in $\mathrm{D}_{2} \mathrm{O}$. Assignment of the proton signals was achieved by combination of COSY, TOCSY, and NOESY measurements. The data reveal that for peptides 9, 11, and 12, one of the two $\beta$-protons $\mathrm{CH}_{2} \mathrm{NH}_{\text {of }}$ the $\beta^{2,2}-h$ bis-Arg is significantly down-field shifted $(2.4,1.8 \mathrm{ppm}$, and $2.8 \mathrm{ppm}$ respectively for 9, 11, and 12) compared to the other $(3.5 \mathrm{ppm})$, which is not the case for peptide 14 . Moreover, the presence of the $t \mathrm{Bu}$ group on the indole moiety has an important effect on the chemical shift of this proton since for peptides 8 and 10, the chemical shift of this proton is 3.1-3.2 ppm. Altogether, these data suggest a close proximity between the $\beta$-protons $\mathrm{CH}_{2} \mathrm{NH}$ of the $\beta^{2,2}$-hbis-Arg and the indole moiety in peptides 9, 11, and 12 , most likely because of cation- $\pi$ interactions. Regardless of its nature, this specific conformation might favor the interaction of the peptide with the bacterial membrane and bring an explanation for the different biological behaviors of the two isomers 12 and $\mathbf{1 4}$ towards Gram-negative bacteria.

Regarding hemolysis (Figure 6), significant hemolytic effect was observed only at concentrations much higher than the antibacterial MIC values for the four most active peptides 11-14, indicating a good selectivity of the compounds for bacterial cells over mammalian cells. Moreover, no cytotoxicity was observed for the 4 peptides 11-14 on human SHSYS5 cells. Finally, while introduction of fluorenyl or naphtyl group led to improved antibacterial activity for peptides 17-19, this enhancement was, however, accompanied by a decreased selectivity on bacteria, and a significant increase in hemolysis and cytotoxicity on human cells (Table 1). We then evaluated the influence of an additional hydrophobic group on the C-terminal end (peptides 20-22). While replacement of methyl ester with benzyl ester (20) or benzamide (21) gave peptides with enhanced efficiency, the incorporation of an alkyl chain (22) completely abolished the antimicrobial activity, probably reflecting an inappropriate balance between hydrophobicity and charge in this peptide.

Altogether, we selected peptide $\mathbf{1 1}$ as the best candidate for further analysis of its potential as therapeutic agent, thanks to its lack of haemolytic and cytolytic activity on mammalian cells and the easier synthesis of $\beta^{2,2}-h$-bis-Orn-OH compared to $\beta^{3,3}-h$-bis-Orn-OH. Since the incorporation of $\beta$-amino acids into peptides is known to improve their metabolic stability, the serum stability of this compound was first evaluated in human plasma (See Figure 10), where it appeared to be completely stable over $24 \mathrm{~h}$, as expected for $\beta$-amino acids containing peptides sequences compared to a positive control peptide (4NGG) that was fully degraded in $20 \mathrm{mn}$ (See 4. Materials and Methods).

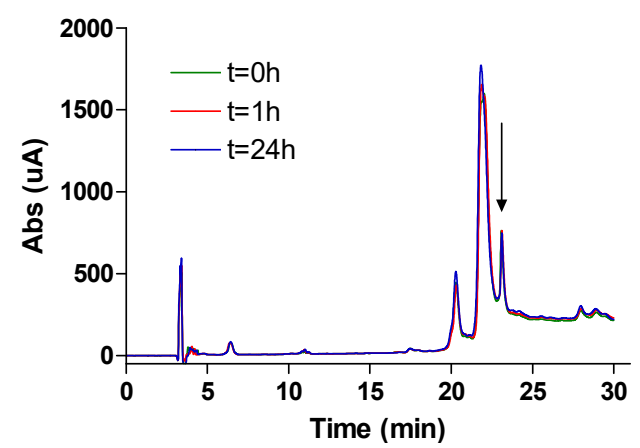

Figure 10. Serum stability of compound 11 evaluated in human plasma (See Supporting Information).

The potency of peptide $\mathbf{1 1}$ was finally assessed in vivo in septic mice. In order to analyze its potential, mice were subjected to the acute model of sepsis "high grad sepsis" in which less than 50\% of the mice survived to the procedure (See SI). In our technical conditions, $100 \%$ of the CLP-induced control mice succumbed during the five days following the induction of sepsis (Figure 9). However, the mice treated with one peritoneal injection of the peptide at $1 \mu \mathrm{g} / \mathrm{g}$ show a significant increase of the 
survival rate. Indeed, $50 \%$ of the mice treated with peptide 11 survived the acute peritonitis. The results revealed that the injection of peptide $\mathbf{1 1}$ induced an increase in the survival rate of CLP-treated mice.

Finally, this study validates these polycationic residues as new tools for the design of short bioactive antimicrobial cationic peptides. These new unnatural arginine analogs might be useful tools for other applications for which cationic residues are a key player, such as cell-penetrating peptides or RNA ligands.

\section{Materials and Methods}

\subsection{General Considerations}

All reactions were carried out under argon atmosphere with dry commercial or freshly distilled solvents under anhydrous conditions unless otherwise stated. All reagents were purchased from commercial suppliers and used without further purification. Flash chromatography was performed using silica gel Merck 60 (0.040-0.063 $\mu \mathrm{m}$, Molsheim, France). Analytical thin-layer chromatography (TLC) was performed using silica gel Merck 60 on alumina, visualized by UV fluorescence at $254 \mathrm{~nm}$, and revealed with ninhydrin $(0.3 \%$ in $n$-butanol/AcOH) or phosphomolybdic acid (solution in EtOH).

\subsection{Solid Phase Peptide Synthesis}

All reactions were carried out in Polypropylene Torviq syringes (sizes 5, 10, 20, or $50 \mathrm{~mL}$ ) equipped with a porous polypropylene disc at the bottom and closed with an appropriate cap. HMBA resin (4-(Hydroxymethyl)benzoyl-aminoethyl) polystyrene (200-400 mesh, 0.8-1.2 mmol/g) was purchased from Iris Biotech (Marktredwitz, Germany). The loading of the Fmoc amino acid coupled resin was determined using a Cary3 Uv/vIS spectrometer (Agilent, Santa-Clara, CA, USA). $O$-(Benzotriazol-1-yl)- $N, N, N^{\prime}, N^{\prime}$-tetramethyluronium hexafluorophosphate (HBTU) and 2-(1H-9azabenzotriazole-1-yl)-1,1,3,3-tetramethyluronium hexafluorophosphate (HATU) were purchased from Iris Biotech. Solvents were purchased from VWR in HPLC grade and used without further purification. Purifications were performed by reverse-phase HPLC either on a Waters preparative HPLC system connected to a Breeze software (Fisher Scientific, Illkirch, France), using a Waters XBridge column (RP C18, $19 \times 50 \mathrm{~mm}, 5 \mu \mathrm{m}, 135 \AA$ ) at a flow rate of $14 \mathrm{~mL} / \mathrm{min}$ or a Dionex semi-preparative HPLC-system connected to a Chromeleon software (Fisher Scientific, Illkirch, France), using a C18 semi-preparative column from $\mathrm{AIT}$ at a flow rate of $5 \mathrm{~mL} / \mathrm{min}$; and using as eluent $\mathrm{A}, \mathrm{H}_{2} \mathrm{O}$ containing $0.1 \%$ of TFA, and as eluent $\mathrm{B}, \mathrm{CH}_{3} \mathrm{CN}$ containing $0.1 \%$ of TFA. UV detection was done at $220 \mathrm{~nm}$ and $280 \mathrm{~nm}$. Purification gradients were chosen to get a ramp of approximately $1 \%$ solution B per minute in the interest area. Peptide fractions from purification were analyzed by analytical HPLC, pooled according to their purity, partly concentrated under vacuum, and freeze-dried on an Alpha 2/4 freeze dryer from Bioblock Scientific (Fisher Bioblock Scientific, Rungis, France) to get the expected peptide as a powder.

\subsection{Product Characterisation}

NMR spectra were recorded on Bruker ARX 250 (Bruker, France SAS, Wissembourg, France) or Brucker Avance III 300 spectrometers (Bruker, France SAS, Wissembourg, France) unless otherwise noted. Proton chemical shifts values $(\delta)$ are reported in parts per million (ppm) downfield from tetramethylsilane (TMS) unless noted otherwise. Coupling constants $(J)$ are reported in $\mathrm{Hertz}(\mathrm{Hz})$. Carbon chemical shifts values $(\delta)$ are reported in parts permillion (ppm) with reference to internal solvent $\mathrm{CDCl}_{3}(77.00 \mathrm{ppm})$ or $\mathrm{CD}_{3} \mathrm{OD}$ (49.00 ppm). Multiplicities are abbreviated as follows: Singlet $(\mathrm{s})$, doublet $(\mathrm{d})$, triplet $(\mathrm{t})$, quartet $(\mathrm{q})$, multiplet $(\mathrm{m})$, and broad singlet (bs). Signal assignments were made using COSY and HSQC experiments, and for peptides NOESY (250 ms mixing time), TOCSY (80 ms mixing time), and DQF-COSY spectra. High-resolution mass spectra (HRMS) were obtained on a Finnigan MAT 95 instrument and are given as experimental (found) and theoretical (calcd). Analytical RP-HPLC were performed on either a Waters system connected to a Breeze software or a Dionex system 
connected to a Chromeleon software. Waters system consisted of a binary pump (Waters 1525) and a dual wavelength Uv/visible Absorbance detector (Waters 2487, Saint-Quentin-en-Yveline, France). Dionex system consisted in an analytical automated LC system (Ultimate 3000) equipped with an auto sampler, a pump block composed of two ternary gradient pumps, and a dual wavelength detector. The analyses were performed on C18 analytical columns (from AIT (Paris, France) or Higgins (San Diego, CA, USA)) using as eluent $\mathrm{A}, \mathrm{H}_{2} \mathrm{O}$ containing $0.1 \%$ of TFA and as eluent $\mathrm{B}, \mathrm{CH}_{3} \mathrm{CN}$ containing $0.1 \%$ of TFA, at a flow rate of $1 \mathrm{~mL} / \mathrm{min}$. UV detection was done at 220 and $280 \mathrm{~nm}$. Peptides were characterized by MALDI-TOF MS (DE-Pro, PerSeptive Biosystems, Framingham, MA, USA) in positive ion reflector mode using the matrix $\alpha$-cyano-4-hydroxy-cinnamic acid (CHCA). Peptide molecular weights were determined for the free amine and not for the TFA salts.

\subsubsection{Synthesis of $\mathrm{H}-\beta^{2,2} h$ bis-Orn(Boc) ${ }_{2} \mathrm{OMe} 1$ and Fmoc $\beta^{2,2} h$ bis-Orn(Boc) ${ }_{2} \mathrm{OH} 2$ (Scheme 5)}

Methyl 2,4-dicyano-2-(2-cyanoethyl)butanoate 23: Methyl 2-cyanoacetate (10 g, $100 \mathrm{mmol})$ was mixed with acrylonitrile $(11.7 \mathrm{~g}, 220 \mathrm{mmol})$ in a three-necked round bottom flask equipped with a condenser and an addition funnel. Triethylamine $(6.8 \mathrm{~mL}, 50 \mathrm{mmol})$ was added dropwise at $0{ }^{\circ} \mathrm{C}$ through the addition funnel. The reaction was stirred continuously and allowed to react overnight at $\mathrm{rt}$. After confirming completion of the reaction by TLC, AcOEt was added. The organic layer was washed with $5 \%$ citric acid solution and brine, dried over $\mathrm{MgSO}_{4}$, filtered, and evaporated. The product precipitated overnight. The solid was washed with AcOEt and obtained as a pale yellow powder $(19.27 \mathrm{~g}, 93 \%$ yield); $\mathbf{R}_{\mathbf{f}}(\mathrm{Cy} / \mathrm{AcOEt}, 1: 1)=0.47 ;{ }^{1} \mathrm{H}$ NMR $\left(250 \mathrm{MHz}, \mathrm{CDCl}_{3}\right) \delta 3.87\left(\mathrm{~s}, 3 \mathrm{H}, \mathrm{CO}_{2} \mathrm{CH}_{3}\right), 2.37-2.62(\mathrm{~m}, 4 \mathrm{H}$, $\left.\mathrm{CH}_{2} \beta\right), 2.31\left(\mathrm{ddd}, J=15.5 \mathrm{~Hz}, 8.6 \mathrm{~Hz}, 6.8 \mathrm{~Hz}, 2 \mathrm{H}, \mathrm{CH}_{2} \gamma\right), 2.14(\mathrm{ddd}, J=14.2 \mathrm{~Hz}, 8.6 \mathrm{~Hz}, 6.1 \mathrm{~Hz}, 2 \mathrm{H}$, $\left.\mathrm{CH}_{2} \gamma\right) ;{ }^{13} \mathrm{C}$ NMR $\left(75 \mathrm{MHz}, \mathrm{CDCl}_{3}\right): \delta 166.6(\mathrm{C}, \mathrm{C}=\mathrm{O}), 117.2(2 \mathrm{C}, \mathrm{C} \equiv \mathrm{N} \gamma), 116.1(\mathrm{C}, \mathrm{C} \equiv \mathrm{N} \alpha), 54.30\left(\mathrm{CH}_{3}\right.$, $\left.\mathrm{CO}_{2} \mathrm{CH}_{3}\right), 47.6(\mathrm{C}, \mathrm{C} \alpha), 32.1\left(2 \mathrm{CH}_{2}, \mathrm{CH}_{2} \beta\right), 13.6\left(2 \mathrm{CH}_{2}, \mathrm{CH}_{2} \gamma\right)$; MS-ESI+: calcd for $\mathrm{C}_{10} \mathrm{H}_{11} \mathrm{~N}_{3} \mathrm{O}_{2}$ 205.09, calcd for $\mathrm{C}_{10} \mathrm{H}_{11} \mathrm{~N}_{3} \mathrm{O}_{2} \mathrm{Na} 228.08$, found $228.07[\mathrm{M}+\mathrm{Na}]^{+}$.

Methyl 2-cyano-4-(Boc)amine-2-(3-(Boc)amine propyl)pentanoate 4: Compound 23 (10 g, 49 mmol) was dissolved in methanol $(25 \mathrm{~mL})$. $\mathrm{Boc}_{2} \mathrm{O}(23.5 \mathrm{~g}, 108 \mathrm{mmol})$ and $\mathrm{PtO}_{2}(2.2 \mathrm{~g}, 9.8 \mathrm{mmol})$ were added and the reaction mixture was stirred at $\mathrm{rt}$ for 3 days under 5 bars of $\mathrm{H}_{2}$ pressure. The reaction mixture was filtered through a celite pad and evaporated to dryness. The crude compound was purified by flash chromatography (Cy/AcOEt 100:0 $\rightarrow$ 70:30) to afford yellowish oil ( $5 \mathrm{~g}, 21 \%$ yield); $\mathbf{R}_{\mathbf{f}}$ (Cy/AcOEt, $1: 1)=0.56 ;{ }^{1} \mathrm{H}$ NMR $\left(300 \mathrm{MHz}, \mathrm{CDCl}_{3}\right): \delta(\mathrm{ppm}) 4.69(\mathrm{bs}, 2 \mathrm{H}, \mathrm{NH}), 3.76\left(\mathrm{~s}, 3 \mathrm{H}, \mathrm{CO}_{2} \mathrm{CH}_{3}\right), 3.08-3.20$ (m, $\left.4 \mathrm{H}, \mathrm{CH}_{2} \delta\right), 1.44-2\left(\mathrm{~m}, 8 \mathrm{H}, \mathrm{CH}_{2} \mathrm{\beta}_{\alpha} \delta \mathrm{CH}_{2} \gamma\right), 1.37-1.50\left(\mathrm{~m}, 18 \mathrm{H}, \mathrm{C}\left(\mathrm{CH}_{3}\right)_{3}\right) . ;{ }^{13} \mathrm{C} \mathrm{NMR}(62.5 \mathrm{MHz}$, $\left.\mathrm{CDCl}_{3}\right) \delta 169.1(\mathrm{C}, \mathrm{C}=\mathrm{O}$ ester $), 155.8\left(2 \mathrm{C}, \mathrm{C}=\mathrm{O}\right.$ carbamate), $118.7(\mathrm{C}, \mathrm{C} \equiv \mathrm{N}), 79.3\left(2 \mathrm{C}, \mathrm{C}\left(\mathrm{CH}_{3}\right)_{3}\right), 53.3$

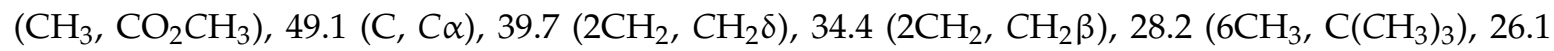
$\left(2 \mathrm{CH}_{2}, \mathrm{CH}_{2} \gamma\right)$.; MS-ESI+: calcd for $\mathrm{C}_{20} \mathrm{H}_{35} \mathrm{~N}_{3} \mathrm{O}_{6} 413.25$, calcd for $\mathrm{C}_{20} \mathrm{H}_{35} \mathrm{~N}_{3} \mathrm{O}_{6} \mathrm{Na} 436.24$, found 436.24 $[\mathrm{M}+\mathrm{Na}]^{+}$.

$H-\beta^{2,2}$ hbis-Orn $(B o c)_{2}$ OMe 1: Compound 4 (2.35 g, $\left.4.9 \mathrm{mmol}\right)$ was dissolved in methanol $(100 \mathrm{~mL})$. Raney nickel was added, and the mixture was stirred under 5 bars of $\mathrm{H}_{2}$ pressure at $\mathrm{rt}$ for 3 days. The reaction mixture was filtered through a celite pad and evaporated to dryness. The product was used in peptide synthesis without further purification. (2.0 g, 98\% yield); $\mathbf{R}_{\mathbf{f}}(\mathrm{Cy} / \mathrm{AcOEt}, 1: 1)=0.56 ;{ }^{1} \mathrm{H} \mathrm{NMR}$ $(300 \mathrm{MHz}, \mathrm{MeOD}) \delta 3.68\left(\mathrm{~s}, 3 \mathrm{H}, \mathrm{CO}_{2} \mathrm{CH}_{3}\right), 3.01\left(\mathrm{t}, J=6.7 \mathrm{~Hz}, 4 \mathrm{H}, \mathrm{CH}_{2} \delta\right), 2.77\left(\mathrm{~s}, 2 \mathrm{H}, \mathrm{CH}_{2} \beta \varepsilon\right), 1.55-1.60$ $\left(\mathrm{m}, 4 \mathrm{H}, \mathrm{CH}_{2} \beta\right), 1.32-1.43\left(\mathrm{~m}, 22 \mathrm{H}, \mathrm{CH}_{2} \gamma\right.$ and $\left.\mathrm{C}\left(\mathrm{CH}_{3}\right)_{3}\right) ;{ }^{13} \mathrm{C} \mathrm{NMR}(75 \mathrm{MHz}, \mathrm{MeOD}) \delta 177.9(\mathrm{C}, \mathrm{C}=\mathrm{O}$ ester), $158.6\left(2 \mathrm{C}, \mathrm{C}=\mathrm{O}\right.$ carbamate), $79.9\left(2 \mathrm{C}, \mathrm{C}\left(\mathrm{CH}_{3}\right)_{3}\right), 52.4\left(\mathrm{CH}_{3}, \mathrm{CO}_{2} \mathrm{CH}_{3}\right), 51.5(\mathrm{C}, \mathrm{C} \alpha), 45.9\left(\mathrm{CH}_{2}\right.$, $\left.\mathrm{CH}_{2} \beta \varepsilon\right)$, $41.6\left(2 \mathrm{CH}_{2}, \mathrm{CH}_{2} \delta\right), 31.2\left(2 \mathrm{CH}_{2}, \mathrm{CH}_{2} \beta\right), 28.8\left(6 \mathrm{CH}_{3}, \mathrm{C}\left(\mathrm{CH}_{3}\right)_{3}\right), 25.4\left(2 \mathrm{CH}_{2}, \mathrm{CH}_{2} \gamma\right)$; HRMS-ESI+: calcd for $\mathrm{C}_{20} \mathrm{H}_{39} \mathrm{~N}_{3} \mathrm{O}_{6} 417.2839$, found $418.2915[\mathrm{M}+\mathrm{H}]^{+}$.

Fmoc $\beta^{2,2}$ hbis-Orn (Boc) $)_{2} \mathrm{OH}$ 2: Compound 4 (2.3 g, $\left.5.6 \mathrm{mmol}\right)$ was dissolved in methanol (125 mL). An aqueous solution of sodium hydroxide $(2 \mathrm{M})(12.5 \mathrm{~mL}, 25 \mathrm{mmol})$ and Raney nickel were added. The mixture was stirred under 5 bars of $\mathrm{H}_{2}$ pressure at $\mathrm{rt}$ for 7 days. The reaction mixture was filtered through a celite pad and evaporated to dryness. The crude compound was dissolved in a 1:1 mixture of THF and water $(150 \mathrm{~mL})$. FmocOSu $(2.3 \mathrm{~g}, 6.8 \mathrm{mmol})$ and $\mathrm{K}_{2} \mathrm{CO}_{3}(1.7 \mathrm{~g}, 12.2 \mathrm{mmol})$ were added. 
The solution was allowed to react at rt overnight. After confirming the completion of the reaction by TLC, THF was evaporated. The resulting aqueous solution was acidified to $\mathrm{pH}=2 \mathrm{by}$ dropwise addition of $1 \mathrm{M}$ hydrochloric acid at $0{ }^{\circ} \mathrm{C}$. The product was extracted with AcOEt, dried over $\mathrm{MgSO}_{4}$, filtered, and concentrated in vacuo. The crude compound was purified by flash chromatography $\left(\mathrm{Cy} / \mathrm{AcOEt} / \mathrm{AcOH}\right.$ 100:0:1 $\rightarrow$ 75:25:1) to afford a white powder (2.5 g, 72\% yield); $\mathbf{R}_{\mathbf{f}}(\mathrm{Cy} / \mathrm{AcOEt} / \mathrm{AcOH}$, 7:3:0.1) = 0.27; ${ }^{1} \mathrm{H}$ NMR $\left(250 \mathrm{MHz}, \mathrm{CDCl}_{3}\right) \delta 7.75(\mathrm{~d}, J=7.2 \mathrm{~Hz}, 2 \mathrm{H}, \mathrm{CH} \mathrm{Ar}), 7.58(\mathrm{~d}, J=7.2 \mathrm{~Hz}, 2 \mathrm{H}, \mathrm{CH}$ Ar), 7.19-7.39 (m, 4H, CH Ar), 5.54 (bs, 1H, NH Fmoc), 4.95 (bs, 2H, NH Boc), 4.40 (d, J = 6.5 Hz, 2H, $\mathrm{CH}_{2}$ Fmoc), 4.20 (t, J = 6.5 Hz, 1H, CH Fmoc), 3.38-3.41 (m, 2H, CH $\mathrm{CH}_{2} \beta$ ), 3.07 (m, 4H, $\left.\mathrm{CH}_{2} \delta\right), 1.20-1.67$ $\left(\mathrm{m}, 26 \mathrm{H}, \mathrm{CH}_{2} \beta, \mathrm{CH}_{2} \gamma\right.$ and $\left.\mathrm{C}\left(\mathrm{CH}_{3}\right)_{3}\right) ;{ }^{13} \mathrm{C} \mathrm{NMR}\left(62.5 \mathrm{MHz} \mathrm{CDCl}_{3}\right) \delta 176.5(\mathrm{C}, \mathrm{C}=\mathrm{O}$ acid $), 157.20,156.4$ (3C, C=O carbamate), 143.9, 141.3 (4C, C Ar), 129.1, 128.2, 127.7, 127.1, 125.3, 125.1, $120.0(8 \mathrm{CH}, \mathrm{CH}$ Ar), $79.3\left(2 \mathrm{C}, \mathrm{C}\left(\mathrm{CH}_{3}\right)_{3}\right), 67.0\left(\mathrm{CH}_{2}, \mathrm{CH}_{2} \mathrm{Fmoc}\right), 49.8\left(\mathrm{CH}_{2}, \mathrm{CH}_{2} \beta \varepsilon\right), 47.2(\mathrm{CH}, \mathrm{CH} \mathrm{Fmoc}), 40.7\left(2 \mathrm{CH}_{2}\right.$, $\left.\mathrm{CH}_{2} \delta\right), 40.6(\mathrm{C}, \mathrm{C} \alpha), 30.6\left(2 \mathrm{CH}_{2}, \mathrm{CH}_{2} \beta\right), 28.4\left(6 \mathrm{CH}_{3}, \mathrm{C}\left(\mathrm{CH}_{3}\right)_{3}\right), 24.3\left(2 \mathrm{CH}_{2}, \mathrm{CH}_{2} \gamma\right)$; HRMS-ESI+: calcd for $\mathrm{C}_{34} \mathrm{H}_{47} \mathrm{~N}_{3} \mathrm{O}_{8}$ 625.3255, calcd for $\mathrm{C}_{34} \mathrm{H}_{47} \mathrm{~N}_{3} \mathrm{O}_{8} \mathrm{Na} 648,3153$, found 648.3261 [M + Na] ${ }^{+}$.

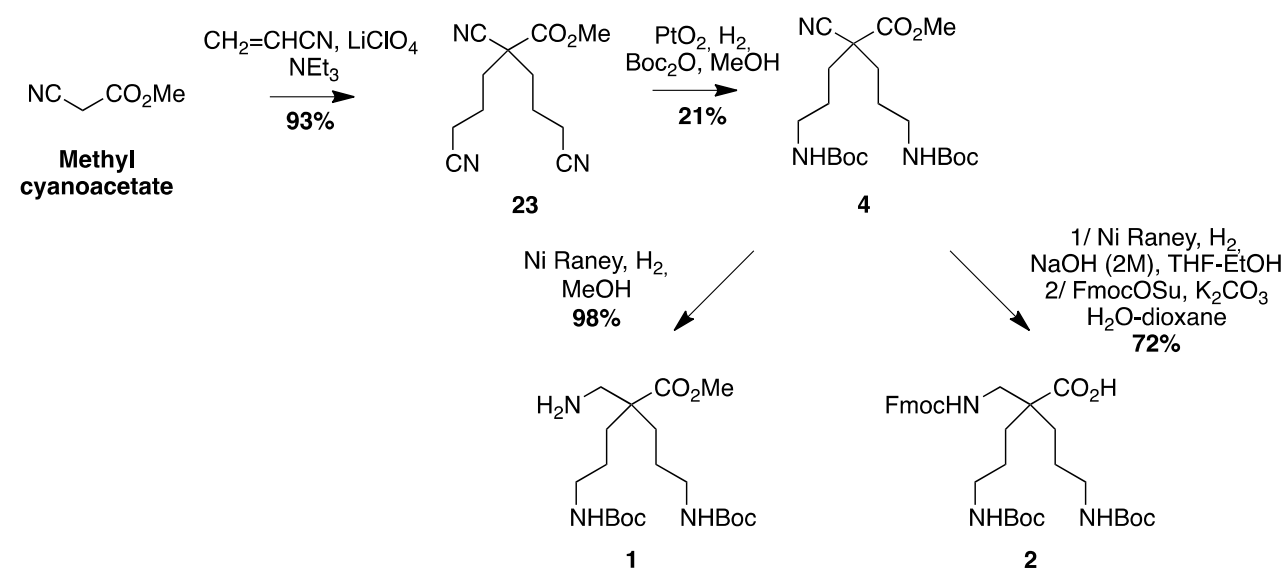

Scheme 5. Synthesis of $\mathrm{H}-\beta^{2,2} \mathrm{~h}$ bis-Orn(Boc) ${ }_{2} \mathrm{OMe} 1$ and $\mathrm{Fmoc} \beta^{2,2} \mathrm{~h}$ bis-Orn(Boc) ${ }_{2} \mathrm{OH}$.

4.3.2. Synthesis of Boc- $\beta^{3,3}$ hbis-Orn(Boc) ${ }_{2} \mathrm{OH} 3$ (Scheme 6)

1-Benzyl 3-tert-butyl 2,2-bis(2-cyanoethyl)malonate 24: Benzyl tert-butylmalonate (25 g, $96.4 \mathrm{mmol})$ was mixed with acrylonitrile $(14 \mathrm{~mL}, 210 \mathrm{mmol})$. Triethylamine $(5.3 \mathrm{~mL}, 40 \mathrm{mmol})$ was added dropwise, followed by lithium perchlorate $(5.4 \mathrm{~g}, 50 \mathrm{mmol})$. The reaction was stirred continuously and allowed to react overnight. After confirming completion of the reaction by TLC, AcOEt was added to the reaction mixture. The organic layer was washed with 5\% citric acid solution and brine, dried over $\mathrm{MgSO}_{4}$, filtered, and evaporated. The crude compound was purified by flash chromatography $(\mathrm{Cy} / \mathrm{AcOEt}$, 100:0 to 8:2) to afford a yellow oil (30.2 g, 88\% yield); $\mathbf{R}_{\mathbf{f}}(\mathrm{Cy} / \mathrm{AcOEt}, 8: 2)=0.37 ;{ }^{1} \mathrm{H} \mathrm{NMR}(250 \mathrm{MHz}$, $\left.\mathrm{CDCl}_{3}\right) \delta 7.37$ (m, 5H, CH Ar), 5.20 (s, 2H, CH $\left.\mathrm{CH}_{2} \mathrm{Ph}\right), 2.17-2.43\left(\mathrm{~m}, 8 \mathrm{H}, \mathrm{CH}_{2} \beta \alpha \vee \delta \mathrm{CH}_{2} \gamma\right), 1.35$ (s, $9 \mathrm{H}$, $\left.\mathrm{C}\left(\mathrm{CH}_{3}\right)_{3}\right) ;{ }^{13} \mathrm{C} \mathrm{NMR}\left(62.5 \mathrm{MHz}, \mathrm{CDCl}_{3}\right) \delta 169.2,167.9$ (2C, C=O), 134.5 (C, C Ar), 128.9, 128.8, 128.5, 127, $126.2(5 \mathrm{CH}, \mathrm{CH} \mathrm{Ar}), 118.5(2 \mathrm{C}, \mathrm{C} \equiv \mathrm{N}), 84\left(\mathrm{C}, \mathrm{C}\left(\mathrm{CH}_{3}\right)_{3}\right), 67.9\left(\mathrm{CH}_{2}, \mathrm{CH}_{2} \mathrm{Ph}\right), 56.2(\mathrm{C}, \mathrm{C} \alpha), 29.5\left(2 \mathrm{CH}_{2}\right.$, $\left.\mathrm{CH}_{2} \beta\right), 27.6\left(3 \mathrm{CH}_{3}, \mathrm{C}\left(\mathrm{CH}_{3}\right)_{3}\right), 13\left(2 \mathrm{CH}_{2}, \mathrm{CH}_{2} \gamma\right)$; HRMS-ESI+: calcd for $\mathrm{C}_{20} \mathrm{H}_{24} \mathrm{~N}_{2} \mathrm{O}_{4} 356.1736$, calcd for $\mathrm{C}_{20} \mathrm{H}_{24} \mathrm{~N}_{2} \mathrm{O}_{4} \mathrm{Na} 379,1634$, found $379.1628[\mathrm{M}+\mathrm{Na}]^{+}$.

2-(Tert-butoxycarbonyl)-4-cyano-2-(2-cyanoethyl)butanoic acid 5: Compound 24 (18 g, $51 \mathrm{mmol})$ was dissolved in $\mathrm{MeOH}(500 \mathrm{~mL})$. Ammonium formate $(16.7 \mathrm{~g}, 265 \mathrm{mmol})$ and $\mathrm{Pd} / \mathrm{C}(5.1 \mathrm{~g}, 100 \mathrm{mg} / \mathrm{mmol})$ were added and the reaction mixture was stirred for $3 \mathrm{~h}$. Afterward, the reaction mixture was filtered through a celite pad to remove the $\mathrm{Pd} / \mathrm{C}$ before evaporation to dryness. The product was diluted with dichloromethane. The organic layer was washed with $10 \%$ citric acid solution and brine, dried over $\mathrm{MgSO}_{4}$, filtered, and evaporated to afford an oil. The product was used in the following step without further purification. (11.34 $\mathrm{g}, 83 \%$ yield); $\mathbf{R}_{\mathbf{f}}(\mathrm{Cy} / \mathrm{AcOEt} / \mathrm{AcOH}, 8: 2: 0.1)=0.1 ;{ }^{1} \mathrm{H} \mathrm{NMR}(250 \mathrm{MHz}$, $\left.\mathrm{CDCl}_{3}\right) \delta 2.41-2.54\left(\mathrm{~m}, 4 \mathrm{H}, \mathrm{CH}_{2} \beta\right), 2.20\left(\mathrm{t}, J=7.5 \mathrm{~Hz}, 4 \mathrm{H}, \mathrm{CH}_{2} \gamma\right), 1.51\left(\mathrm{~s}, 9 \mathrm{H}, \mathrm{C}\left(\mathrm{CH}_{3}\right)_{3}\right) ;{ }^{13} \mathrm{C} \mathrm{NMR}$ 
$\left(62.5 \mathrm{MHz}, \mathrm{CDCl}_{3}\right) \delta 173.1(\mathrm{C}, \mathrm{C}=\mathrm{O}$ acid $), 168.3\left(\mathrm{C}, \mathrm{C}=\mathrm{O}\right.$ ester), $118.5(2 \mathrm{C}, \mathrm{C} \equiv \mathrm{N}), 84.8\left(\mathrm{C}, \mathrm{C}\left(\mathrm{CH}_{3}\right)_{3}\right)$, $56.2(\mathrm{C}, \mathrm{C} \alpha), 30.0\left(2 \mathrm{CH}_{2}, \mathrm{CH}_{2} \beta\right), 27.8\left(3 \mathrm{CH}_{3}, \mathrm{C}\left(\mathrm{CH}_{3}\right)_{3}\right), 13.1\left(2 \mathrm{CH}_{2}, \mathrm{CH}_{2} \gamma\right)$; HRMS-ESI+: calcd for $\mathrm{C}_{13} \mathrm{H}_{18} \mathrm{~N}_{2} \mathrm{O}_{4}$ 266.1267, calcd for $\mathrm{C}_{13} \mathrm{H}_{18} \mathrm{~N}_{2} \mathrm{O}_{4} \mathrm{Na} 289,1165$, found $289.1159[\mathrm{M}+\mathrm{Na}]^{+}$.

1-Tert-butyl 4-methyl 2,2-bis(2-cyanoethyl)succinate 6: Compound 5 ( $9.0 \mathrm{~g}, 34 \mathrm{mmol}$ ) was dissolved in DCM under Argon. 1-Chloro- $N, N$-2-trimethylpropenylamine $(9.0 \mathrm{~mL}, 68 \mathrm{mmol})$ was added. The solution was stirred for $2 \mathrm{~h}$ then concentrated in vacuo. The residue was dissolved in dry acetonitrile $(170 \mathrm{~mL})$ and cooled to $0^{\circ} \mathrm{C}$. DIEA $(11.9 \mathrm{~mL}, 68 \mathrm{mmol})$ and a $2 \mathrm{M}$ solution of trimethylsilyldiazomethane in $\mathrm{Et}_{2} \mathrm{O}$ ( $34 \mathrm{~mL}, 68 \mathrm{mmol}$ ) was added. The reaction mixture was stirred at $0^{\circ} \mathrm{C}$ for $16 \mathrm{~h}$. The organic solvents were evaporated in vacuo. The residue was dissolved in AcOEt and washed with $10 \%$ citric acid, saturated $\mathrm{NaHCO}_{3}$ and brine. Finally, the organic layer was dried over $\mathrm{MgSO}_{4}$, filtered, and evaporated to dryness. The crude compound was dissolved in DMF $(180 \mathrm{~mL})$ and $\mathrm{MeOH}(90 \mathrm{~mL})$ then $\mathrm{Ag}_{2} \mathrm{O}$ (39.4 g, $170 \mathrm{mmol}$ ) was added. The reaction mixture was refluxed for $10 \mathrm{~min}$. After evaporation of $\mathrm{MeOH}$, diethyl ether and a saturated solution of $\mathrm{NH}_{4} \mathrm{Cl}$ were added slowly and the mixture was filtered through a celite pad. The organic layer was separated and washed with a saturated solution of $\mathrm{NH}_{4} \mathrm{Cl}$, dried over $\mathrm{MgSO}_{4}$, filtered, and evaporated. The crude compound was purified by flash chromatography (Cy/AcOEt, 100:0 to 60:40) to afford a yellow oil (2.1 g, 21\% yield); $\mathbf{R}_{\mathbf{f}}$ (Cy/AcOEt, 1:1) $=0.6 ;{ }^{1} \mathrm{H}$ NMR $\left(300 \mathrm{MHz}, \mathrm{CDCl}_{3}\right) \delta 3.71\left(\mathrm{~s}, 3 \mathrm{H}, \mathrm{CO}_{2} \mathrm{CH}_{3}\right), 2.61\left(\mathrm{~s}, 2 \mathrm{H}, \mathrm{CH}_{2} \alpha\right), 2.27-2.37\left(\mathrm{~m}, 4 \mathrm{H}, \mathrm{CH}_{2} \gamma\right)$, 1.91-2.07 (m, 4H, CH $\left.\mathrm{CH}_{2} \delta\right), 1.48\left(\mathrm{~s}, 9 \mathrm{H}, \mathrm{C}\left(\mathrm{CH}_{3}\right)_{3}\right) ;{ }^{13} \mathrm{C} \mathrm{NMR}\left(75 \mathrm{MHz}, \mathrm{CDCl}_{3}\right) \delta 171.4,170.1(2 \mathrm{C}, \mathrm{C}=\mathrm{O})$, $118.8(2 \mathrm{C}, \mathrm{C} \equiv \mathrm{N}), 82.5\left(\mathrm{C}, \mathrm{C}\left(\mathrm{CH}_{3}\right)_{3}\right), 51.6\left(\mathrm{CH}_{3}, \mathrm{CO}_{2} \mathrm{CH}_{3}\right), 46.6\left(\mathrm{CH}_{2}, \mathrm{CH}_{2} \alpha\right), 37.4(\mathrm{C}, \mathrm{C} \beta), 30.6\left(2 \mathrm{CH}_{2}\right.$, $\left.\mathrm{CH}_{2} \gamma\right), 27.5\left(3 \mathrm{CH}_{3}, \mathrm{C}\left(\mathrm{CH}_{3}\right)_{3}\right), 12.3\left(2 \mathrm{CH}_{2}, \mathrm{CH}_{2} \delta\right)$; HRMS-ESI+: calcd for $\mathrm{C}_{15} \mathrm{H}_{22} \mathrm{~N}_{2} \mathrm{O}_{4}$ 294.1580, calcd for $\mathrm{C}_{15} \mathrm{H}_{22} \mathrm{~N}_{2} \mathrm{O}_{4} \mathrm{Na} 317,1478$, found $317.4718[\mathrm{M}+\mathrm{Na}]^{+}$.

2,2-Bis(2-cyanoethyl)-4-methoxy-4-oxobutanoic acid 25: Compound 6 (1.3 g, $4.4 \mathrm{mmol})$ was dissolved in DCM $(40 \mathrm{~mL})$. Triisopropylsilane $(900 \mu \mathrm{L}, 4.4 \mathrm{mmol})$ and TFA $(40 \mathrm{~mL})$ were added. The reaction mixture was stirred for 1 hour before evaporation to dryness. The crude compound was purified by flash chromatography (Cy/AcOEt/AcOH, 100:0:1 to 50:50:1) to afford a colorless oil (900 mg, 86\% yield); $\mathbf{R}_{\mathbf{f}}(\mathrm{Cy} / \mathrm{AcOEt} / \mathrm{AcOH}, 5: 5: 0.1)=0.34 ;{ }^{1} \mathrm{H} \mathrm{NMR}\left(300 \mathrm{MHz}, \mathrm{CDCl}_{3}\right) \delta 3.66\left(\mathrm{~s}, 3 \mathrm{H}, \mathrm{CO}_{2} \mathrm{CH}_{3}\right), 2.65$ (s, 2H, CH $\left.\mathrm{CH}_{2} \alpha\right), 2.30-2.49\left(\mathrm{~m}, 4 \mathrm{H}, \mathrm{CH}_{2} \gamma\right), 1.98-2.16\left(\mathrm{~m}, 4 \mathrm{H}, \mathrm{CH}_{2} \delta\right) ;{ }^{13} \mathrm{C} \mathrm{NMR}\left(75 \mathrm{MHz}, \mathrm{CDCl}_{3}\right) \delta 177.9$ $(\mathrm{C}, \mathrm{C}=\mathrm{O}$ acid $), 170.5(\mathrm{C}, \mathrm{C}=\mathrm{O}$ ester $), 118.7(2 \mathrm{C}, \mathrm{C} \equiv \mathrm{N}), 52.4\left(\mathrm{CH}_{3}, \mathrm{CO}_{2} \mathrm{CH}_{3}\right), 46.3(\mathrm{C}, \mathrm{C} \beta), 37.0\left(\mathrm{CH}_{2}\right.$, $\left.\mathrm{CH}_{2} \alpha\right), 30.8\left(2 \mathrm{CH}_{2}, \mathrm{CH}_{2} \gamma\right), 12.8\left(2 \mathrm{CH}_{2}, \mathrm{CH}_{2} \delta\right)$; HRMS-ESI+: calcd for $\mathrm{C}_{11} \mathrm{H}_{14} \mathrm{~N}_{2} \mathrm{O}_{4}$ 238.0954, calcd for $\mathrm{C}_{11} \mathrm{H}_{14} \mathrm{~N}_{2} \mathrm{O}_{4} \mathrm{Na} 261,0852$, found $261.0845[\mathrm{M}+\mathrm{Na}]^{+}$.

Methyl 3-((tert-butoxycarbonyl)amino)-5-cyano-3-(2-cyanoethyl)pentanoate 7: Compound 25 (450 mg, $1.9 \mathrm{mmol})$ was dissolved in dry acetone $(15 \mathrm{~mL})$ and cooled to $0^{\circ} \mathrm{C} . \mathrm{NEt}_{3}(300 \mu \mathrm{L}, 2.3 \mathrm{mmol})$ and $\mathrm{ClCO}_{2} \mathrm{Et}(200 \mu \mathrm{L}, 2.1 \mathrm{mmol})$ were added. The reaction mixture was stirred for $1.5 \mathrm{~h}$. A solution of $\mathrm{NaN}_{3}$ ( $309 \mathrm{mg}, 4.75 \mathrm{mmol})$ in $\mathrm{H}_{2} \mathrm{O}(8.5 \mathrm{~mL})$ was added and the mixture was stirred at $0{ }^{\circ} \mathrm{C}$ for 2 additional hours. Acetone was evaporated and the compound was extracted with toluene. The organic layer was dried over $\mathrm{MgSO}_{4}$ and filtered. The volume was reduced by evaporation to $20 \mathrm{~mL}$. tert-BuOH $(15 \mathrm{~mL})$ was added and the reaction was refluxed for $16 \mathrm{~h}$. The solvent was evaporated and the crude compound purified by flash chromatography (Cy/AcOEt, 100:0 to 7:3) to afford a white powder (200 mg, 35\% yield); $\mathbf{R}_{\mathbf{f}}(\mathrm{Cy} / \mathrm{AcOEt}, 1: 1)=0.44 ;{ }^{1} \mathrm{H}$ NMR $\left(300 \mathrm{MHz}, \mathrm{CDCl}_{3}\right) \delta 5.17$ (bs, $\left.1 \mathrm{H}, \mathrm{NHBoc}\right), 3.71$ $\left(\mathrm{s}, 3 \mathrm{H}, \mathrm{CO}_{2} \mathrm{CH}_{3}\right), 2.60\left(\mathrm{~s}, 2 \mathrm{H}, \mathrm{CH}_{2} \alpha\right), 2.22-2.45\left(\mathrm{~m}, 6 \mathrm{H}, \mathrm{CH}_{2} \gamma\right.$ and $\left.\mathrm{CH}_{2} \delta_{1}\right), 1.99-2.12\left(\mathrm{~m}, 2 \mathrm{H}, \mathrm{CH}_{2} \delta_{2}\right)$, $1.40\left(\mathrm{~s}, 9 \mathrm{H}, \mathrm{C}\left(\mathrm{CH}_{3}\right)_{3}\right) ;{ }^{13} \mathrm{C}$ NMR $\left(75 \mathrm{MHz}, \mathrm{CDCl}_{3}\right) \delta 170.4(\mathrm{C}, \mathrm{C}=\mathrm{O}$ ester $), 154.3$ (C, $\mathrm{C}=\mathrm{O}$ carbamate), $119.2(2 \mathrm{C}, \mathrm{C} \equiv \mathrm{N}), 80.5$ and $80.4\left(2 \mathrm{C}, \mathrm{C}\left(\mathrm{CH}_{3}\right)_{3}\right), 55.3(\mathrm{C}, \mathrm{C} \beta), 52.4\left(\mathrm{CH}_{3}, \mathrm{CO}_{2} \mathrm{CH}_{3}\right), 39.5\left(\mathrm{CH}_{2}, \mathrm{CH}_{2} \alpha\right), 31.8$ $\left(2 \mathrm{CH}_{2}, \mathrm{CH}_{2} \gamma\right), 28.3\left(3 \mathrm{CH}_{3}, \mathrm{C}\left(\mathrm{CH}_{3}\right)_{3}\right), 12.0\left(2 \mathrm{CH}_{2}, \mathrm{CH}_{2} \delta\right)$; HRMS-ESI+: calcd for $\mathrm{C}_{15} \mathrm{H}_{23} \mathrm{~N}_{3} \mathrm{O}_{4} 309.1689$, calcd for $\mathrm{C}_{15} \mathrm{H}_{23} \mathrm{~N}_{3} \mathrm{O}_{4} \mathrm{Na} 332,1587$, found $332.1581[\mathrm{M}+\mathrm{Na}]^{+}$.

Methyl-3,6-bis((tert-butoxycarbonyl)amino)-3-(3-((tert-butoxycarbonyl)amino)propyl) hexanoate $\mathbf{2 6}$ Compound 7 (145 mg, $0.47 \mathrm{mmol}$ ) was dissolved in a 9:1 mixture of methanol and chloroform. $\mathrm{PtO}_{2}$ $\left(16 \mathrm{mg}, 0.07 \mathrm{mmol}\right.$ ) was added and the reaction mixture was stirred under 5 bars of $\mathrm{H}_{2}$ pressure at $\mathrm{rt}$ for 3 days. The reaction mixture was filtered through a celite pad and evaporated to dryness. The crude 
product was dissolved in a 1:1 mixture of $\mathrm{THF} / \mathrm{H}_{2} \mathrm{O}$ and $\mathrm{Boc}_{2} \mathrm{O}$ was added. After stirring overnight, THF was evaporated and the product was extracted with DCM. The organic layer was washed with brine, dried over $\mathrm{MgSO}_{4}$, filtered, and evaporated in vacuo. The crude compound was purified by flash chromatography (Cy/AcOEt, 7:3) to afford a colorless oil (150 mg, 62\% yield); $\mathbf{R}_{\mathbf{f}}(\mathrm{Cy} / \mathrm{AcOEt}$, 1:1) $=0.68 ;{ }^{1} \mathrm{H}$ NMR (300 MHz, $\left.\mathrm{CDCl}_{3}\right) \delta 4.85$ (bs, 1H, NH Boc), 4.72 (bs, 2H, NH Boc), 3.64 (s, 3H, $\left.\mathrm{CO}_{2} \mathrm{CH}_{3}\right), 3.02-3.11\left(\mathrm{~m}, 4 \mathrm{H}, \mathrm{CH}_{2} \varepsilon\right), 2.61\left(\mathrm{~s}, 2 \mathrm{H}, \mathrm{CH}_{2} \alpha\right), 1.56-1.77\left(\mathrm{~m}, 4 \mathrm{H}, \mathrm{CH}_{2} \gamma\right), 1.34-1.48(\mathrm{~m}, 31 \mathrm{H}$, $\mathrm{CH}_{2} \delta$ and $\left.\mathrm{C}\left(\mathrm{CH}_{3}\right)_{3}\right) ;{ }^{13} \mathrm{C} \mathrm{NMR}\left(75 \mathrm{MHz}, \mathrm{CDCl}_{3}\right) \delta 171.7(\mathrm{C}, \mathrm{C}=\mathrm{O}$ ester $), 156.0(2 \mathrm{C}, \mathrm{C}=\mathrm{O}$ carbamate), $154.5\left(\mathrm{C}, \mathrm{C}=\mathrm{O}\right.$ carbamate), $79.1\left(3 \mathrm{C}, \mathrm{C}\left(\mathrm{CH}_{3}\right)_{3}\right), 56.1(\mathrm{C}, \mathrm{C} \beta), 51.6\left(\mathrm{CH}_{3}, \mathrm{CO}_{2} \mathrm{CH}_{3}\right), 40.5\left(2 \mathrm{CH}_{2}, \mathrm{CH}_{2} \varepsilon\right)$, $40.3\left(\mathrm{CH}_{2}, \mathrm{CH}_{2} \alpha\right), 33.3\left(2 \mathrm{CH}_{2}, \mathrm{CH}_{2} \beta\right), 28.4\left(9 \mathrm{CH}_{3}, \mathrm{C}\left(\mathrm{CH}_{3}\right)_{3}\right), 23.8\left(2 \mathrm{CH}_{2}, \mathrm{CH}_{2} \gamma\right)$; HRMS-ESI+: calcd for $\mathrm{C}_{25} \mathrm{H}_{47} \mathrm{~N}_{3} \mathrm{O}_{8}$ 517.3363, calcd for $\mathrm{C}_{25} \mathrm{H}_{47} \mathrm{~N}_{3} \mathrm{O}_{8} \mathrm{Na} 540,3261$, found 540.3255 [M + Na] ${ }^{+}$.

Boc- $\beta^{3,3}$ hbis-Orn $(\mathrm{Boc})_{2} \mathrm{OH}$ 3: Compound $26(0.130 \mathrm{~g}, 0.25 \mathrm{mmol})$ was dissolved in a 1:1 mixture of $\mathrm{THF} / \mathrm{H}_{2} \mathrm{O}$. $\mathrm{LiOH}(12 \mathrm{mg}, 0.5 \mathrm{mmol})$ was added and the reaction mixture was stirred at rt for 5 days. THF was evaporated and the resulting aqueous solution was acidified to $\mathrm{pH}=2$ by dropwise addition of $1 \mathrm{M}$ hydrochloric acid at $0{ }^{\circ} \mathrm{C}$. The product was extracted with DCM and the organic layer was washed with brine, dried over $\mathrm{MgSO}_{4}$, filtered, and evaporated to afford a white powder $(120 \mathrm{mg}, 98 \%$ yield). The product was used in following step without any further purification; $\mathbf{R}_{\mathbf{f}}(\mathrm{Cy} / \mathrm{AcOEt}, 1: 1)=$ 0.20; ${ }^{1} \mathrm{H}$ NMR $(300 \mathrm{MHz}, \mathrm{MeOD}) \delta 3.01\left(\mathrm{t}, \mathrm{J}=6.6 \mathrm{~Hz}, 4 \mathrm{H}, \mathrm{CH}_{2} \varepsilon\right), 2.62\left(\mathrm{~s}, 2 \mathrm{H}, \mathrm{CH}_{2} \alpha\right), 1.73\left(\mathrm{~m}, 4 \mathrm{H}, \mathrm{CH}_{2} \gamma\right)$, $1.42\left(\mathrm{~m}, 31 \mathrm{H}, \mathrm{CH}_{2} \delta\right.$ and $\left.\mathrm{C}\left(\mathrm{CH}_{3}\right)_{3}\right) ;{ }^{13} \mathrm{C} \mathrm{NMR}(75 \mathrm{MHz}, \mathrm{MeOD}) \delta 158.6(3 \mathrm{C}, \mathrm{C}=\mathrm{O}$ carbamate), 80.0 (3C, $\left.\mathrm{C}\left(\mathrm{CH}_{3}\right)_{3}\right), 57.2(\mathrm{C}, \mathrm{C} \beta), 41.7\left(3 \mathrm{CH}_{2}, \mathrm{CH}_{2} \alpha\right.$ and $\left.\mathrm{CH}_{2} \varepsilon\right), 34.3\left(2 \mathrm{CH}_{2}, \mathrm{CH}_{2} \gamma\right), 29.0\left(9 \mathrm{CH}_{3}, \mathrm{C}\left(\mathrm{CH}_{3}\right)_{3}\right), 25.0$ $\left(2 \mathrm{CH}_{2}, \mathrm{CH}_{2} \delta\right)$; HRMS-ESI+: calcd for $\mathrm{C}_{24} \mathrm{H}_{45} \mathrm{~N}_{3} \mathrm{O}_{8} 503.3207$, calcd for $\mathrm{C}_{24} \mathrm{H}_{45} \mathrm{~N}_{3} \mathrm{O}_{8} \mathrm{Na}_{526}, 3105$, found $526.3099[\mathrm{M}+\mathrm{Na}]^{+}$; IR (ATR) $v\left(\mathrm{~cm}^{-1}\right): 3346.9(-\mathrm{OH}$ acid), 2962.3, 2975.8, 2872.9, 2495.0, 1686.5 (C=O acid), 1514.6, 1479.5, 1453.5, 1392.0, 1365.3, 1273.7, 1248.7, 1162.3, 1092.6, 985.2, 866.5, 778.8 .

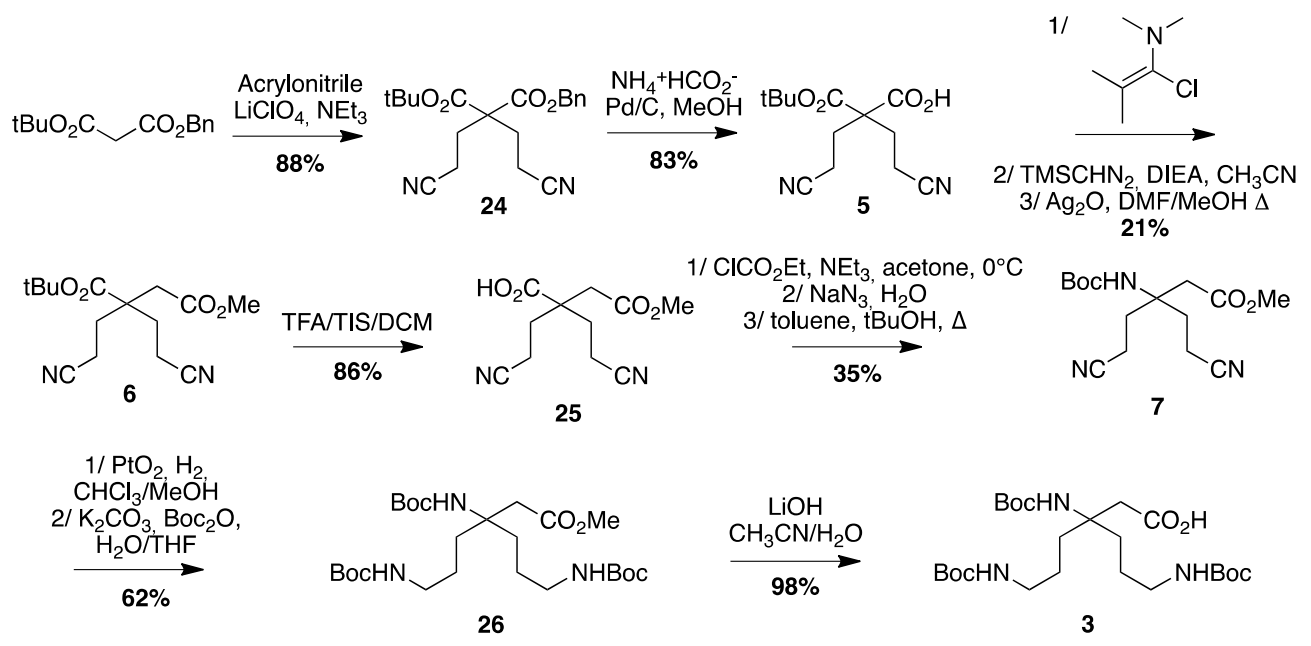

Scheme 6. Synthesis of Boc- $\beta^{3,3}$ hbis-Orn $(\mathrm{Boc})_{2} \mathrm{OH} 3$.

\subsubsection{Synthesis of Fmoc-Tbt-OH (Scheme 7)}

(S)-2-((((9H-Fluoren-9-yl)methoxy)carbonyl)amino)-3-(2,4,6-tri-tert-butyl-1H-indol-3-yl) propanoic Acid: A mixture of $\mathrm{H}-\mathrm{Trp}-\mathrm{OH}(3 \mathrm{~g}, 14.6 \mathrm{mmol})$ and tert-BuOH $(31 \mathrm{~mL}, 323 \mathrm{mmol})$ in TFA $(90 \mathrm{~mL})$ was stirred at $\mathrm{rt}$ for 20 days. The resulting dark solution was evaporated to dryness to give a black oil, and water $(50 \mathrm{~mL})$ was added. To the resulting suspension was added $\mathrm{KHCO}_{3}$ until $\mathrm{pH}=8-9$. THF (50 mL) and FmocOSu $(5.4 \mathrm{~g}, 16.0 \mathrm{mmol})$ were added and the mixture was stirred for $16 \mathrm{~h}$. THF was evaporated and the solution was acidified to $\mathrm{pH}=2$. The compound was extracted with AcOEt, dried over $\mathrm{MgSO}_{4}$, filtered, and concentrated in vacuo. The crude compound was purified by flash chromatography (Cy/AcOEt/AcOH 100:0:1 to 50:50:1) to afford a white powder (6 g, 70\% yield); $\mathbf{R}_{\mathbf{f}}(\mathrm{Cy} / \mathrm{AcOEt} / \mathrm{AcOH}$, 5:5:0.1) = 0.66; ${ }^{1} \mathrm{H}$ NMR $\left(300 \mathrm{MHz}, \mathrm{CDCl}_{3}\right) \delta$ 7.12-8.08 (m, 10H, CH Ar), 4.65-4.88 (m, 1H, CH Fmoc), 4.22-4.43 (m, 2H, CH $\mathrm{Fmoc}_{2}, 4.17(\mathrm{t}, J=6.8 \mathrm{~Hz}, 1 \mathrm{H}, \mathrm{CH \alpha}), 3.56-3.74\left(\mathrm{~m}, 1 \mathrm{H}, \mathrm{CH}_{2} \beta_{1}\right), 3.42(\mathrm{dd}, J=$ 
$\left.14.8 \mathrm{~Hz}, 9.1 \mathrm{~Hz}, 1 \mathrm{H}, \mathrm{CH}_{2} \beta_{2}\right), 1.57\left(\mathrm{~s}, 18 \mathrm{H}, \mathrm{C}\left(\mathrm{CH}_{3}\right)_{3}\right), 1.45\left(\mathrm{~s}, 9 \mathrm{H}, \mathrm{C}\left(\mathrm{CH}_{3}\right)_{3}\right) ;{ }^{13} \mathrm{C} \mathrm{NMR}\left(75 \mathrm{MHz} \mathrm{CDCl}_{3}\right)$ $\delta 177.7$ (C, C=O acid), 156.1 (C, C=O carbamate), 143.8, 143.7, 142.9, 142.7, 141.2, 132.0, 130.2, 129.8 (9C, C Ar), 127.6, 127.0, 125.2, 125.1, 119.8, 116.9, 111.6 (10C, CH Ar), 103.9 (C, C Ar), $67.2\left(\mathrm{CH}_{2}, \mathrm{CH}_{2} \mathrm{Fmoc}_{\text {, }}\right.$ $55.3(\mathrm{CH}, \mathrm{CH} \alpha), 47.0\left(\mathrm{CH}, \mathrm{CH}\right.$ Fmoc), $34.8\left(2 \mathrm{C}, \mathrm{C}\left(\mathrm{CH}_{3}\right)_{3}\right), 33.1\left(\mathrm{C}, \mathrm{C}\left(\mathrm{CH}_{3}\right)_{3}\right), 32.0,30.9,30.6\left(9 \mathrm{CH}_{3}\right.$, $\left.\mathrm{C}\left(\mathrm{CH}_{3}\right)_{3}\right), 27.6\left(\mathrm{CH}_{2}, \mathrm{CH}_{2} \beta\right)$; HRMS-ESI+: calcd for $\mathrm{C}_{38} \mathrm{H}_{46} \mathrm{~N}_{2} \mathrm{O}_{4} 594.3458$, calcd for $\mathrm{C}_{38} \mathrm{H}_{46} \mathrm{~N}_{2} \mathrm{O}_{4} \mathrm{Na}$ 617.3356, found $617.3350[\mathrm{M}+\mathrm{Na}]^{+}$.
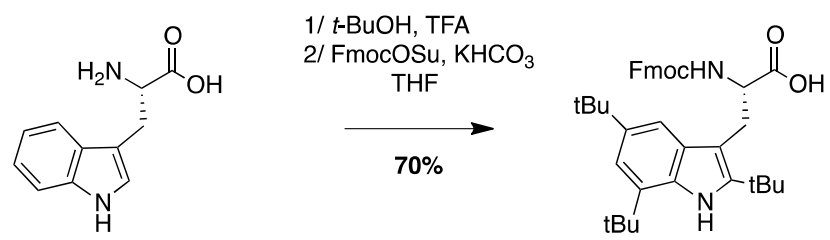

Scheme 7. Synthesis of Fmoc-Tbt-OH.

4.3.4. Synthesis of Peptide A: Arg-Tbt-Arg- $\mathrm{NH}_{2}$

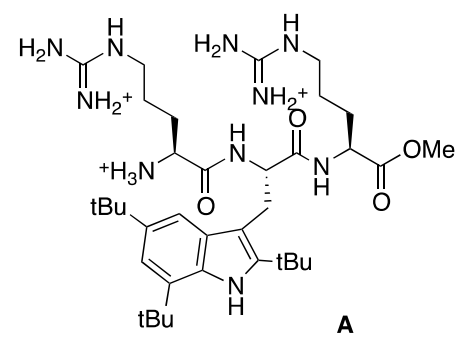

Fmoc Rink Amide resin loaded at $0.43 \mathrm{mmol} / \mathrm{g}(162 \mathrm{mg}, 0.07 \mathrm{mmol})$ was washed with DMF and allowed to swell in DMF for $15 \mathrm{~min}$. Fmoc deprotection was achieved through treatment of the resin with a solution of $20 \%$ piperidine (v:v) in DMF ( $5 \mathrm{~min}, 3$ times), followed by washing with NMP. Fmoc-Arg(Pbf)-OH (4 eq, $0.28 \mathrm{mmol}, 182 \mathrm{mg}$ ) was dissolved in dry NMP and HATU (3.6 eq, $0.25 \mathrm{mmol}$, $95 \mathrm{mg}$ ) and DIEA (10 eq, $0.7 \mathrm{mmol}, 130 \mu \mathrm{L}$ ) were added. The resulting solution was added to the resin and the mixture was stirred for $2 \mathrm{~h}$ then filtrated and washed with NMP. Removal of the Fmoc protecting group was achieved by treatment of the resin with 20\% (v:v) piperidine in DMF (3 times for $5 \mathrm{~min})$. The resin was washed with NMP. Fmoc-Tbt-OH (4 eq, $0.28 \mathrm{mmol}, 166 \mathrm{mg}$ ) was dissolved in NMP (1.5 mL). HATU (3.6 eq, $0.25 \mathrm{mmol}, 95 \mathrm{mg})$ and DIEA (10 eq, $0.7 \mathrm{mmol}, 130 \mu \mathrm{L})$ were added. The solution was added to the resin and the coupling reaction was allowed to proceed for $1.5 \mathrm{~h}$ at room temperature. The solution was removed by filtration and the resin was washed with DMF. After removal of the Fmoc protective group (20\% piperidine in DMF, 5 min, 3 times) and washing of the resin with NMP, a solution of Fmoc-Arg(Pbf)-OH (4 eq, $0.28 \mathrm{mmol}, 182 \mathrm{mg}$ ), HATU (3.6 eq, $0.25 \mathrm{mmol}$, $95 \mathrm{mg})$, and DIEA (10 eq, $0.7 \mathrm{mmol}, 130 \mu \mathrm{L})$ in NMP $(2 \mathrm{~mL})$ was added and the reaction mixture was stirred for $2 \mathrm{~h}$ then filtrated and washed with NMP. Simultaneous final deprotection and cleavage from the resin was achieved by treating the resin with a TFA/TIS/ $\mathrm{H}_{2} \mathrm{O}$ cocktail $(95: 2.5: 2.5,3 \mathrm{~mL})$ for $4 \mathrm{~h}$. The crude peptide was precipitated through addition of cold diethyl ether. Purification by preparative RP-HPLC using a gradient of $15 \%$ to $90 \% \mathrm{MeCN}$ in $30 \mathrm{~min}$ gives after lyophilisation peptide A as a white powder with a purity of $>95 \%$. MALDI-TOF: calcd for $\mathrm{C}_{36} \mathrm{H}_{62} \mathrm{~N}_{10} \mathrm{O}_{3} 683$, found $684.4[\mathrm{M}+\mathrm{H}]^{+}$, $706.4[\mathrm{M}+\mathrm{Na}]^{+}, 722.4[\mathrm{M}+\mathrm{K}]^{+}$; $\operatorname{HPLC}($ Water/ACN $(0.1 \% \mathrm{TFA}) ; 15 \%$ to $100 \% \mathrm{ACN}$ in $30 \mathrm{~min}): \operatorname{tr}=$ $10.19 \mathrm{~min}$.

\subsubsection{Synthesis of Peptide B, Tbt-Arg-OMe B (Scheme 8)}

Boc-Tbt-OH (50 mg, $0.11 \mathrm{mmol})$ was dissolved in DMF. HBTU (42 mg, $0.11 \mathrm{mmol})$ and DIEA ( $40 \mu \mathrm{L}$, $0.22 \mathrm{mmol}$ ) were added and the mixture was stirred for $5 \mathrm{~min}$ before addition of $\mathrm{H}-\mathrm{A} \rho \gamma(\mathrm{Pbf}) \mathrm{OMe}(52 \mathrm{mg}$, $0.11 \mathrm{mmol}$ ). The reaction mixture was stirred at room temperature for $5 \mathrm{~h}$, then diluted with $\mathrm{Et}_{2} \mathrm{O}$ and washed with an aqueous saturated solution of $\mathrm{NH}_{4} \mathrm{Cl}$. The organic layer was dried over $\mathrm{MgSO}_{4}$, 
filtered, and evaporated to dryness. The crude compound was purified by flash chromatography (Cy/AcOEt, 100:0 to 50:50) to afford the pure protected dipeptide as a white powder $(80 \mathrm{mg}, 80 \%$ yield). Treatment of this compound with a cocktail of TFA/TIS/ $\mathrm{H}_{2} \mathrm{O}$ (95:2.5:2.5) for $4 \mathrm{~h}$, followed by evaporation to dryness lead to peptide $\mathbf{B}$, which was purified by preparative RP-HPLC using a gradient of $30 \%$ to $50 \% \mathrm{MeCN}$ in $30 \mathrm{~min}$. After lyophilisation, peptide $\mathbf{B}$ was obtained as white powder with purity $>98 \%$; ${ }^{1} \mathrm{H}$ NMR $(300 \mathrm{MHz}, \mathrm{MeOD}) \delta 7.24(\mathrm{~s}, 1 \mathrm{H}, \mathrm{CH}$ indole), $7.11(\mathrm{~s}, 1 \mathrm{H}, \mathrm{CH}$ indole), $4.25(\mathrm{t}, J=$ 6, $1 \mathrm{H}, \mathrm{CH} \alpha \mathrm{Arg}), 4.08$ (t, $J=8.1,1 \mathrm{H}, \mathrm{CH} \alpha \mathrm{Tbt}), 3.42\left(\mathrm{~d}, J=8.1,1 \mathrm{H}, \mathrm{CH}_{2} \beta \mathrm{Tbt}\right), 3.39\left(\mathrm{~s}, 3 \mathrm{H}, \mathrm{COOCH}_{3}\right)$, 3.09-3.15 (m, 2H, CH $\left.\mathrm{CH}_{2} \delta \mathrm{Arg}\right), 1.70-1.74\left(\mathrm{~m}, 1 \mathrm{H}, \mathrm{CH}_{2} \gamma_{1} \mathrm{Arg}\right), 1.44-1.57\left(\mathrm{~m}, 3 \mathrm{H}, \mathrm{CH}_{2} \gamma_{2}\right.$ and $\left.\mathrm{CH}_{2} \beta \mathrm{Arg}\right)$, $1.54\left(\mathrm{~s}, 9 \mathrm{H}, \mathrm{C}\left(\mathrm{CH}_{3}\right)_{3}\right), 1.50\left(\mathrm{~s}, 9 \mathrm{H}, \mathrm{C}\left(\mathrm{CH}_{3}\right)_{3}\right), 1.37$ (s, 9H, C( $\left.\left.\mathrm{CH}_{3}\right)_{3}\right)$; MALDI-TOF: calcd for $\mathrm{C}_{30} \mathrm{H}_{50} \mathrm{~N}_{6} \mathrm{O}_{3}$ 542.4 , found $543.2[\mathrm{M}+\mathrm{H}]^{+}, 565.2[\mathrm{M}+\mathrm{Na}]^{+} ;$HPLC (Water/ACN $(0.1 \% \mathrm{TFA}) ; 5 \%$ to $100 \% \mathrm{ACN}$ in $30 \mathrm{~min}: \operatorname{tr}=15.15 \mathrm{~min}$.
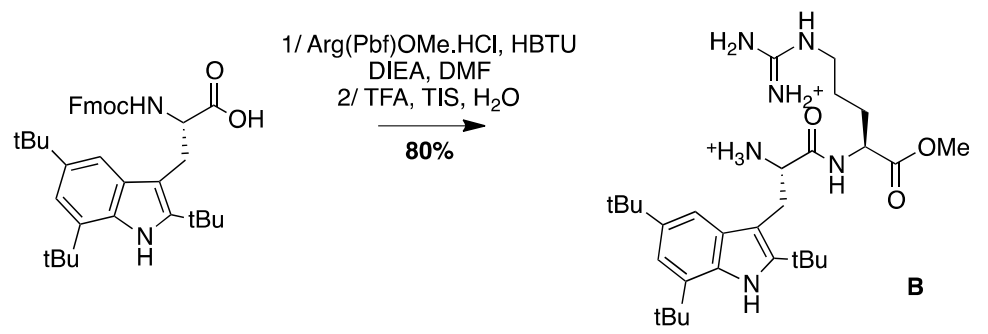

Scheme 8. Synthesis of Peptide B, Tbt-Arg-OMe B.

\subsubsection{Synthesis of Peptides $\mathbf{8}-\mathbf{1 2}$ by LPPS (Scheme 9)}

\section{Synthesis of Trp- $\beta^{2,2} h$ bis-Orn-OMe 8 and Gdm-Trp- $\beta^{2,2} h$ bis-Arg-OMe 10}

Boc Trp- $\beta^{2,2} h$ bis-Orn (Boc) ${ }_{2}-\mathrm{OMe}$ 15: Boc-Tbt-OH (60 mg, $\left.0.2 \mathrm{mmol}\right)$ was dissolved in DMF (6 mL). HBTU (76 mg, $0.2 \mathrm{mmol}$ ) and DIEA ( $80 \mu \mathrm{L}, 0.4 \mathrm{mmol})$ were added and the mixture was stirred for $5 \mathrm{~min}$ before addition of $\mathrm{H}-\beta^{2,2} \mathrm{hbis}-\mathrm{Orn}(\mathrm{Boc})_{2} \mathrm{OMe} \mathbf{1}(84 \mathrm{mg}, 0.2 \mathrm{mmol})$. The reaction mixture was stirred at room temperature overnight, then diluted with $\mathrm{Et}_{2} \mathrm{O}$ and washed with an aqueous saturated solution of $\mathrm{NH}_{4} \mathrm{Cl}$. The organic layer was dried over $\mathrm{MgSO}_{4}$, filtered, and evaporated to dryness. The crude compound was purified by flash chromatography (Cy/AcOEt, 70:30) to afford $\mathbf{1 5}$ as a white powder (140 mg, 99\% yield). ${ }^{1} \mathrm{H}$ NMR (300 MHz, MeOD) $\delta 7.71(\mathrm{~d}, J=7.8,1 \mathrm{H}, \mathrm{CH} \mathrm{Ar}), 7.38(\mathrm{~d}, J=7.2$, $1 \mathrm{H}, \mathrm{CH} \mathrm{Ar}), 7.19(\mathrm{td}, J=7.2,1.1,1 \mathrm{H}, \mathrm{CH} \mathrm{Ar}), 7.13(\mathrm{td}, J=7.8,1.1,1 \mathrm{H}, \mathrm{CH} \mathrm{Ar}), 7.06(\mathrm{~d}, J=2.1,1 \mathrm{H}, \mathrm{CH}$ Ar), 5.91 (br, 1H, NH Boc), 5.36 (br, 1H, NH Boc), 4.78 (br, 1H, CH $\alpha$ Trp), 4.72 (br, 1H, $\mathrm{CH}_{2} \beta_{1}$ Trp), 4.52 (br, $1 \mathrm{H}, \mathrm{CH}_{2} \beta_{2}$ Trp), 3.66 (s, 3H, $\mathrm{CO}_{2} \mathrm{CH}_{3}$ ), 3.30-3.35 (m, 2H, $\mathrm{CH}_{2} \beta \varepsilon_{1} \beta^{2,2} h$ bis-Orn), 3.09-3.23 (m, 2H, $\mathrm{CH}_{2} \beta \varepsilon_{2} \beta^{2,2} h$ bis-Orn), 2.95-3.04 (m, $4 \mathrm{H}, \mathrm{CH}_{2} \delta \beta^{2,2} h$ bis-Orn), 1.52 (s, 27H, $\left.\mathrm{C}\left(\mathrm{CH}_{3}\right){ }_{3}\right), 1.42-1.15(\mathrm{~m}, 8 \mathrm{H}$, $\mathrm{CH}_{2} \beta \alpha v \delta \mathrm{CH}_{2} \gamma \beta^{2,2} h$ bis-Orn).

Trp- $\beta^{2,2}$ h bis-Orn-OMe 8: Compound 15 (70 mg, $\left.0.1 \mathrm{mmol}\right)$ was dissolved in DCM ( 0.4 M) and an equivalent volume of TFA/TIS/ $\mathrm{H}_{2} \mathrm{O}$ (95:2.5:2.5). The mixture was stirred at $\mathrm{rt}$ for $1 \mathrm{~h}$ then evaporated to dryness. The crude product was purified by preparative RP-HPLC using a gradient of $10 \%$ to $50 \%$ $\mathrm{MeCN}$ in $30 \mathrm{~min}$. After lyophilisation compound 8 was obtained as white powder with purity $>95 \%$ (30 mg, 70\% yield); ${ }^{1} \mathrm{H}$ NMR $\left(500 \mathrm{MHz}, \mathrm{D}_{2} \mathrm{O}\right) \delta 7.68(\mathrm{~d}, J=8,1 \mathrm{H}, \mathrm{CH} \mathrm{Ar}), 7.55(\mathrm{~d}, J=12.8,1 \mathrm{H}, \mathrm{CH} \mathrm{Ar})$, $7.33(\mathrm{~s}, 1 \mathrm{H}, \mathrm{CH} \mathrm{Ar}), 7.30(\mathrm{t}, J=8,1 \mathrm{H}, \mathrm{CH} \mathrm{Ar}), 7.22(\mathrm{t}, J=7.5,1 \mathrm{H}, \mathrm{CH} \mathrm{Ar}), 4.42(\mathrm{dd}, J=9.5,6,1 \mathrm{H}, \mathrm{CH} \alpha$ $\operatorname{Trp}$ ), 3.66 (s, 3H, $\mathrm{CO}_{2} \mathrm{CH}_{3}$ ), 3.51 (d, $J=14.5,1 \mathrm{H}, \mathrm{CH}_{2} \beta \varepsilon_{1} \beta^{2,2} h$ bis-Arg), 3.41 (dd, J = 14.2, 6, $1 \mathrm{H}, \mathrm{CH}_{2} \beta_{1}$ $\operatorname{Trp}$ ), 3.35 (dd, $\left.J=14.2,9.5,1 \mathrm{H}, \mathrm{CH}_{2} \beta_{2} \operatorname{Trp}\right), 3.15\left(\mathrm{~d}, J=14.5,1 \mathrm{H}, \mathrm{CH}_{2} \beta \varepsilon_{2} \beta^{2,2}\right.$ hbis-Arg), 2.81 (t, $J=7.8$, $1 \mathrm{H}, \mathrm{CH}_{2} \delta_{1} \beta^{2,2} h$ bis-Arg), $2.71\left(\mathrm{t}, J=7.8,1 \mathrm{H}, \mathrm{CH}_{2} \delta_{2} \beta^{2,2} h\right.$ bis-Arg), $1.49-1.53\left(\mathrm{~m}, 1 \mathrm{H}, \mathrm{CH}_{2} \gamma_{1} \beta^{2,2} h\right.$ bis-Arg), $1.35-1.39\left(\mathrm{~m}, 3 \mathrm{H}, \mathrm{CH}_{2} \gamma_{1^{\prime}}\right.$ and $\mathrm{CH}_{2} \gamma_{2} \beta^{2,2} h$ bis-Arg), $1.24\left(\mathrm{td}, J=13.2,3.7,1 \mathrm{H}, \mathrm{CH}_{2} \beta_{1} \beta^{2,2} h\right.$ bis-Arg), $1.05-1.12$ (m, $2 \mathrm{H}, \mathrm{CH}_{2} \beta_{1^{\prime}}$ and $\mathrm{CH}_{2} \beta_{2} \beta^{2,2}$ hbis-Arg), 0.88-0.95 (m, $1 \mathrm{H}, \mathrm{CH}_{2} \beta_{2^{\prime}} \beta^{2,2}$ hbis-Arg); MALDI-TOF: calcd for $\mathrm{C}_{21} \mathrm{H}_{33} \mathrm{~N}_{5} \mathrm{O}_{3} 403.3$, calcd for $\mathrm{C}_{21} \mathrm{H}_{33} \mathrm{~N}_{5} \mathrm{O}_{3} \mathrm{Na} 426.3$, found $404.5[\mathrm{M}+\mathrm{H}]^{+}, 426.5$ $[\mathrm{M}+\mathrm{Na}]^{+}, 442.5[\mathrm{M}+\mathrm{K}]^{+} ; \mathrm{HPLC}$ (Water/ACN $(0.1 \% \mathrm{TFA}) ; 5 \%$ to $100 \% \mathrm{ACN}$ in $\left.30 \mathrm{~min}\right): \operatorname{tr}=7.18 \mathrm{~min}$ (Figure 11). 


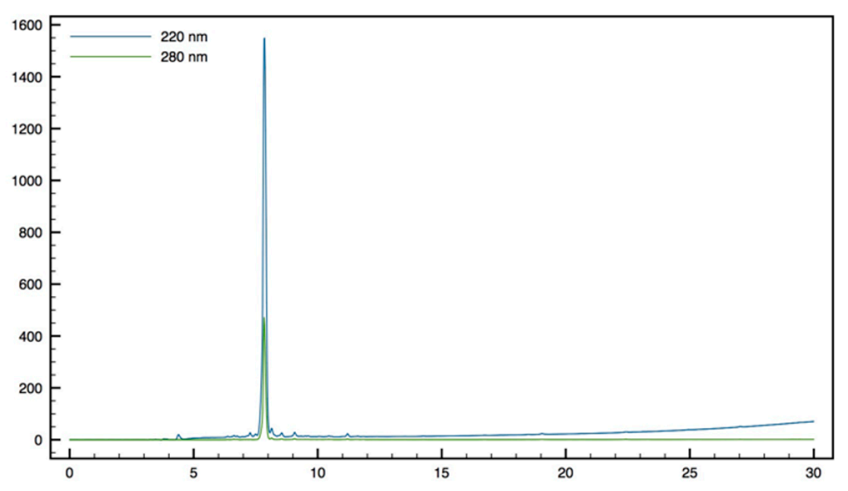

Figure 11. HPLC profile of Trp- $\beta^{2,} h$ bis-Orn-OMe 8.

Gdm-Trp- $\beta^{2,2}$ hbis-Arg-OMe 10: Compound 15 (70 mg, $\left.0.1 \mathrm{mmol}\right)$ was dissolved in DCM ( 0.4 M) and an equivalent volume of TFA/TIS/ $\mathrm{H}_{2} \mathrm{O}$ (95:2.5:2.5). The mixture was stirred at $\mathrm{rt}$ for $1.5 \mathrm{~h}$ then evaporated to dryness. The crude compound was dissolved in $6 \mathrm{~mL}$ of THF 1,3-Di-Boc2-(trifluoromethylsulfonyl)guanidine $(137 \mathrm{mg}, 0.35 \mathrm{mmol})$ and $\mathrm{NEt}_{3}(60 \mu \mathrm{L}, 0.4 \mathrm{mmol})$ were added and the reaction mixture was stirred at rt overnight. After evaporation of THF, a solution of TFA/TIS/ $\mathrm{H}_{2} \mathrm{O}$ (95:2.5:2.5) was added and the mixture was stirred at $\mathrm{rt}$ for $2 \mathrm{~h}$. The crude product was purified by preparative RP-HPLC using a gradient of $10 \%$ to $50 \% \mathrm{MeCN}$ in $30 \mathrm{~min}$. After lyophilisation, compound 10 was obtained as white powder with purity $>98 \%$ ( $31 \mathrm{mg}, 57 \%$ yield); ${ }^{1} \mathrm{H} \mathrm{NMR}(300 \mathrm{MHz}$, $\left.\mathrm{D}_{2} \mathrm{O}\right) \delta 7.69(\mathrm{~d}, J=7.5,1 \mathrm{H}, \mathrm{CH} \mathrm{Ar}), 7.36(\mathrm{~d}, J=8.1,1 \mathrm{H}, \mathrm{CH} \mathrm{Ar}), 7.31(\mathrm{~s}, 1 \mathrm{H}, \mathrm{CH} \mathrm{Ar}), 7.26(\mathrm{td}, J=7.5,0.9$, $1 \mathrm{H}, \mathrm{CH} \mathrm{Ar}), 7.22(\mathrm{td}, J=7.2,0.9,1 \mathrm{H}, \mathrm{CH} \mathrm{Ar}), 4.62(\mathrm{t}, J=7.5,1 \mathrm{H}, \mathrm{CH} \alpha \operatorname{Trp}), 3.69\left(\mathrm{~s}, 3 \mathrm{H}, \mathrm{CO}_{2} \mathrm{CH}_{3}\right), 3.47$ $\left(\mathrm{d}, J=14.1,1 \mathrm{H}, \mathrm{CH}_{2} \beta \varepsilon_{1} \beta^{2,2} h\right.$ bis-Arg), $3.35\left(\mathrm{~d}, J=7.5,2 \mathrm{H}, \mathrm{CH}_{2} \beta \operatorname{Trp}\right.$ ), $3.21\left(\mathrm{~d}, J=14.4,1 \mathrm{H}, \mathrm{CH}_{2} \beta \varepsilon_{2} \beta^{2,2}\right.$ hbis-Arg), $3.05\left(\mathrm{t}, J=6.6,1 \mathrm{H}, \mathrm{CH}_{2} \delta_{1} \beta^{2,2} h\right.$ bis-Arg), 2.98 (dd, $J=11.7,6.6,1 \mathrm{H}, \mathrm{CH}_{2} \delta_{2} \beta^{2,2} h$ bis-Arg), 1.29-1.43 (m, $4 \mathrm{H}, \mathrm{CH}_{2} \gamma \beta^{2,2}$ hbis-Arg), 1.09-1.28 (m, 4H, $\mathrm{CH}_{2} \beta \beta^{2,2}$ hbis-Arg); MALDI-TOF: calcd for $\mathrm{C}_{32} \mathrm{H}_{57} \mathrm{~N}_{5} \mathrm{O}_{3} 529.3$, calcd for $\mathrm{C}_{32} \mathrm{H}_{57} \mathrm{~N}_{5} \mathrm{O}_{3} \mathrm{Na} 552.3$, found $530.6[\mathrm{M}+\mathrm{H}]^{+}, 552.6[\mathrm{M}+\mathrm{Na}]^{+}, 513.6$ $\left[\mathrm{M}+\mathrm{H}-\mathrm{NH}_{3}\right]^{+}$; HPLC (Water/ACN (0.1\% TFA); $5 \%$ to $100 \% \mathrm{ACN}$ in $30 \mathrm{~min}$ ): $\operatorname{tr}=9.62 \mathrm{~min}$ (Figure 12).

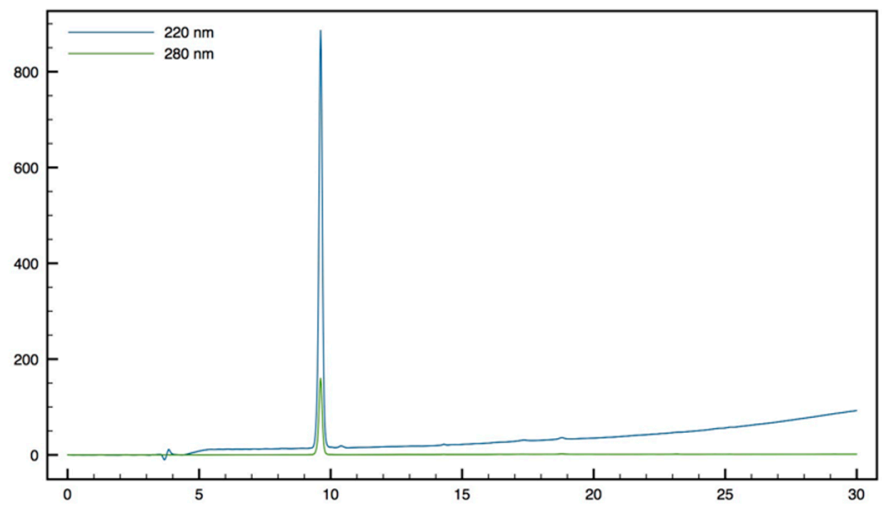

Figure 12. HPLC profile of Gdm-Trp- $\beta^{2,2}$ h bis-Arg-OMe 10.

Synthesis of Tbt- $\beta^{2,2}$ hbis-Orn-OMe 9, Tbt- $\beta^{2,2} \mathrm{~h}$ bis-Arg-OMe 11 and Gua-Tbt- $\beta^{2,2} \mathrm{~h}$ bis-Arg-OMe 12

Fmoc-Tbt- $\beta^{2,2}$ hbis-Orn (Boc) ${ }_{2} \mathrm{OMe}$ 16: Fmoc-Tbt-OH ( $400 \mathrm{mg}, 0.64 \mathrm{mmol}$ ) was dissolved in DMF (24 mL). HBTU ( $244 \mathrm{mg}, 0.64 \mathrm{mmol})$ and DIEA $(240 \mu \mathrm{L}, 1.28 \mathrm{mmol})$ were added and the mixture was stirred for $3 \mathrm{~h}$ before addition of $\mathrm{H}-\beta^{2,2} h$ bis-Orn(Boc) ${ }_{2} \mathrm{OMe} \mathbf{1}(268 \mathrm{mg}, 0.64 \mathrm{mmol})$. The reaction mixture was stirred at room temperature overnight, then diluted with $\mathrm{Et}_{2} \mathrm{O}$ and washed with an aqueous saturated solution of $\mathrm{NH}_{4} \mathrm{Cl}$. The organic layer was dried over $\mathrm{MgSO}_{4}$, filtered, and evaporated to dryness. The crude compound was purified by flash chromatography (Cy/AcOEt, 100:0 to 70:30) to afford the pure protected dipeptide as a white powder $\left(450 \mathrm{mg}, 70 \%\right.$ yield). ${ }^{1} \mathrm{H}$ NMR $(300 \mathrm{MHz}, \mathrm{MeOD}) \delta 8.22(\mathrm{~s}$, 
1H, NH indole), 7.75 (d, $J=7.2,1 \mathrm{H}, \mathrm{CH}$ Ar Fmoc), 7.55 (d, $J=7.2,1 \mathrm{H}, \mathrm{CH}$ Ar Fmoc), 7.41 (s, 1H, CH Ar indole), 7.35 (t, $J=7.2,1 \mathrm{H}, \mathrm{CH}$ Ar Fmoc), 7.24 (dt, $J=11.7$ and 7.2, 1H, CH Ar Fmoc), $7.12(\mathrm{~s}, 1 \mathrm{H}$, $\mathrm{CH}$ indole), 4.27-4.33 (m, 3H, CH $\alpha$ Tbt and $\mathrm{CH}_{2}$ Fmoc), 4.12 ( $\mathrm{t}, J=6.9,1 \mathrm{H}, \mathrm{CH}$ Fmoc), 3.55 (s, 3H, $\left.\mathrm{CO}_{2} \mathrm{CH}_{3}\right), 3.43\left(\mathrm{dd}, J=14.19 .3,1 \mathrm{H}, \mathrm{CH}_{2} \beta_{1} \mathrm{Tbt}\right), 3.39\left(\mathrm{~d}, J=14.1,1 \mathrm{H}, \mathrm{CH}_{2} \beta \varepsilon_{1} \beta^{2,2} h\right.$ bis-Orn), 3.23 (dd, $J=14.4,6.3,1 \mathrm{H}, \mathrm{CH}_{2} \beta_{2} \mathrm{Tbt}$ ), 2.9 (m, $4 \mathrm{H}, \mathrm{CH}_{2} \delta \beta^{2,2} h$ bis-Orn), 2.79 (d, $J=14.1,1 \mathrm{H}, \mathrm{CH}_{2} \beta \varepsilon_{2} \beta^{2,2}$ hbis-Orn), $1.52\left(\mathrm{~s}, 9 \mathrm{H}, \mathrm{C}\left(\mathrm{CH}_{3}\right)_{3}\right.$ indole), $1.47\left(\mathrm{~s}, 9 \mathrm{H}, \mathrm{C}\left(\mathrm{CH}_{3}\right)_{3}\right.$ indole), $1.36-1.44\left(\mathrm{~m}, 35 \mathrm{H}, \mathrm{C}\left(\mathrm{CH}_{3}\right)_{3}\right.$ indole, $\mathrm{C}\left(\mathrm{CH}_{3}\right)_{3}$ Boc, $\mathrm{CH}_{2} \beta \beta^{2,2}$ hbis-Orn and $\mathrm{CH}_{2} \gamma \beta^{2,2} h$ bis-Orn); ${ }^{13} \mathrm{C}$ NMR (75 MHz, MeOD) $\delta 177.1(\mathrm{C}$, $\mathrm{C}=\mathrm{O}$ amide), 174.9 ( $\mathrm{C}, \mathrm{C}=\mathrm{O}$ ester), 158.4 ( $\mathrm{C}=\mathrm{O}$ Boc), 157.9 ( $\mathrm{C}=\mathrm{O}$ Fmoc), 145.2, 145.1, 143.6, 142.9, 142.5, 133.1, 131.8, 131.3 (8C, C Ar), 128.7, 128.2, 126.2, 120.9 (4CH, CH Ar Fmoc), 117.3, 113.4 (2CH, CH Ar indole), 106.2 (C, $\mathrm{C} \mathrm{Ar}), 79.8\left(\mathrm{C}, \mathrm{C}\left(\mathrm{CH}_{3}\right)_{3} \mathrm{Boc}\right), 68.1\left(\mathrm{CH}_{2}, \mathrm{CH}_{2} \mathrm{Fmoc}\right), 58.5(\mathrm{CH}, \mathrm{CH} \alpha \mathrm{Tbt}), 52.3\left(\mathrm{CH}_{3}\right.$, $\left.\mathrm{CO}_{2} \mathrm{CH}_{3}\right), 50.7$ (C, $\mathrm{C} \alpha \beta^{2,2}$ hbis-Orn), 48.3 ( $\mathrm{CH}, \mathrm{CH}$ Fmoc), $42.9\left(\mathrm{CH}_{2}, \mathrm{CH}_{2} \beta \varepsilon \beta^{2,2}\right.$ hbis-Orn), $41.6\left(\mathrm{CH}_{2}\right.$, $\mathrm{CH}_{2} \delta \beta^{2,2}$ hbis-Orn), 35.7, 35.5 and $34.3\left(3 \mathrm{C}, \mathrm{C}\left(\mathrm{CH}_{3}\right)_{3}\right.$ indole), $32.7\left(\mathrm{CH}_{3}, \mathrm{C}\left(\mathrm{CH}_{3}\right)_{3}\right.$ indole), 32.4 and 32.1 $\left(\mathrm{CH}_{2}, \mathrm{CH}_{2} \gamma \beta^{2,2} h\right.$ bis-Orn $), 31.3\left(\mathrm{CH}_{3}, \mathrm{C}\left(\mathrm{CH}_{3}\right)_{3}\right.$ indole $), 30.9\left(\mathrm{CH}_{3}, \mathrm{C}\left(\mathrm{CH}_{3}\right)_{3}\right.$ indole $), 29\left(\mathrm{CH}_{2}, \mathrm{CH}_{2} \beta\right.$ $\mathrm{Tbt}), 28.8\left(6 \mathrm{CH}_{3}, \mathrm{C}\left(\mathrm{CH}_{3}\right)_{3} \mathrm{Boc}\right), 25.5$ and $25.3\left(\mathrm{CH}_{2}, \mathrm{CH}_{2} \beta \beta^{2,2} h\right.$ bis-Orn $)$.

H-Tbt- $\beta^{2,2}$ h bis-OrnOMe 9: Compound $16(60 \mathrm{mg}, 0.06 \mathrm{mmol})$ was dissolved in a 20\% solution of piperidine in DCM and allowed to react for $1 \mathrm{~h}$ before evaporation to dryness. A solution of TFA/TIS/ $\mathrm{H}_{2} \mathrm{O}$ (95:2.5:2.5) was added and the mixture was stirred at $\mathrm{rt}$ for $1 \mathrm{~h}$. The crude product was purified by preparative RP-HPLC using a gradient of $30 \%$ to $50 \% \mathrm{MeCN}$ in $30 \mathrm{~min}$. After lyophilisation 9 was obtained as white powder with a purity of $98 \%(20 \mathrm{mg}, 58 \%$ yield $) ;{ }^{1} \mathrm{H}$ NMR $\left(300 \mathrm{MHz}, \mathrm{D}_{2} \mathrm{O}\right) \delta$ 8.54 (s, 1H, NH indole), 7.26 (s, 1H, CH Ar), 7.22 (s, 1H, CH Ar), 4.03 (dd, $J=9.3,6,1 \mathrm{H}, \mathrm{CH} \alpha \mathrm{Tbt}$ ), 3.50 (s, $\left.3 \mathrm{H}, \mathrm{CO}_{2} \mathrm{CH}_{3}\right), 3.37$ (d, J = 14.2, $1 \mathrm{H}, \mathrm{CH}_{2} \beta \varepsilon_{1} \beta^{2,2} h$ bis-Orn), $3.34\left(\mathrm{~d}, J=14.1,2 \mathrm{H}, \mathrm{CH}_{2} \beta \mathrm{Tbt}\right), 2.80(\mathrm{~m}$, $4 \mathrm{H}, \mathrm{CH}_{2} \delta \beta^{2,2} h$ bis-Orn), 2.33 (d, $J=14.2,1 \mathrm{H}, \mathrm{CH}_{2} \beta \varepsilon_{2} \beta^{2,2} h$ bis-Orn), 1.31-1.44 (m, 35H, $\mathrm{CH}_{2} \beta \beta^{2,2} h$ bis-Orn, $\mathrm{CH}_{2} \gamma \beta^{2,2} h$ bis-Orn and $\left.\mathrm{C}\left(\mathrm{CH}_{3}\right)_{3}\right)$; MALDI-TOF: calcd for $\mathrm{C}_{32} \mathrm{H}_{57} \mathrm{~N}_{5} \mathrm{O}_{3} 571.5$, found 572.6 $[\mathrm{M}+\mathrm{H}]^{+}$; HPLC (Water/ACN (0.1\% TFA); 30\% to 50\% ACN in $30 \mathrm{~min}$ ): $\operatorname{tr}=12.73 \mathrm{~min}$ (Figure 13).

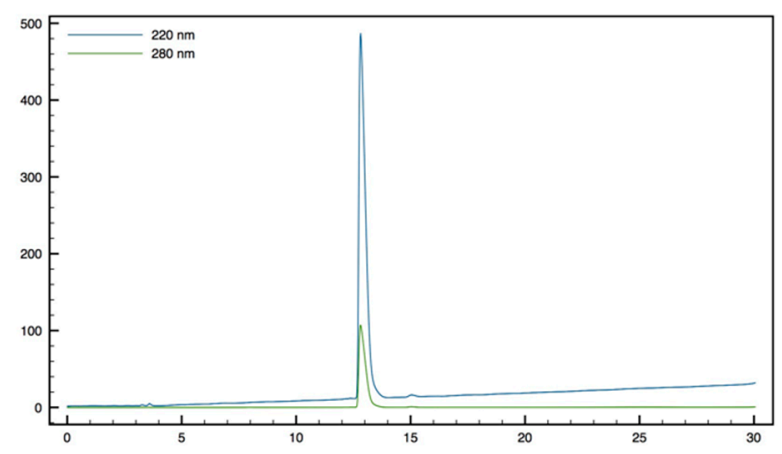

Figure 13. HPLC profile of $\mathrm{H}-\mathrm{Tbt}-\beta^{2,2}$ h bis-OrnOMe 9.

H-Tbt- $\beta^{2,2}$ h bis-Arg-OMe 11 and Gua-Tbt- $\beta^{2,2}$ h bis-Arg-OMe 12: Compound 9 (10 mg, $\left.0.013 \mathrm{mmol}\right)$ was dissolved in $1 \mathrm{~mL}$ of THF. 1,3-Di-Boc-2-(trifluoromethylsulfonyl) guanidine ( $30 \mathrm{mg}, 0.08 \mathrm{mmol}$ ) and DIEA $(27 \mu \mathrm{L}, 0.156 \mathrm{mmol})$ were added and the reaction mixture was stirred at $\mathrm{rt}$ for $2 \mathrm{~h}$. After evaporation of THF, a solution of TFA/TIS/ $\mathrm{H}_{2} \mathrm{O}$ (95:2.5:2.5) was added and the mixture was stirred at $\mathrm{rt}$ for $2 \mathrm{~h}$. The crude product was evaporated in vacuo and purified by preparative RP-HPLC using a gradient of $30 \%$ to $50 \% \mathrm{MeCN}$ in $30 \mathrm{~min}$. Two pics were collected separately at 14 and $18 \mathrm{~min}$ corresponding, respectively, to compounds $\mathbf{1 1}$ and 12. After lyophilisation, the two compounds $\mathbf{1 1}$ ( $5 \mathrm{mg}, 59 \%$ yield) and $\mathbf{1 2}$ ( $2 \mathrm{mg}, 22 \%$ yield) were obtained as white powders with purity $>99 \%$.

H-Tbt- $\beta^{2,2} h$ bis-Arg-OMe 11: ${ }^{1} \mathrm{H}$ NMR (500 MHz, $\left.\mathrm{D}_{2} \mathrm{O}\right) \delta 7.29$ (s, $1 \mathrm{H}, \mathrm{CH}$ indole), 7.27 (s, $1 \mathrm{H}, \mathrm{CH}$ indole), $4.14(\mathrm{dd}, J=11.2,5.5,1 \mathrm{H}, \mathrm{CH} \alpha \mathrm{Tbt}), 3.61\left(\mathrm{dd}, J=14.5,5,1 \mathrm{H}, \mathrm{CH}_{2} \beta_{1} \mathrm{Tbt}\right), 3.57\left(\mathrm{~s}, 3 \mathrm{H}, \mathrm{CO}_{2} \mathrm{CH}_{3}\right), 3.44$ (dd, $\left.J=13.5,12,2 \mathrm{H}, \mathrm{CH}_{2} \beta_{2} \mathrm{Tbt}\right), 3.21$ (d, $J=14.5,1 \mathrm{H}, \mathrm{CH}_{2} \beta \varepsilon_{1} \beta^{2,2} h$ bis-Arg), 3.04 (m, $J=4 \mathrm{H}, \mathrm{CH}_{2} \delta$ $\beta^{2,2} h$ bis-Arg), $\left.1.83\left(\mathrm{~d}, J=14.5,1 \mathrm{H}, \mathrm{CH}_{2} \beta \varepsilon_{2} \beta^{2,2} h \text { bis-Arg), } 1.55 \text { (s, 9H, C(CH3) }\right)_{3}\right), 1.49\left(\mathrm{~s}, 9 \mathrm{H}, \mathrm{C}\left(\mathrm{CH}_{3}\right)_{3}\right)$, 1.39 (s, 9H, $\left.\mathrm{C}\left(\mathrm{CH}_{3}\right)_{3}\right), 1.1-1.34\left(\mathrm{~m}, 8 \mathrm{H}, \mathrm{CH}_{2} \beta \beta^{2,2} h\right.$ bis-Arg and $\mathrm{CH}_{2} \gamma \beta^{2,2} h$ bis-Arg); MALDI-TOF: 
calcd for $\mathrm{C}_{35} \mathrm{H}_{61} \mathrm{~N}_{5} \mathrm{O}_{3} 655.5$, calcd for $\mathrm{C}_{35} \mathrm{H}_{61} \mathrm{~N}_{5} \mathrm{O}_{3} \mathrm{Na} 678.5$, found $656.4[\mathrm{M}+\mathrm{H}]^{+}, 678.4[\mathrm{M}+\mathrm{Na}]^{+}$, $694.4\left[\mathrm{M}+\mathrm{K}^{+}, 639.4\left[\mathrm{M}+\mathrm{H}-\mathrm{NH}_{3}\right]^{+} ; \mathrm{HPLC}\right.$ (Water/ACN $(0.1 \% \mathrm{TFA}) ; 30 \%$ to $50 \% \mathrm{ACN}$ in $30 \mathrm{~min}$ : $\operatorname{tr}=16.11 \mathrm{~min}$ (Figure 14).

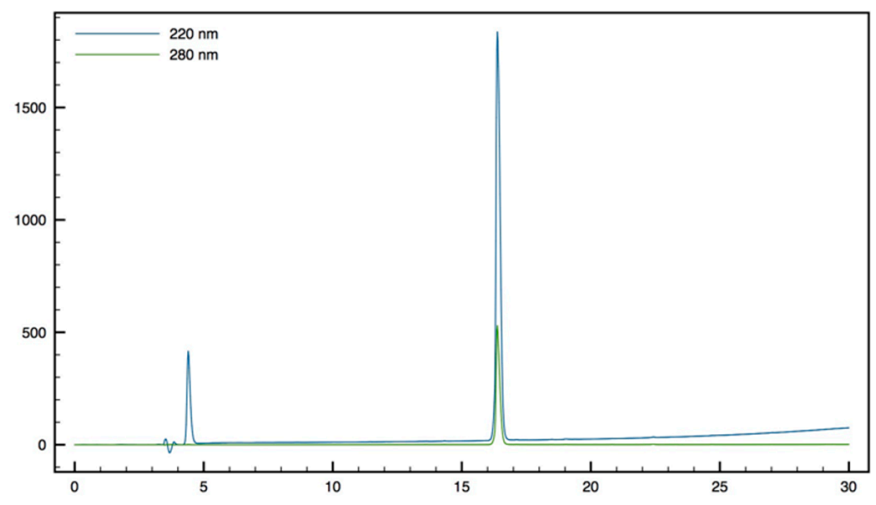

Figure 14. HPLC profile of $H$-Tbt- $\beta^{2,2}$ h bis-Arg-OMe 11.

Gua-Tbt- $\beta^{2,2}$ h bis-Arg-OMe 12: ${ }^{1} \mathrm{H}$ NMR (300 MHz, MeOD) $\delta 8.35$ (s, 1H, NH indole), 7.31 (d, J = 1.5, $1 \mathrm{H}, \mathrm{CH} \mathrm{Ar}), 7.14(\mathrm{~d}, J=1.5,1 \mathrm{H}, \mathrm{CH} \mathrm{Ar}), 4.39(\mathrm{t}, J=7.2,1 \mathrm{H}, \mathrm{CH} \alpha \mathrm{Tbt}), 3.65\left(\mathrm{~s}, 3 \mathrm{H}, \mathrm{CO}_{2} \mathrm{CH}_{3}\right), 3.52(\mathrm{~d}, J=$ 14.2, $1 \mathrm{H}, \mathrm{CH}_{2} \beta \varepsilon_{1} \beta^{2,2} h$ bis-Arg), 3.47 (dd, $\left.J=11.1,7.2,2 \mathrm{H}, \mathrm{CH}_{2} \beta \mathrm{Tbt}\right), 3.01-3.13\left(\mathrm{~m}, 4 \mathrm{H}, \mathrm{CH}_{2} \delta \beta^{2,2} h\right.$ bis-Arg), 2.82 (d, J = 14.2, 1H, $\mathrm{CH}_{2} \beta \varepsilon_{2} \beta^{2,2} h$ bis-Arg), 1.26-1.64 (m, 35H, $\mathrm{CH}_{2} \beta \beta^{2,2} h$ bis-Arg, $\mathrm{CH}_{2} \gamma \beta^{2,2}$ $h$ bis-Arg and $\left.\mathrm{C}\left(\mathrm{CH}_{3}\right)_{3}\right)$; MALDI-TOF: calcd for $\mathrm{C}_{36} \mathrm{H}_{63} \mathrm{~N}_{11} \mathrm{O}_{3} 697.5$, calcd for $\mathrm{C}_{36} \mathrm{H}_{63} \mathrm{~N}_{11} \mathrm{O}_{3} \mathrm{Na} 720.5$, found $698.4[\mathrm{M}+\mathrm{H}]^{+}, 720.4[\mathrm{M}+\mathrm{Na}]^{+}, 736.3[\mathrm{M}+\mathrm{K}]^{+}, 681.3\left[\mathrm{M}+\mathrm{H}-\mathrm{NH}_{3}\right]^{+} ;$HPLC (Water/ACN (0.1\% TFA); $30 \%$ to $70 \% \mathrm{ACN}$ in $30 \mathrm{~min}$ ): $\operatorname{tr}=14.08 \mathrm{~min}$ (Figure 15 ).

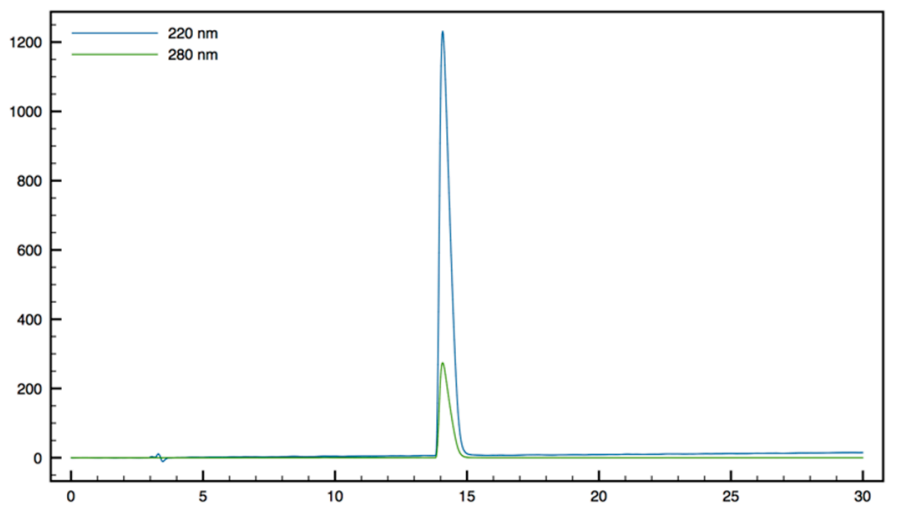

Figure 15. HPLC profile of Gua-Tbt- $\beta^{2,2}$ h bis-Arg-OMe 12.

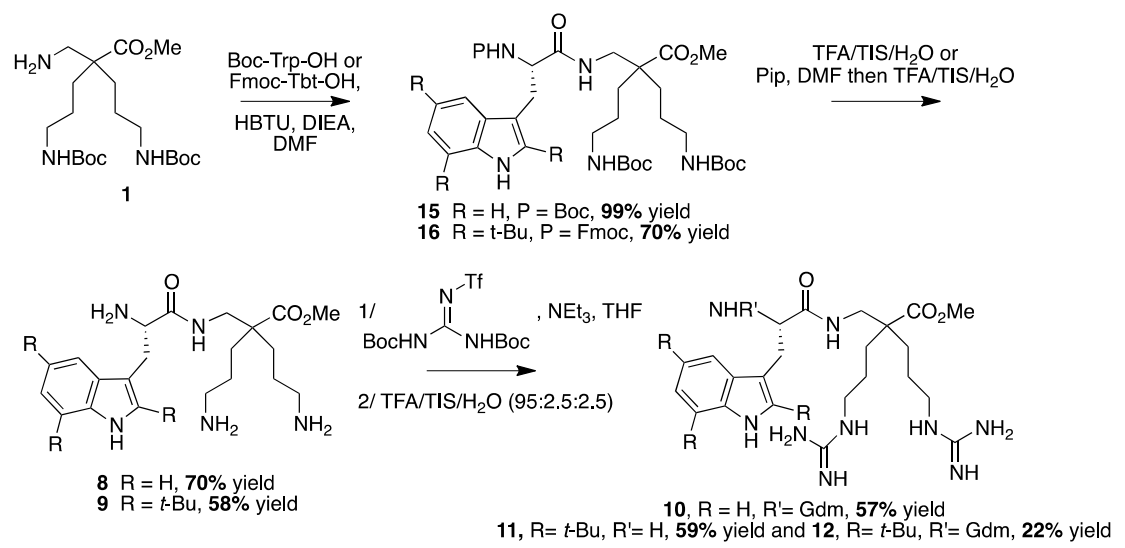

Scheme 9. Synthesis of peptides $8-12$ by LPPS. 


\subsubsection{Synthesis of Peptides 13 and 14 by SPPS (Scheme 10)}

$H-\beta^{3,3}-h$-bis-Arg-Tbt-OMe 13: HMBA-AM resin $(108 \mathrm{mg}, 0.1 \mathrm{mmol})$ was washed five times with DMF, DCM, and DMF, then allowed to swell in DMF for $30 \mathrm{~min}$. Fmoc-Tbt-OH (4 eq, $0.4 \mathrm{mmol}, 238 \mathrm{mg}$ ) was dissolved in dry DCM. The solution was cooled to $0{ }^{\circ} \mathrm{C}$, DIC ( $\left.4 \mathrm{eq}, 0.4 \mathrm{mmol}, 60 \mu \mathrm{L}\right)$ was added. The reaction was stirred for $1.5 \mathrm{~h}$ and the solvent was then removed in vacuo. The resulting anhydride was dissolved in DMF and added to the resin. A solution of DMAP (0.1 eq, $0.04 \mathrm{mmol}, 5 \mathrm{mg}$ ) in DMF was added and the resin was shaken for $1 \mathrm{~h}$ before washing with DMF, DCM, and DMF (resin loading $=0.84 \mathrm{mmol} / \mathrm{g}$ ). Removal of the Fmoc protecting group was achieved by treatment of the resin with 20\% (v:v) piperidine in DMF 3 times for $5 \mathrm{~min}$. The resin was washed five times with DMF. Boc- $\beta^{3,3} h$ bis-Orn(Boc) ${ }_{2} \mathrm{OH} 3$ (2 eq, $0.18 \mathrm{mmol}, 90 \mathrm{mg}$ ) was dissolved in DMF (1.2 mL). HATU (1.8 eq, $0.17 \mathrm{mmol}, 65 \mathrm{mg}$ ) and DIEA (2 eq, $0.18 \mathrm{mmol}, 23 \mu \mathrm{L}$ ) were added. The solution was added to the resin $(0.09 \mathrm{mmol}, 108 \mathrm{mg})$ and the coupling reaction was allowed to proceed for $2 \mathrm{~h}$ at room temperature. The solution was removed by filtration and the resin was washed with DMF five times. Reaction completion was monitored by Kaiser test. Boc removal was performed by treating the resin with a TFA/TIS/ $\mathrm{H}_{2} \mathrm{O}$ cocktail (95:2.5:2.5) for $5 \mathrm{~h}$. The free amines were then reacted with 1,3-Di-Boc-2-(trifluoromethylsulfonyl)guanidine (10 eq, $1.8 \mathrm{mmol}, 700 \mathrm{mg})$ and $\mathrm{NEt}_{3}\left(10 \mathrm{eq}_{\text {, }}\right.$ $1.8 \mathrm{mmol}, 240 \mu \mathrm{L}$ ) in DMF overnight. The resin was filtrated and the Boc groups were removed with a TFA/TIS/ $\mathrm{H}_{2} \mathrm{O}$ cocktail (95:2.5:2.5) at $\mathrm{rt}$ for $3 \mathrm{~h}$. After filtration, peptide $\mathbf{1 4}$ was cleaved from the resin using a mixture of MeOH/DMF/DIEA (5:5:1) for $16 \mathrm{~h}$ at $50{ }^{\circ} \mathrm{C}$. The solution was filtrated, and solvents were evaporated. The crude product was purified by preparative RP-HPLC using a gradient of $30 \%$ to $70 \% \mathrm{MeCN}$ in $30 \mathrm{~min}$. After lyophilisation peptide 13 was obtained as a white powder with a purity of >95\% (47 mg, 75\% yield); ${ }^{1} \mathrm{H}$ NMR (500 MHz, $\left.\mathrm{D}_{2} \mathrm{O}\right) \delta 7.37$ (d, $J=1.7,1 \mathrm{H}, \mathrm{CH}$ Ar indole), 7.28 (d, $J=1.7$, 1H, CH Ar indole), 4.69 (t, $J=7.5,1 \mathrm{H}, \mathrm{CH} \alpha \mathrm{Tbt}), 3.48-3.53\left(\mathrm{~m}, 1 \mathrm{H}, \mathrm{CH}_{2} \beta_{1} \mathrm{Tbt}\right), 3.68(\mathrm{dd}, J=10.5,1$, $\left.1 \mathrm{H}, \mathrm{CH}_{2} \beta_{2} \mathrm{Tbt}\right), 3.25\left(\mathrm{t}, J=6.5,1 \mathrm{H}, \mathrm{CH}_{2} \varepsilon_{1} \beta^{2,2} h\right.$ bis-Arg), $3.17\left(\mathrm{t}, J=6.5,1 \mathrm{H} \mathrm{CH} \varepsilon_{2} \beta^{2,2} h\right.$ bis-Arg), $2.69\left(\mathrm{~d}, J=16,1 \mathrm{H}, \mathrm{CH}_{2} \alpha_{1} \beta^{2,2} h\right.$ bis-Arg), $2.55\left(\mathrm{~d}, J=16,1 \mathrm{H}, \mathrm{CH}_{2} \alpha_{2} \beta^{2,2} h\right.$ bis-Arg), 1.70-1.75 (m, 4H, $\mathrm{CH}_{2} \gamma \beta^{2,2} h$ bis-Arg), 1.64-1.68 (m, 2H, $\mathrm{CH}_{2} \delta_{1} \beta^{2,2} h$ bis-Arg), 1.55-1.61 (m, 2H, $\mathrm{CH}_{2} \delta_{2} \beta^{2,2} h$ bis-Arg), $1.42\left(\mathrm{~s}, 9 \mathrm{H}, \mathrm{C}\left(\mathrm{CH}_{3}\right)_{3}\right), 1.40\left(\mathrm{~s}, 9 \mathrm{H}, \mathrm{C}\left(\mathrm{CH}_{3}\right)_{3}\right), 1.29\left(\mathrm{~s}, 9 \mathrm{H}, \mathrm{C}\left(\mathrm{CH}_{3}\right)_{3}\right)$; MALDI-TOF: calcd for $\mathrm{C}_{35} \mathrm{H}_{61} \mathrm{~N}_{9} \mathrm{O}_{2}$ 655.5, calcd for $\mathrm{C}_{35} \mathrm{H}_{61} \mathrm{~N}_{9} \mathrm{O}_{2} \mathrm{Na} 678.5$, found $656.5[\mathrm{M}+\mathrm{H}]^{+}, 678.5[\mathrm{M}+\mathrm{Na}]^{+}, 694.5[\mathrm{M}+\mathrm{K}]^{+} ; \mathrm{HPLC}$ (Water/ACN (0.1\% TFA); $5 \%$ to $100 \% \mathrm{ACN}$ in $30 \mathrm{~min}): \operatorname{tr}=19.29 \mathrm{~min}$ (Figure 16).

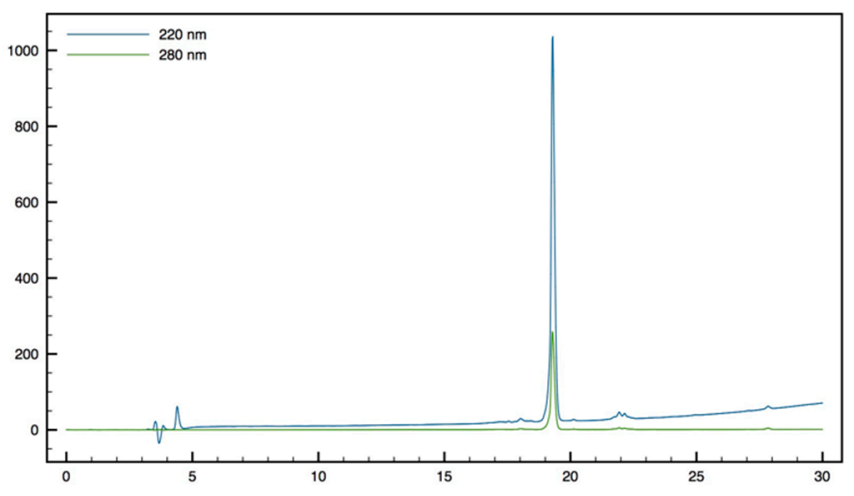

Figure 16. HPLC profile of H- $\beta^{3,3}$-h-bis-Arg-Tbt-OMe 13.

Gdm- $\beta^{2,2}-h$-bis-Arg-Tbt-OMe 14: HMBA-AM resin (185 mg, $0.2 \mathrm{mmol}$ ) was washed five times with DMF, DCM. and DMF, then allowed to swell in DMF for $30 \mathrm{~min}$. Fmoc-Tbt-OH (4 eq, $0.4 \mathrm{mmol}, 238 \mathrm{mg}$ ) was dissolved in dry DCM. The solution was cooled to $0{ }^{\circ} \mathrm{C}$, and DIC ( $\left.4 \mathrm{eq}, 0.4 \mathrm{mmol}, 60 \mu \mathrm{L}\right)$ was added. The reaction was stirred for $30 \mathrm{~min}$ and the solvent was then removed in vacuo. The resulting anhydride was dissolved in DMF and added to the resin. A solution of DMAP (0.1 eq, $0.04 \mathrm{mmol}$, $5 \mathrm{mg}$ ) in DMF was added and the resin was shaken for $1 \mathrm{~h}$ before washing with DMF, DCM, and DMF (resin loading $=0.4 \mathrm{mmol} / \mathrm{g}$ ). Removal of the Fmoc protecting group was achieved by treatment 
of the resin with 20\% (v:v) piperidine in DMF 3 times for $5 \mathrm{~min}$. The resin was washed five times with DMF. Fmoc- $\beta^{2,2} h$ bis-Orn(Boc) $)_{2} \mathrm{OH} 2$ (3 eq, $0.22 \mathrm{mmol}, 141 \mathrm{mg}$ ) was dissolved in DMF (1.5 mL). HATU ( $1.8 \mathrm{eq}, 0.21 \mathrm{mmol}, 80 \mathrm{mg}$ ) and DIEA ( $4 \mathrm{eq}, 0.88 \mathrm{mmol}, 150 \mu \mathrm{L}$ ) were added. The solution was added to the resin $(0.07 \mathrm{mmol}, 185 \mathrm{mg})$ and the reaction was allowed to proceed at $50{ }^{\circ} \mathrm{C}$ for $16 \mathrm{~h}$. The solution was removed by filtration and the resin was washed with DMF five times. The reaction being incomplete as revealed by a Kaiser test, the same coupling procedure was repeated a second time. The resin was then treated with a $20 \%$ solution of piperidine in DMF for 5 min 3 times. Boc removal was performed by treatment with a TFA/TIS/ $\mathrm{H}_{2} \mathrm{O}$ cocktail (95:2.5:2.5) for $1 \mathrm{~h}$. The free amines were then reacted with 1,3-Di-Boc-2-(trifluoromethylsulfonyl)guanidine (5 eq, $0.35 \mathrm{mmol}, 137 \mathrm{mg}$ ) and $\mathrm{NEt}_{3}$ (10 eq, $0.7 \mathrm{mmol}, 90 \mu \mathrm{L}$ ) in DMF overnight. The resin was filtrated and the Boc groups were removed with a TFA/TIS/ $\mathrm{H}_{2} \mathrm{O}$ cocktail (95:2.5:2.5) at rt for $3 \mathrm{~h}$. After filtration, peptide $\mathbf{1 4}$ was cleaved from the resin using a mixture of $\mathrm{MeOH} / \mathrm{DMF} / \mathrm{DIEA}(5: 5: 1)$ for $16 \mathrm{~h}$ at $50^{\circ} \mathrm{C}$. The solution was filtrated, and solvents were evaporated. The crude product was purified by preparative RP-HPLC using a gradient of $40 \%$ to $90 \% \mathrm{MeCN}$ in $30 \mathrm{~min}$. After lyophilisation, peptide 14 was obtained as white powder with a purity of $>95 \%$ ( $34 \mathrm{mg}, 72 \%$ yield); ${ }^{1} \mathrm{H}$ NMR $\left(300 \mathrm{MHz}, \mathrm{D}_{2} \mathrm{O}\right) \delta 7.36(\mathrm{~s}, 1 \mathrm{H}, \mathrm{CH}$ indole), $7.19(\mathrm{~s}, 1 \mathrm{H}, \mathrm{CH}$ indole), $4.7(\mathrm{~m}, 1 \mathrm{H}, \mathrm{CH \alpha} \mathrm{Tbt}), 3.61\left(\mathrm{~s}, 3 \mathrm{H}, \mathrm{CO}_{2} \mathrm{CH}_{3}\right), 3.53\left(\mathrm{dd}, J=15.3,6.6,1 \mathrm{H}, \mathrm{CH}_{2} \beta_{1} \mathrm{Tbt}\right), 3.31-3.36$ (m, $2 \mathrm{H}, \mathrm{CH}_{2} \beta_{2}$ Tbt and $\mathrm{CH}_{2} \beta \varepsilon_{1} \beta^{2,2} h$ bis-Arg), $2.88\left(\mathrm{t}, J=7,1 \mathrm{H}, \mathrm{CH}_{2} \delta_{1} \beta^{2,2} h\right.$ bis-Arg), 2.85 (t, $J=7$, $1 \mathrm{H}, \mathrm{CH}_{2} \delta_{2} \beta^{2,2} h$ bis-Arg), 2.83 (d, J = 14.5, $1 \mathrm{H}, \mathrm{CH}_{2} \beta \varepsilon_{2} \beta^{2,2} h$ bis-Arg), 1.42 (s, 9H, C( $\left.\left.\mathrm{CH}_{3}\right)_{3}\right), 1.39$ (s, $\left.9 \mathrm{H}, \mathrm{C}\left(\mathrm{CH}_{3}\right)_{3}\right), 1.27\left(\mathrm{~s}, 9 \mathrm{H}, \mathrm{C}\left(\mathrm{CH}_{3}\right)_{3}\right), 1.14-1.33\left(\mathrm{~m}, 8 \mathrm{H}, \mathrm{CH}_{2} \beta\right.$ and $\mathrm{CH}_{2} \gamma \beta^{2,2} h$ bis-Arg); MALDI-TOF: calcd for $\mathrm{C}_{36} \mathrm{H}_{63} \mathrm{~N}_{11} \mathrm{O}_{3} 697.5$, calcd for $\mathrm{C}_{36} \mathrm{H}_{63} \mathrm{~N}_{11} \mathrm{O}_{3} \mathrm{Na} 720.5$, found $698.5[\mathrm{M}+\mathrm{H}]^{+}, 720.4[\mathrm{M}+\mathrm{Na}]^{+}$, $736.4[\mathrm{M}+\mathrm{K}]^{+}$; HPLC (Water/ACN (0.1\% TFA); $30 \%$ to $70 \% \mathrm{ACN}$ in $30 \mathrm{~min}$ ): $\operatorname{tr}=16.5 \mathrm{~min}$ (Figure 17).

4.3.8. Synthesis of Fmoc-Tbt- $\beta^{2,2}-h$-bis-Orn-OMe 17a and Fmoc-Tbt- $\beta^{2,2}-h$-bis-Arg-OMe 17b (Scheme 11)

Fmoc-Tbt- $\beta^{2,2}-h$-bis-Orn-OMe 17a: Compound 16 (42 mg, $\left.0.042 \mathrm{mmol}\right)$ was treated with a mixture of TFA/TIS/ $\mathrm{H}_{2} \mathrm{O}(95: 2.5: 2.5, \mathrm{~V}=1 \mathrm{~mL})$ at $\mathrm{rt}$ for $3 \mathrm{~h}$ and then evaporated to dryness. The crude product was purified by preparative RP-HPLC using a gradient of $50 \%$ to $100 \% \mathrm{MeCN}$ in $30 \mathrm{~min}$. After lyophilisation compound 17a was obtained as white powder with purity $>99 \%$ ( $27 \mathrm{mg}, 95 \%$ yield); ${ }^{1} \mathrm{H}$ NMR (300 MHz, CD $\left.3 \mathrm{OD}\right) \delta 7.80(\mathrm{~d}, J=7.5 \mathrm{~Hz}, 2 \mathrm{H}, \mathrm{CH}$ Fmoc), 7.60 (t, $J=8.8 \mathrm{~Hz}, 2 \mathrm{H}, \mathrm{CH}$ Fmoc), 7.37-7.42 (m, 5H, CH indole and $\mathrm{CH}$ Fmoc), $7.13(\mathrm{~d}, J=1.4 \mathrm{~Hz}, 1 \mathrm{H}, \mathrm{CH}$ indole), $4.44(\mathrm{dt}, J=9.8 \mathrm{~Hz}$, $7.7 \mathrm{~Hz}, 1 \mathrm{H}, \mathrm{CH}$ Fmoc), 4.17-4.24 (m, 3H, $\mathrm{CH}_{2}$ Fmoc and $\left.\mathrm{CH} \alpha \mathrm{Tbt}\right), 3.59$ (d, J = 14.2 Hz, $1 \mathrm{H}, \mathrm{CH}_{2} \beta \varepsilon_{1}$ $\beta^{2,2} h$ bis-Arg), 3.41 (dd, $\left.J=14.6 \mathrm{~Hz}, 9 \mathrm{~Hz}, 1 \mathrm{H}, \mathrm{CH}_{2} \beta_{1} \mathrm{Tbt}\right), 3.26\left(\mathrm{dd}, J=14.2 \mathrm{~Hz}, 5.8 \mathrm{~Hz}, 1 \mathrm{H}, \mathrm{CH}_{2} \beta_{2}\right.$ Tbt), 2.88 (d, $J=14.2 \mathrm{~Hz}, 1 \mathrm{H}, \mathrm{CH}_{2} \beta \varepsilon_{2} \beta^{2,2} h$ bis-Arg), 2.79-2.82 (m, $4 \mathrm{H}, \mathrm{CH}_{2} \delta \beta^{2,2} h$ bis-Arg), 1.22-1.69 (m, 35H, C( $\left.\mathrm{CH}_{3}\right)_{3}, \mathrm{CH}_{2} \beta \beta^{2,2} h$ bis-Arg and $\mathrm{CH}_{2} \gamma \beta^{2,2} h$ bis-Arg); MALDI-TOF: calcd for $\mathrm{C}_{48} \mathrm{H}_{67} \mathrm{~N}_{5} \mathrm{O}_{5}$ 793.5, found $794.5[\mathrm{M}+\mathrm{H}]^{+}, 816.4[\mathrm{M}+\mathrm{Na}]^{+}, 832.4[\mathrm{M}+\mathrm{K}]^{+} ;$HPLC (Water/ACN $(0.1 \% \mathrm{TFA}) ; 50 \%$ to $100 \% \mathrm{ACN}$ in $10 \mathrm{~min}: \operatorname{tr}=6.29 \mathrm{~min}$ (Figure 18).

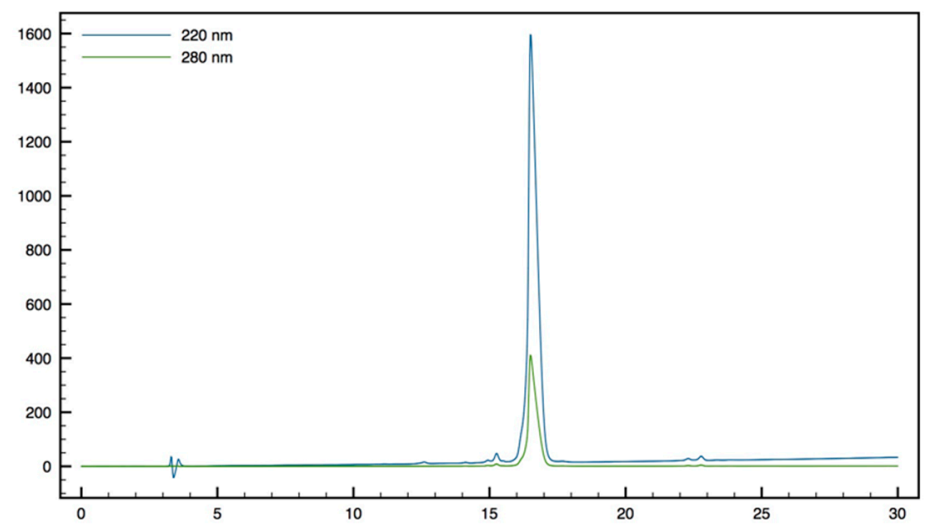

Figure 17. HPLC profile of Gdm- $\beta^{2,2}$-h-bis-Arg-Tbt-OMe 14. 


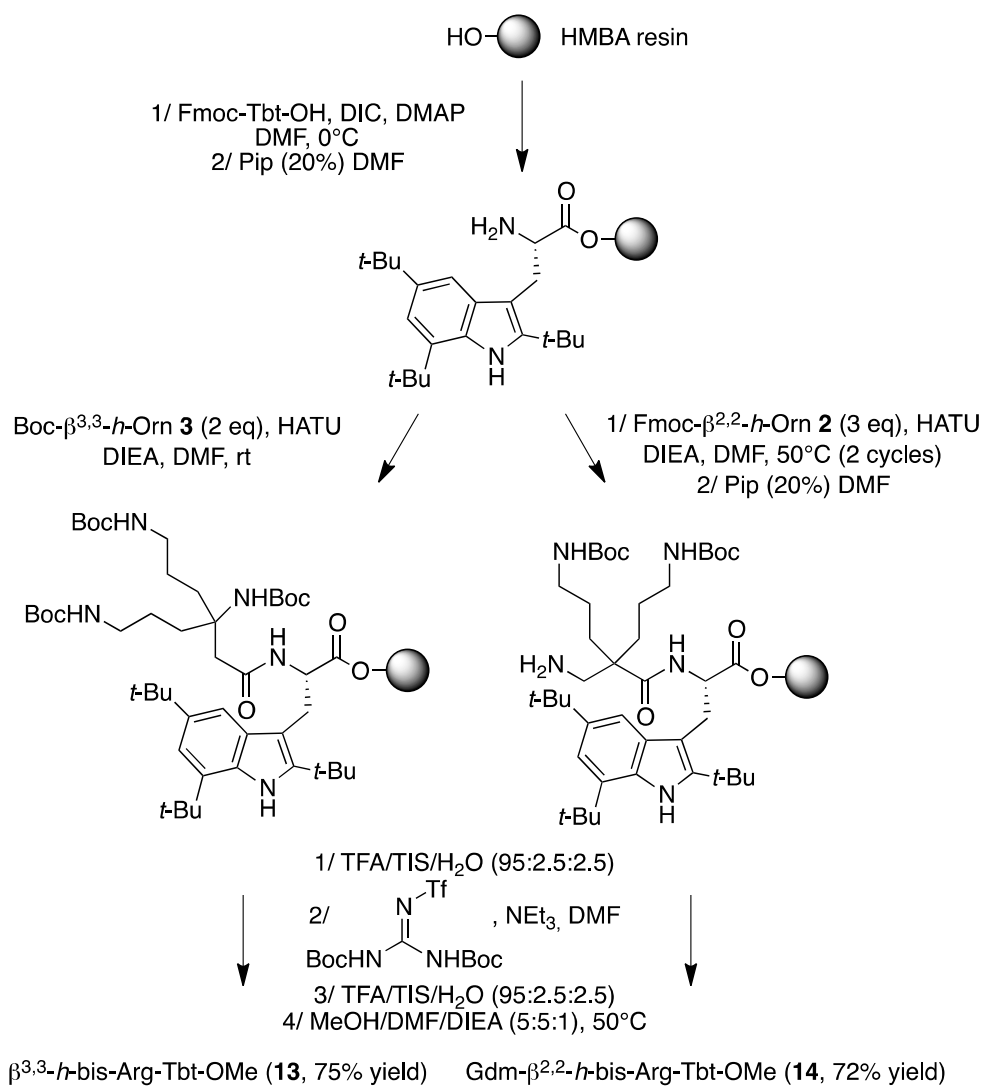

Scheme 10. Synthesis of peptides 13 and 14 by SPPS.

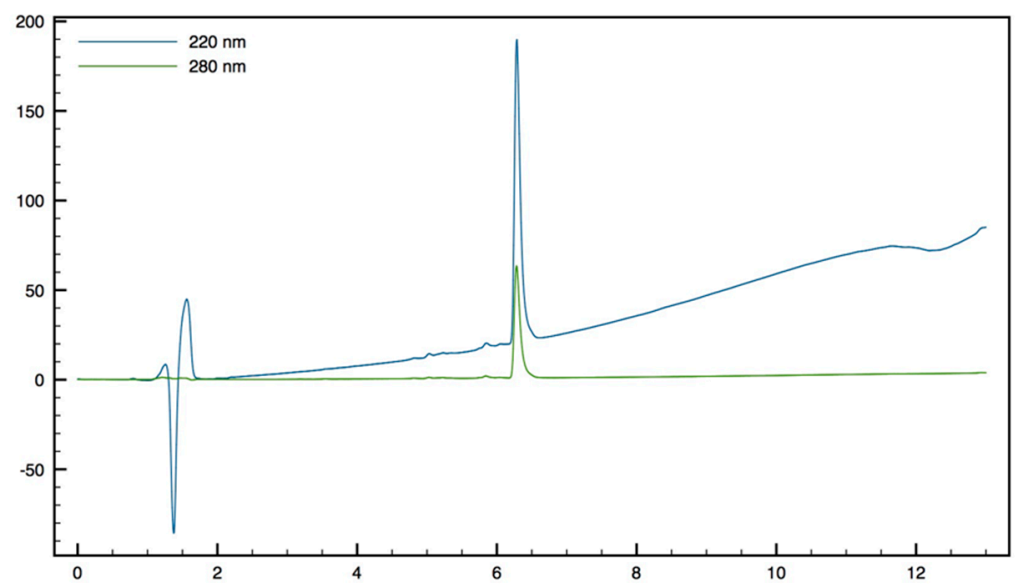

Figure 18. HPLC profile of Fmoc-Tbt- $\beta^{2,2}$-h-bis-Orn-OMe 17a.

Synthesis of Fmoc-Tbt- $\beta^{2,2}-h$-bis-Arg-OMe 17b

Compound 17a (50 mg, $0.05 \mathrm{mmol})$ was dissolved $1 \mathrm{~mL}$ of THF. 1,3-Di-Boc-2(trifluoromethylsulfonyl)guanidine ( $51 \mathrm{mg}, 0.13 \mathrm{mmol}$ ) and $\mathrm{NEt}_{3}(35 \mu \mathrm{L}, 0.26 \mathrm{mmol})$ were added and the reaction mixture was stirred at $\mathrm{rt}$ for $24 \mathrm{~h}$. After evaporation of THF, a solution of TFA/TIS/ $\mathrm{H}_{2} \mathrm{O}$ (95:2.5:2.5, $2 \mathrm{~mL}$ ) was added and the mixture was stirred at $\mathrm{rt}$ for $45 \mathrm{~min}$. The crude product was evaporated in vacuo and purified by preparative RP-HPLC using a gradient of $30 \%$ to $100 \% \mathrm{MeCN}$ in $30 \mathrm{~min}$. After lyophilisation compound $\mathbf{1 7 b}$ was obtained as white powders with purity $>99 \%(25 \mathrm{mg}$, $57 \%$ yield); ${ }^{1} \mathrm{H}$ NMR $\left(300 \mathrm{MHz}, \mathrm{CD}_{3} \mathrm{OD}\right) \delta 7.80(\mathrm{~d}, J=7.5 \mathrm{~Hz}, 2 \mathrm{H}, \mathrm{CH}$ arom Fmoc), $7.60(\mathrm{~d}, J=7.5 \mathrm{~Hz}$, $2 \mathrm{H}, \mathrm{CH}$ arom Fmoc), 7.39 (t, $J=7.5 \mathrm{~Hz}, 2 \mathrm{H}, \mathrm{CH}$ arom Fmoc), $7.33(\mathrm{~s}, 1 \mathrm{H}, \mathrm{CH}$ arom indole), $7.27(\mathrm{t}, J=$ $7.5 \mathrm{~Hz}, 2 \mathrm{H}, \mathrm{CH}$ arom Fmoc), 7.13 (s, 1H, CH indole), 4.27-4.38 (m, 2H, CH $\mathrm{CH}_{2}$. $)$, 4.18-4.22 (m, 2H, $\mathrm{CH}$ Fmoc and $\mathrm{CH} \alpha \mathrm{Tbt}), 3.56\left(\mathrm{~d}, J=11.8 \mathrm{~Hz}, 1 \mathrm{H}, \mathrm{CH}_{2} \beta \varepsilon_{1} \beta^{2,2} h\right.$ bis-Arg), $3.40(\mathrm{dd}, J=14.6 \mathrm{~Hz}, 9.1 \mathrm{~Hz}$, 
$1 \mathrm{H}, \mathrm{CH}_{2} \beta_{1} \mathrm{Tbt}$ ), 3.25 (dd, $\left.J=14.6 \mathrm{~Hz}, 5.5 \mathrm{~Hz}, 1 \mathrm{H}, \mathrm{CH}_{2} \beta_{2} \mathrm{Tbt}\right), 3-3.07\left(\mathrm{~m}, 4 \mathrm{H}, \mathrm{CH}_{2} \delta \beta^{2,2} h\right.$ bis-Arg), $2.72\left(\mathrm{~d}, J=14.3 \mathrm{~Hz}, 2 \mathrm{H}, \mathrm{CH}_{2} \beta \varepsilon_{2} \beta^{2,2} h\right.$ bis-Arg), $1.34-1.53\left(\mathrm{~m}, 35 \mathrm{H}, \mathrm{C}\left(\mathrm{CH}_{3}\right)_{3}, \mathrm{CH}_{2} \beta \beta^{2,2} h\right.$ bis-Arg and $\mathrm{CH}_{2} \gamma \beta^{2,2} h$ bis-Arg); MALDI-TOF: calcd for $\mathrm{C}_{50} \mathrm{H}_{71} \mathrm{~N}_{9} \mathrm{O}_{5}$ 877.6, found $878.4[\mathrm{M}+\mathrm{H}]^{+}, 916.4[\mathrm{M}+\mathrm{K}]^{+}$; HPLC (Water/ACN (0.1\% TFA); 5\% to $100 \%$ ACN in $30 \mathrm{~min}$ : tr $=24.59 \mathrm{~min}$ (Figure 19).

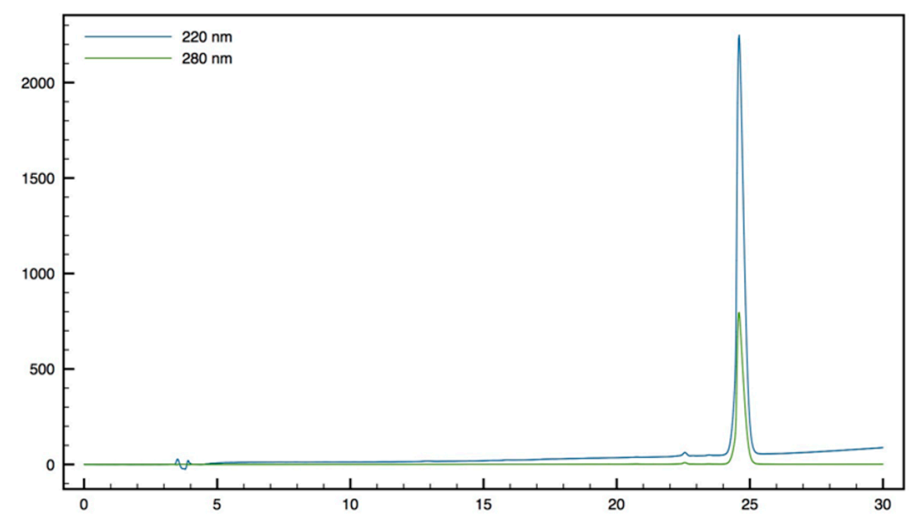

Figure 19. HPLC profile of Fmoc-Tbt- $\beta^{2,2}-h$-bis-Arg-OMe 17b.

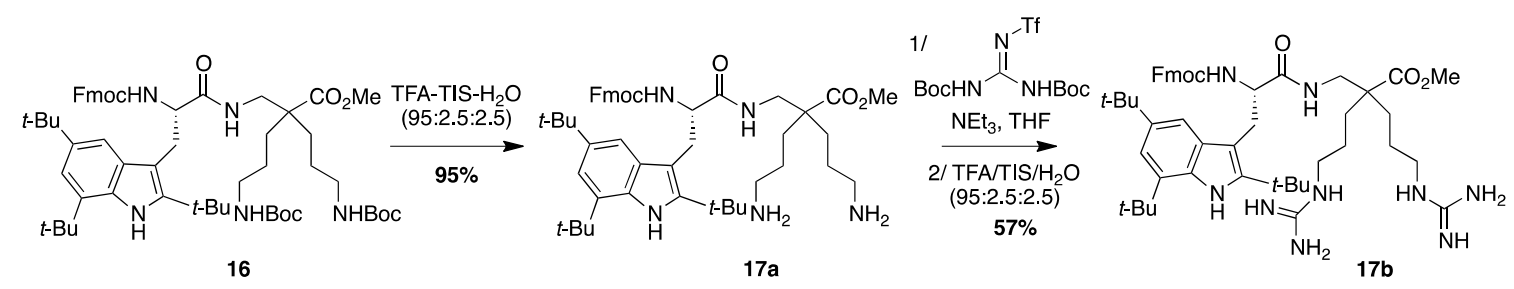

Scheme 11. Synthesis of Fmoc-Tbt- $\beta^{2,2}-h$-bis-Orn-OMe 17a and Fmoc-Tbt- $\beta^{2,2}-h$-bis-Arg-OMe 17b.

4.3.9. Synthesis of Fluo-Tbt- $\beta^{2,2}$ h bis-Orn-OMe 18 (Scheme 12)

Compound 16 (43 mg, $0.043 \mathrm{mmol})$ was dissolved in THF $(1 \mathrm{~mL})$ and treated with DBU $(0.2 \mu \mathrm{L}$, $0.0013 \mathrm{mmol})$ and octanethiol $(75 \mu \mathrm{L}, 0.43 \mathrm{mmol})$ at $\mathrm{rt}$ for $10 \mathrm{~min}$ and then evaporated to dryness. The crude compound was purified by flash chromatography (DCM/MeOH/NEt ${ }_{3}, 100: 0: 0$ to 80:20:1) affording a white powder $(17 \mathrm{mg}, 99 \%$ yield). The product was dissolved in $2 \mathrm{~mL}$ of THF. 2,7-di-tert-butylfluorène-9-carboxylic acid ( $17 \mathrm{mg}, 0.05 \mathrm{mmol})$, HBTU (16 mg, $0.043 \mathrm{mmol})$, and DIEA $(75 \mu \mathrm{L}, 0.43 \mathrm{mmol})$ were added and the reaction mixture was stirred at rt overnight. After evaporation of THF, a solution of TFA/TIS/ $\mathrm{H}_{2} \mathrm{O}(95: 2.5: 2.5,2 \mathrm{~mL})$ was added and the mixture was stirred at $\mathrm{rt}$ for $45 \mathrm{~min}$ and then evaporated. The crude product was purified by preparative RP-HPLC using a gradient of $50 \%$ to $100 \% \mathrm{MeCN}$ in $30 \mathrm{~min}$. After lyophilisation compound $\mathbf{1 8}$ was obtained as white powder with purity $>99 \%(24 \mathrm{mg}, 65 \%$ yield $) ;{ }^{1} \mathrm{H} \mathrm{NMR}\left(300 \mathrm{MHz}, \mathrm{CD}_{3} \mathrm{OD}\right) \delta 7.79$ (s, $\mathrm{CH}$ arom fluorenyl), $7.71(\mathrm{~d}, J=8 \mathrm{~Hz}, 2 \mathrm{H}, \mathrm{CH}$ arom fluorenyl), 7.59 (s, $\mathrm{CH}$ arom fluorenyl), $7.49(\mathrm{~d}, J=8 \mathrm{~Hz}, 2 \mathrm{H}$, $\mathrm{CH}$ arom fluorenyl), 7.36 (s, $1 \mathrm{H}, \mathrm{CH}$ indole), $7.14(\mathrm{~s}, 1 \mathrm{H}, \mathrm{CH}$ indole), 4.38 (dd, $J=10 \mathrm{~Hz}, 4 \mathrm{~Hz}, 1 \mathrm{H}, \mathrm{CH} \alpha$ $\mathrm{Tbt}), 3.65$ (d, $J=14 \mathrm{~Hz}, 1 \mathrm{H}, \mathrm{CH}_{2} \beta \varepsilon_{1} \beta^{2,2} h$ bis-Arg), 3.56 (dd, $J=14.8 \mathrm{~Hz}, 10.5 \mathrm{~Hz}, 1 \mathrm{H}, \mathrm{CH}_{2} \beta_{1} \mathrm{Tbt}$ ), $3.39\left(\mathrm{dd}, J=14.8 \mathrm{~Hz}, 4 \mathrm{~Hz}, 1 \mathrm{H}, \mathrm{CH}_{2} \beta_{2} \mathrm{Tbt}\right), 2.65$ (d, $J=14.3 \mathrm{~Hz}, 2 \mathrm{H}, \mathrm{CH}_{2} \beta \varepsilon_{2} \beta^{2,2} h$ bis-Arg), 2.52-2.66 (m, $2 \mathrm{H}, \mathrm{CH}_{2} \delta_{1} \beta^{2,2} h$ bis-Arg), 2.38-2.45 (m, 2H, $\mathrm{CH}_{2} \delta \beta^{2,2} h$ bis-Arg), 1.30-1.53 (m, 35H, C $\left(\mathrm{CH}_{3}\right)_{3}$, $\mathrm{CH}_{2} \beta \beta^{2,2} h$ bis-Arg and $\mathrm{CH}_{2} \gamma \beta^{2,2} h$ bis-Arg); MALDI-TOF: calcd for $\mathrm{C}_{55} \mathrm{H}_{81} \mathrm{~N}_{5} \mathrm{O}_{4}$ 875.6, found 876.6 $[\mathrm{M}+\mathrm{H}]^{+}, 898.6[\mathrm{M}+\mathrm{Na}]^{+}, 914.6[\mathrm{M}+\mathrm{K}]^{+} ; \mathrm{HPLC}$ (Water/ACN $(0.1 \% \mathrm{TFA}) ; 45 \%$ to $100 \% \mathrm{ACN}$ in 30 $\min : \operatorname{tr}=21.9 \min$ (Figure 20).

\subsubsection{Synthesis of Np-Tbt- $\beta^{2,2}$ h bis-Orn-OMe 19 (Scheme 13)}

Compound 16 (50 mg, $0.05 \mathrm{mmol})$ was dissolved in THF $(1 \mathrm{~mL})$ and treated with DBU $(0.3 \mu \mathrm{L}$, $0.002 \mathrm{mmol})$ and octanethiol $(90 \mu \mathrm{L}, 0.5 \mathrm{mmol})$ at $\mathrm{rt}$ for $10 \mathrm{~min}$ and then evaporated to dryness. The crude compound was purified by flash chromatography (DCM/MeOH/NEt ${ }_{3}, 100: 0: 0$ to 80:20:1) 
affording a white powder ( $34 \mathrm{mg}, 87 \%$ yield). This compound was dissolved in $4 \mathrm{~mL}$ of THF. 2-Naphtoyl chloride $(9.5 \mathrm{mg}, 0.05 \mathrm{mmol})$ and $\mathrm{NEt}_{3}(14 \mu \mathrm{L}, 0.1 \mathrm{mmol})$ were added and the reaction mixture was stirred at rt overnight. After evaporation of THF, a solution of TFA/TIS/ $\mathrm{H}_{2} \mathrm{O}$ (95:2.5:2.5, $2 \mathrm{~mL}$ ) was added and the mixture was stirred at $\mathrm{rt}$ for $30 \mathrm{~min}$ and then evaporated. The crude product was purified by preparative RP-HPLC using a gradient of 30\% to $100 \% \mathrm{MeCN}$ in $30 \mathrm{~min}$. After lyophilisation compound 19 was obtained as white powder with $96 \%$ purity $\left(22 \mathrm{mg}, 60 \%\right.$ yield); ${ }^{1} \mathrm{H} \mathrm{NMR}(300 \mathrm{MHz}$, $\left.\mathrm{CD}_{3} \mathrm{OD}\right) \delta 8.06(\mathrm{~s}, 1 \mathrm{H}, \mathrm{CH} \mathrm{Np}), 7.91(\mathrm{~d}, J=8.4 \mathrm{~Hz}, 2 \mathrm{H}, \mathrm{CH} \mathrm{Np}), 7.86(\mathrm{~d}, J=7.8 \mathrm{~Hz}, 1 \mathrm{H}, \mathrm{CH} \mathrm{Np}), 7.75(\mathrm{~d}$, $J=8.4 \mathrm{~Hz}, 1 \mathrm{H}, \mathrm{CH} \mathrm{Np}), 7.60(\mathrm{t}, J=6.4 \mathrm{~Hz}, 1 \mathrm{H}, \mathrm{CH} \mathrm{Np}), 7.56(\mathrm{t}, J=6.4 \mathrm{~Hz}, 1 \mathrm{H}, \mathrm{CH} \mathrm{Np}), 7.41(\mathrm{~s}, 1 \mathrm{H}, \mathrm{CH}$ indole), $7.18\left(\mathrm{~s}, 1 \mathrm{H}, \mathrm{CH}\right.$ indole), $4.57(\mathrm{t}, J=7.5 \mathrm{~Hz}, 1 \mathrm{H}, \mathrm{CH} \alpha \mathrm{Tbt}), 3.69\left(\mathrm{~d}, J=14.2,2 \mathrm{H}, \mathrm{CH}_{2} \beta \varepsilon_{1} \beta^{2,2} h\right.$ bis-Arg), 3.63 (dd, $J=14.7 \mathrm{~Hz}, 8.3 \mathrm{~Hz}, 1 \mathrm{H}, \mathrm{CH}_{2} \beta_{1} \mathrm{Tbt}$ ), 3.48 (dd, $J=14.7 \mathrm{~Hz}, 6.6 \mathrm{~Hz}, 1 \mathrm{H}, \mathrm{CH}_{2} \beta_{2} \mathrm{Tbt}$ ), $2.99\left(\mathrm{~d}, J=14.2,2 \mathrm{H}, \mathrm{CH}_{2} \beta \varepsilon_{1} \beta^{2,2} h\right.$ bis-Arg), 2.78-2.88 (m, 4H, $\mathrm{CH}_{2} \delta \beta^{2,2} h$ bis-Arg), 1.18-1.37 (m, 35H, $\mathrm{C}\left(\mathrm{CH}_{3}\right)_{3}, \mathrm{CH}_{2} \beta \beta^{2,2} h$ bis-Arg and $\mathrm{CH}_{2} \gamma \beta^{2,2} h$ bis-Arg); MALDI-TOF: calcd for $\mathrm{C}_{44} \mathrm{H}_{65} \mathrm{~N}_{5} \mathrm{O}_{5} 725.5$, found $726.4[\mathrm{M}+\mathrm{H}]^{+}, 748.4[\mathrm{M}+\mathrm{K}]^{+}, 764.4[\mathrm{M}+\mathrm{K}]^{+}$; HPLC (Water/ACN $(0.1 \% \mathrm{TFA}) ; 5 \%$ to $100 \%$ $\mathrm{ACN}$ in $30 \mathrm{~min}: \operatorname{tr}=21.9 \mathrm{~min}$ (Figure 21).

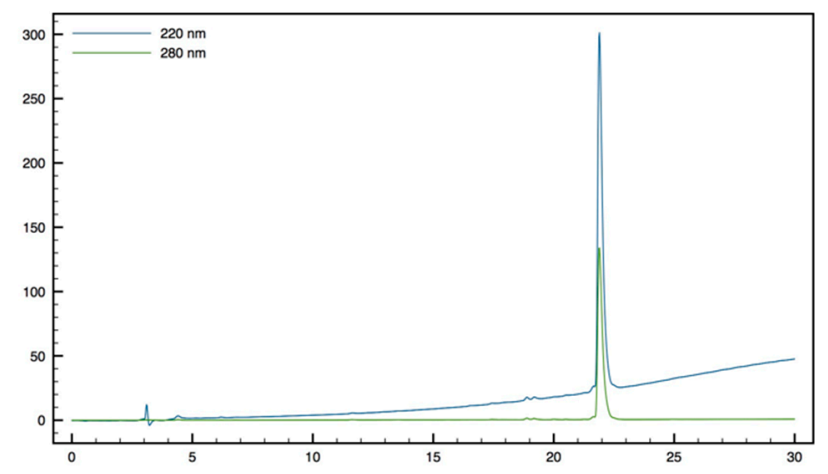

Figure 20. HPLC profile of Fluo-Tbt- $\beta^{2,2}$ h bis-Orn-OMe 18.

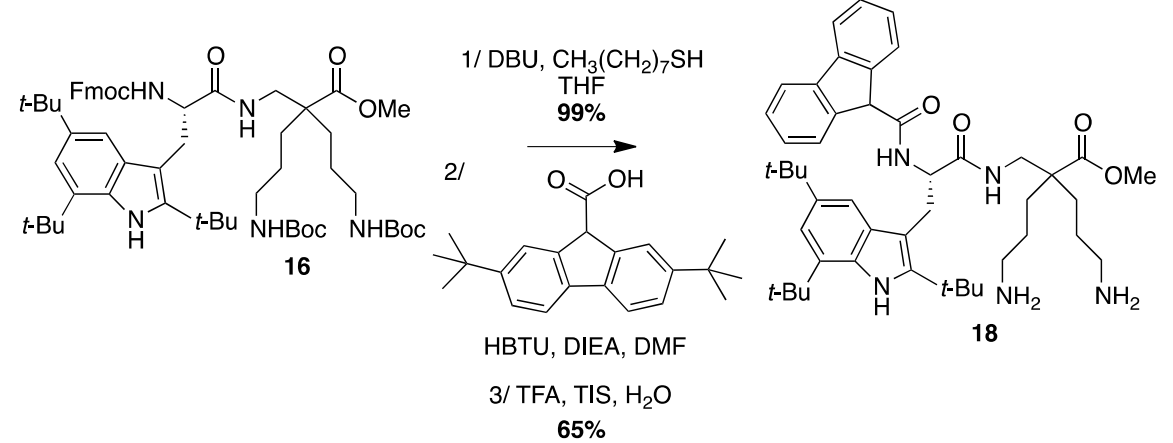

Scheme 12. Synthesis of Fluo-Tbt- $\beta^{2,2}$ h bis-Orn-OMe 18.

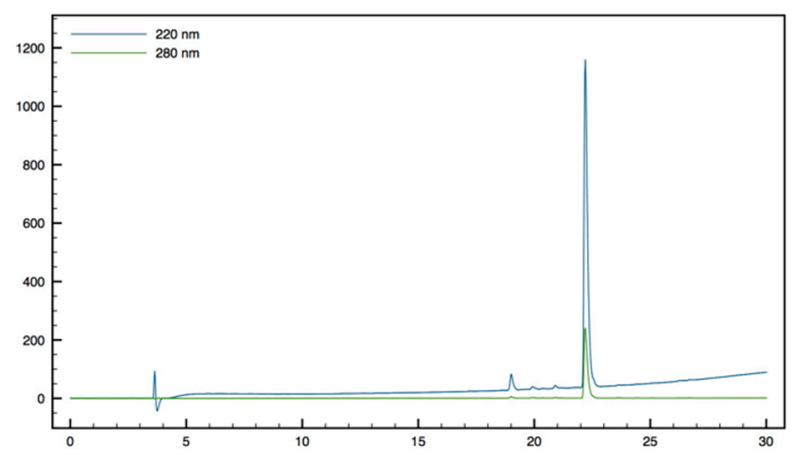

Figure 21. HPLC profile of Np-Tbt- $\beta^{2,2}$ h bis-Orn-OMe 19. 

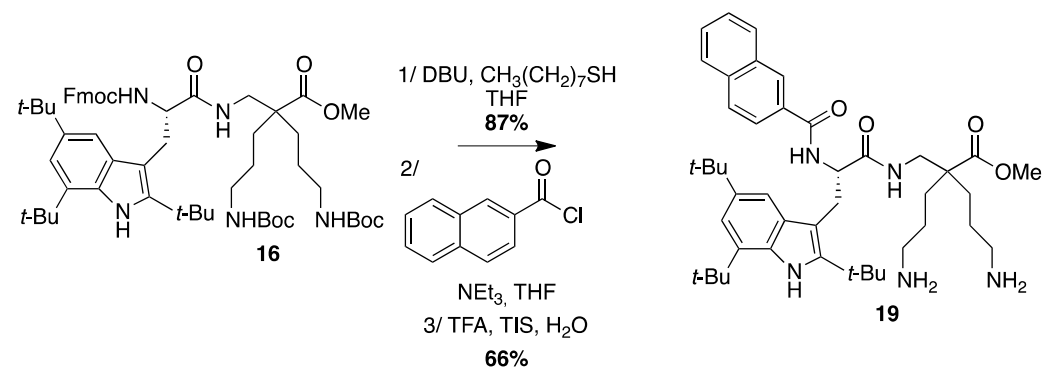

Scheme 13. Synthesis of Np-Tbt- $\beta^{2,2} \mathrm{~h}$ bis-Orn-OMe 19.

\subsubsection{Synthesis of Tbt- $\beta^{2,2} \mathrm{~h}$ bis-Arg-OBn 20 (Scheme 14)}

$\beta^{2,2}$-h-bis-Orn (Boc) ${ }_{2} \mathrm{OBn}$ 27: Fmoc $\beta^{2,2}-h$-bis-Orn(Boc) ${ }_{2} \mathrm{OH} 2$ (300 mg, $\left.0.48 \mathrm{mmol}\right)$ was dissolved in $\mathrm{MeCN}(1.7 \mathrm{~mL})$. After addition of $\mathrm{Cs}_{2} \mathrm{CO}_{3}(188 \mathrm{mg}, 0.58 \mathrm{mmol})$ and benzyl bromide $(63 \mu \mathrm{L}, 0.53 \mathrm{mmol})$, the reaction mixture was heated at $60^{\circ} \mathrm{C}$ under microwave $(150 \mathrm{~W})$ for $10 \mathrm{~min}$. The solution was filtered and evaporated to dryness. The crude compound was dissolved in $\mathrm{AcOEt}$ and washed with an aqueous solution of $\mathrm{NaHCO}_{3} 5 \%$ followed by a solution of citric acid $5 \%$, then dried over $\mathrm{MgSO}_{4}$, filtered, and concentrated in vacuo. The crude compound was purified by flash chromatography (DCM/MeOH/NEt 3 100:0:0.1 to 95:5:0.1) to afford a white powder $\left(80 \mathrm{mg}, 28 \%\right.$ yield); ${ }^{1} \mathrm{H}$ NMR (300 $\left.\mathrm{MHz}, \mathrm{CD}_{3} \mathrm{OD}\right) \delta$ 7.34-7.43 (m, 5H, CH Ar), $5.17\left(\mathrm{~s}, 2 \mathrm{H}, \mathrm{CH}_{2} \mathrm{Ph}\right), 3.01\left(\mathrm{t}, J=6.8 \mathrm{~Hz}, 4 \mathrm{H}, \mathrm{CH}_{2} \delta\right), 2.84\left(\mathrm{~s}, 2 \mathrm{H}, \mathrm{CH}_{2} \beta \varepsilon\right), 1.62$ $\left(\mathrm{dd}, J=9.3 \mathrm{~Hz}, 5.3 \mathrm{~Hz}, 4 \mathrm{H}, \mathrm{CH}_{2} \beta\right), 1.43\left(\mathrm{~s}, 18 \mathrm{H}, \mathrm{C}\left(\mathrm{CH}_{3}\right)_{3}\right), 1.24-1.41\left(\mathrm{~m}, 4 \mathrm{H}, \mathrm{CH}_{2} \gamma\right) ;{ }^{13} \mathrm{C} \mathrm{NMR}(75 \mathrm{MHz}$, $\left.\mathrm{CD}_{3} \mathrm{OD}\right) \delta 176.9$ (C, C=O ester), 158.5 (2C, $\mathrm{C}=\mathrm{O}$ carbamate), 137.5 (C, C Ar), 129.6, 129.4, $129.3(3 \mathrm{CH}$, $\mathrm{CH} \mathrm{Ar}), 79.9\left(2 \mathrm{C}, \mathrm{C}\left(\mathrm{CH}_{3}\right)_{3}\right), 67.5\left(\mathrm{CH}_{2}, \mathrm{CH}_{2} \mathrm{Ph}\right), 51.3\left(\mathrm{CH}_{2}, \mathrm{CH}_{2} \mathrm{\beta \varepsilon}\right), 45.5(\mathrm{C}, \mathrm{C} \alpha), 41.5\left(2 \mathrm{CH}_{2}, \mathrm{CH}_{2} \delta\right)$, $31.1\left(2 \mathrm{CH}_{2}, \mathrm{CH}_{2} \beta\right), 28.8\left(6 \mathrm{CH}_{3}, \mathrm{C}\left(\mathrm{CH}_{3}\right)_{3}\right), 25.3\left(2 \mathrm{CH}_{2}, \mathrm{CH}_{2} \gamma\right)$; HRMS-ESI+: calcd for $\mathrm{C}_{26} \mathrm{H}_{43} \mathrm{~N}_{3} \mathrm{O}_{6}$ 493.3152, found $494.3225[\mathrm{M}+\mathrm{H}]^{+}$.

Fmoc-Tbt- $\beta^{2,2}-h$-bis-Orn (Boc) ${ }_{2} \mathrm{OBn}$ 28: Fmoc-Tbt-OH ( $\left.83 \mathrm{mg}, 0.14 \mathrm{mmol}\right)$ was dissolved in DMF (6 mL). HBTU $(53 \mathrm{mg}, 0.14 \mathrm{mmol})$ and DIEA $(24 \mu \mathrm{L}, 0.14 \mathrm{mmol})$ were added and the mixture was stirred for $5 \mathrm{~min}$ before addition of $\mathrm{H}-\beta^{2,2}-h$-bis-Orn(Boc $)_{2} \mathrm{OBn} 28$ (70 mg, $\left.0.14 \mathrm{mmol}\right)$. The reaction mixture was stirred at room temperature overnight, then diluted with $\mathrm{Et}_{2} \mathrm{O}$ and washed with an aqueous saturated solution of $\mathrm{NH}_{4} \mathrm{Cl}$. The organic layer was dried over $\mathrm{MgSO}_{4}$, filtered, and evaporated to dryness. The crude compound was purified by flash chromatography (Cy/AcOEt, 100:0 to 70:30) to afford the pure protected dipeptide as a white powder $\left(67 \mathrm{mg}, 45 \%\right.$ yield). ${ }^{1} \mathrm{H}$ NMR $(300 \mathrm{MHz}, \mathrm{MeOD}) \delta 7.91(\mathrm{~s}, 1 \mathrm{H}$, $\mathrm{NH}$ indole), 7.66 (d, $J=7.5,1 \mathrm{H}, \mathrm{CH}$ Ar Fmoc), 7.45 (d, J = 7.2, 1H, CH Ar Fmoc), 7.37 (s, 1H, CH Ar indole), 7.3 (t, $J=7.5,1 \mathrm{H}, \mathrm{CH}$ Ar Fmoc), 7.18 (dt, $J=14.7$ and 6.9, 1H, CH Ar Fmoc), 7.09 (s, 1H, CH indole), 5.89 (bs, 2H, NH Boc), 5.71 (bs, 1H, NH Fmoc), 4.87 (s, 2H, $\left.\mathrm{CH}_{2} \mathrm{Ph}\right), 4.20-4.34$ (m, 3H, CH $\alpha$ Tbt and $\mathrm{CH}_{2}$ Fmoc), 4.09 ( $\mathrm{t}, J=7.2,1 \mathrm{H}, \mathrm{CH}$ Fmoc), $3.37\left(\mathrm{~d}, J=14.1,1 \mathrm{H}, \mathrm{CH}_{2} \beta \varepsilon_{1} \beta^{2,2} h\right.$ bis-Orn), $3.31(\mathrm{~d}, J=$ $7.5 \mathrm{~Hz}, 2 \mathrm{H}, \mathrm{CH}_{2} \beta \mathrm{Tbt}$ ), 2.86 (m, $4 \mathrm{H}, \mathrm{CH}_{2} \delta \beta^{2,2} h$ bis-Orn), 2.55 (d, $J=14.1,1 \mathrm{H}, \mathrm{CH}_{2} \beta \varepsilon_{2} \beta^{2,2} h$ bis-Orn), $1.52\left(\mathrm{~s}, 9 \mathrm{H}, \mathrm{C}\left(\mathrm{CH}_{3}\right)_{3}\right.$ indole), $1.47\left(\mathrm{~s}, 9 \mathrm{H}, \mathrm{C}\left(\mathrm{CH}_{3}\right)_{3}\right.$ indole $), 1.36-1.44\left(\mathrm{~m}, 35 \mathrm{H}, \mathrm{C}\left(\mathrm{CH}_{3}\right)_{3}\right.$ indole, $\mathrm{C}\left(\mathrm{CH}_{3}\right)_{3}$ Boc, $\mathrm{CH}_{2} \beta \beta^{2,2} h$ bis-Orn and $\mathrm{CH}_{2} \gamma \beta^{2,2} h$ bis-Orn).

H-Tbt- $\beta^{2,2}$ h bis-Arg-OBn 20: Compound 28 (68 mg, $\left.0.064 \mathrm{mmol}\right)$ was dissolved in DCM ( 0.4 M) and an equivalent volume of TFA. The mixture was stirred at $\mathrm{rt}$ for $1.5 \mathrm{~h}$ then evaporated to dryness. The crude compound was dissolved in $4 \mathrm{~mL}$ of THF.

1,3-Di-Boc-2-(trifluoromethylsulfonyl)guanidine ( $50 \mathrm{mg}, 0.128 \mathrm{mmol}$ ) and $\mathrm{NEt}_{3}(500 \mu \mathrm{L}, 3.2 \mathrm{mmol}$ ) were added and the reaction mixture was stirred at $\mathrm{rt}$ for $16 \mathrm{~h}$. After evaporation of THF, the crude mixture was dissolved in a 20\% solution of piperidine in DCM and allowed to react for $2 \mathrm{~h}$ before evaporation to dryness. A solution of TFA/TIS (95:5) was added and the mixture was stirred at $\mathrm{rt}$ for $1.5 \mathrm{~h}$. After evaporation, the crude product was purified by preparative RP-HPLC using a gradient of $20 \%$ to $90 \% \mathrm{MeCN}$ in $30 \mathrm{~min}$. After lyophilisation compound 20 was obtained as white powder with purity $>99 \%(10 \mathrm{mg}, 22 \%$ yield $) ;{ }^{1} \mathrm{H}$ NMR $\left(300 \mathrm{MHz}, \mathrm{CD}_{3} \mathrm{OD}\right) \delta 8.36(\mathrm{~s}, 1 \mathrm{H}, \mathrm{NH}$ indole), 7.20-7.32 (m, $5 \mathrm{H}, \mathrm{CH} \mathrm{Ph}), 7.28\left(\mathrm{~s}, 1 \mathrm{H}, \mathrm{CH}\right.$ indole), 7.15 (s, $1 \mathrm{H}, \mathrm{CH}$ indole), $5.03\left(\mathrm{~d}, J=12 \mathrm{~Hz}, 1 \mathrm{H}, \mathrm{CH}_{2} \mathrm{Ph}\right), 5.01$ (d, $J=$ 
$\left.12 \mathrm{~Hz}, 1 \mathrm{H}, \mathrm{CH}_{2} \mathrm{Ph}\right), 4.03(\mathrm{t}, J=6.1 \mathrm{~Hz}, 1 \mathrm{H}, \mathrm{CH} \alpha \mathrm{Tbt}), 3.60\left(\mathrm{~d}, J=14.2,1 \mathrm{H}, \mathrm{CH}_{2} \beta \varepsilon_{1} \beta^{2,2} h\right.$ bis-Arg), 3.42 $\left(\mathrm{d}, J=6.6 \mathrm{~Hz}, 2 \mathrm{H}, \mathrm{CH}_{2} \beta \mathrm{Tbt}\right), 2.97-3\left(\mathrm{~m}, 4 \mathrm{H}, \mathrm{CH}_{2} \delta \beta^{2,2} h \mathrm{bis}-\mathrm{Arg}\right), 2.33\left(\mathrm{~d}, J=1.24 \mathrm{~Hz}, 1 \mathrm{H}, \mathrm{CH}_{2} \beta \varepsilon_{2} \beta^{2,2}\right.$ $h$ bis-Arg), $1.20-1.59$ (m, 35H, $\mathrm{C}\left(\mathrm{CH}_{3}\right)_{3}, \mathrm{CH}_{2} \beta \beta^{2,2} h$ bis-Arg and $\mathrm{CH}_{2} \gamma \beta^{2,2} h$ bis-Arg); MALDI-TOF: calcd for $\mathrm{C}_{48} \mathrm{H}_{67} \mathrm{~N}_{5} \mathrm{O}_{5} 731.5$, found $732.4[\mathrm{M}+\mathrm{H}]^{+}, 770.3\left[\mathrm{M}+\mathrm{K}^{+}, 716.3\left[\mathrm{M}+\mathrm{H}-\mathrm{NH}_{3}\right]^{+}\right.$; HPLC (Water/ACN (0.1\% TFA); $40 \%$ to $90 \% \mathrm{ACN}$ in $10 \mathrm{~min}$ : $\operatorname{tr}=7.51 \mathrm{~min}$ (Figure 22).

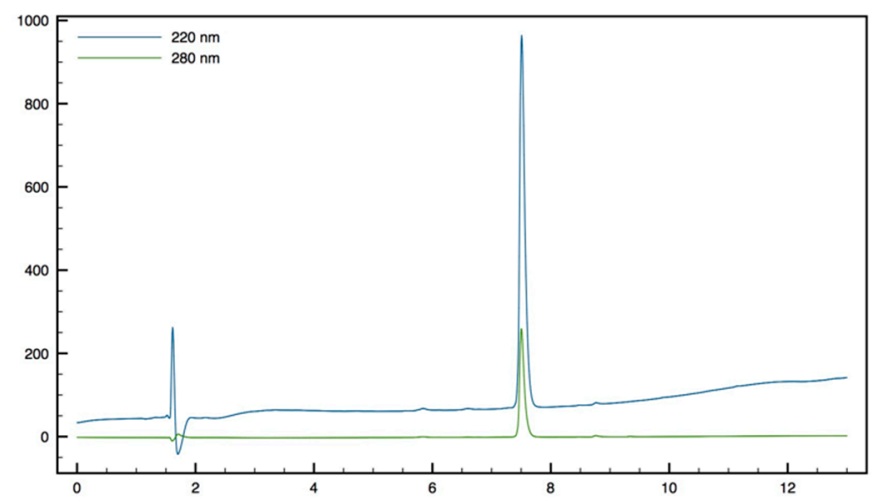

Figure 22. HPLC profile of $H-T b t-\beta^{2,2} h$ bis-Arg-OBn 20.
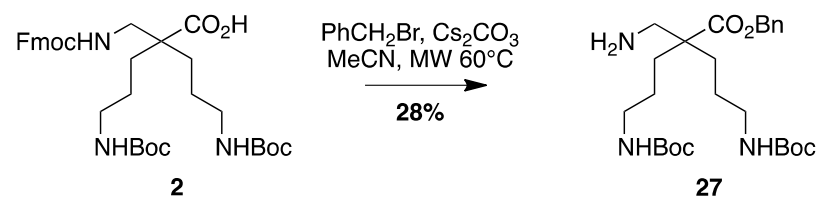

FmocTbt-OH, HBTU DIEA, DMF $45 \%$

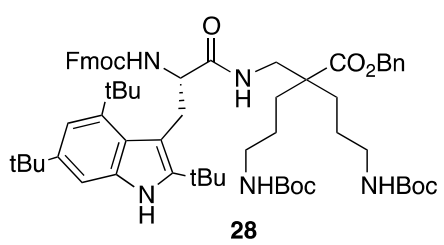

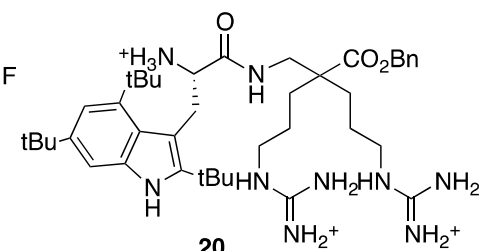

Scheme 14. Synthesis of Tbt- $\beta^{2,2}$ h bis-Arg-OBn 20.

\subsubsection{Synthesis of Tbt- $\beta^{2,2} \mathrm{~h}$ bis-Arg-NHBn 21 (Scheme 15)}

$\beta^{2,2}$-h-bis-Orn(Boc) ${ }_{2} \mathrm{NHBn}$ 29: Fmoc $\beta^{2,2}$-h-bis-Orn(Boc) ${ }_{2} \mathrm{OH} 2$ (300 mg, $0.48 \mathrm{mmol}$ ) was dissolved in DCM (20 mL). DCC (100 mg, $0.48 \mathrm{mmol})$, HOBt (64 mg, $0.48 \mathrm{mmol})$, DMAP (5 mg, $0.05 \mathrm{mmol})$, and benzyl amine ( $56 \mathrm{mg}, 0.53 \mathrm{mmol}$ ) were added. The reaction mixture was stirred at rt overnight. The solution was washed with an aqueous saturated solution of $\mathrm{NaCl}$, dried over $\mathrm{MgSO}_{4}$, filtered, and concentrated in vacuo. The crude compound was purified by flash chromatography (Cy/AcOEt 100:0 to 50:50) to afford a colorless oil (251 mg, 73\% yield); $\mathbf{R}_{\mathbf{f}}(\mathrm{Cy} / \mathrm{AcOEt}, 7: 3)=0.5 ;{ }^{1} \mathrm{H} \mathrm{NMR}(300 \mathrm{MHz}$, $\left.\mathrm{CDCl}_{3}\right) \delta 7.76(\mathrm{~d}, J=7.5 \mathrm{~Hz}, 2 \mathrm{H}, \mathrm{CH} \mathrm{Ar}), 7.58(\mathrm{~d}, J=7.5 \mathrm{~Hz}, 2 \mathrm{H}, \mathrm{CH} \mathrm{Ar}), 7.40(\mathrm{t}, J=7.5 \mathrm{~Hz}, 2 \mathrm{H}, \mathrm{CH}$ $\mathrm{Ar}$ ), 7.25-7.33 (m, 7H, CH Ar), 6.48 (bs, 1H, NH amide), 5.47 (bs, 1H, NH Fmoc), 4.78 (bs, 2H, NH Boc), 4.36-4.42 (m, 4H, CH $\mathrm{Ch}_{2} \mathrm{CH}_{2}$ Fmoc), 4.15-4.20 (m, 1H, CH Fmoc), 3.36-3.38 (m, 2H, CH $\mathrm{C}_{2} \beta \varepsilon$ ), 2.98-3.04 (m, 4H, $\left.\mathrm{CH}_{2} \delta\right), 1.31-1.69\left(\mathrm{~m}, 26 \mathrm{H}, \mathrm{CH}_{2} \beta, \mathrm{C}\left(\mathrm{CH}_{3}\right)_{3}, \mathrm{CH}_{2} \gamma\right) ;{ }^{13} \mathrm{C} \mathrm{NMR}\left(75 \mathrm{MHz}, \mathrm{CD}_{3} \mathrm{OD}\right) \delta$ 175.3 (C, C=O amide), 157.3 (C, $\mathrm{C}=\mathrm{O}$ carbamate), 156.3 (C, $\mathrm{C}=\mathrm{O}$ carbamate), 143.9, 141.4, 138.3 (3C, C Ar), 128.8, 127.8, 127.6, 127.1, 125.1, $120.1(6 \mathrm{CH}, \mathrm{CH} \mathrm{Ar}), 79.2\left(\mathrm{C}, \mathrm{C}\left(\mathrm{CH}_{3}\right)_{3}\right), 66.9\left(\mathrm{CH}_{2}, \mathrm{CH}_{2} \mathrm{Fmoc}\right)$, $49.8(\mathrm{C}, \mathrm{C} \alpha), 47.3\left(\mathrm{CH}, \mathrm{CH}\right.$ Fmoc), $44.6\left(\mathrm{CH}_{2}, \mathrm{CH}_{2} \beta \varepsilon\right), 43.8\left(\mathrm{CH}_{2}, \mathrm{CH}_{2} \mathrm{Ph}\right), 40.7\left(\mathrm{CH}_{2}, \mathrm{CH}_{2} \delta\right), 30.8\left(\mathrm{CH}_{2}\right.$, $\left.\mathrm{CH}_{2} \beta\right), 29.0\left(\mathrm{CH}_{3}, \mathrm{C}\left(\mathrm{CH}_{3}\right)_{3}\right), 24.2\left(\mathrm{CH}_{2}, \mathrm{CH}_{2} \gamma\right)$; Fmoc $\beta^{2,2}$-h-bis-Orn(Boc) ${ }_{2} \mathrm{NHBn}(251 \mathrm{mg}, 0.35 \mathrm{mmol})$ was dissolved in THF $(6 \mathrm{~mL})$. Octanethiol $(600 \mu \mathrm{L}, 3.5 \mathrm{mmol})$ and DBU $(1.5 \mu \mathrm{L}, 0.01 \mathrm{mmol})$ were added. The reaction mixture was stirred for $15 \mathrm{~min}$ then concentrated in vacuo. The crude compound was purified by flash chromatography (DCM/MeOH/NEt 3 100:0:0 to 80:20:0.1) to afford 29 as a colorless oil (150 mg, 87\% yield); ${ }^{1} \mathrm{H}$ NMR (300 MHz, $\left.\mathrm{CDCl}_{3}\right) \delta 8.94$ (bs, $\left.2 \mathrm{H}, \mathrm{NH}_{2}\right), 7.15-7.24$ (m, 5H, CH Ar), 4.75 (bs, 2H, NH Boc), 4.33-4.35 (m, 2H, $\left.\mathrm{CH}_{2} \mathrm{Ph}\right), 2.98-3.11\left(\mathrm{~m}, 4 \mathrm{H}, \mathrm{CH}_{2} \delta\right), 2.80$ (s, 2H, $\left.\mathrm{CH}_{2} \beta \varepsilon\right), 1.01-1.73$ 
(m, 26H, $\left.\mathrm{CH}_{2} \beta, \mathrm{C}\left(\mathrm{CH}_{3}\right)_{3}, \mathrm{CH}_{2} \gamma\right) ;{ }^{13} \mathrm{C}$ NMR $\left(75 \mathrm{MHz}, \mathrm{CD}_{3} \mathrm{OD}\right) \delta 176.3$ (C, $\mathrm{C}=\mathrm{O}$ amide), 156.1 (C, $\mathrm{C}=\mathrm{O}$ carbamate), 139 (C, C Ar), 128.5, 127.3, $127(3 \mathrm{CH}, \mathrm{CH} \mathrm{Ar}), 78.9\left(\mathrm{C}, \mathrm{C}\left(\mathrm{CH}_{3}\right)_{3}\right), 47.3(\mathrm{C}, \mathrm{C} \alpha), 45.3\left(\mathrm{CH}_{2}\right.$,

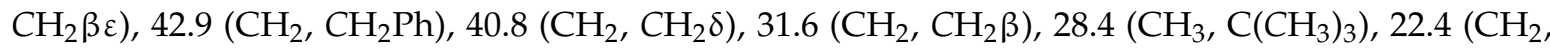
$\mathrm{CH}_{2} \gamma$ ); HRMS-ESI+: calcd for $\mathrm{C}_{26} \mathrm{H}_{44} \mathrm{~N}_{4} \mathrm{O}_{5} 492.3312$, found $515.3199[\mathrm{M}+\mathrm{Na}]^{+}$.

Fmoc-Tbt- $\beta^{2,2}$ h bis-Orn (Boc) ${ }_{2} \mathrm{NHBn}$ 30: Fmoc-Tbt-OH (90 mg, $0.15 \mathrm{mmol}$ ) was dissolved in DMF (6 mL). HBTU $(57 \mathrm{mg}, 0.15 \mathrm{mmol})$ and DIEA $(30 \mu \mathrm{L}, 0.15 \mathrm{mmol})$ were added and the mixture was stirred for $5 \mathrm{~min}$ before addition of $\mathrm{H}-\beta^{2,2} h$ bis-Orn(Boc) ${ }_{2} \mathrm{NHBn} 29(75 \mathrm{mg}, 0.15 \mathrm{mmol})$. The reaction mixture was stirred at room temperature overnight, then diluted with $\mathrm{Et}_{2} \mathrm{O}$ and washed with an aqueous saturated solution of $\mathrm{NH}_{4} \mathrm{Cl}$. The organic layer was dried over $\mathrm{MgSO}_{4}$, filtered, and evaporated to dryness. The crude compound was purified by flash chromatography (Cy/AcOEt, 100:0 to 60:40) to afford the pure protected dipeptide 30 as a white powder (64 mg, 40\% yield). ${ }^{1} \mathrm{H}$ NMR (300 MHz, MeOD) $\delta 7.91$ (s, 1H, NH indole), 7.65 (d, J = 7.5, 2H, CH Ar Fmoc), 7.40 (d, J = 7.4, 2H, CH Ar Fmoc), 7.35 (s, 1H, CH Ar indole), 7.28 ( $\mathrm{t}, J=7.4,2 \mathrm{H}, \mathrm{CH}$ Ar Fmoc), 7.03-7.20 (m, 8H, CH Ar Fmoc, $\mathrm{CH}$ indole, $\mathrm{CH}$ benzyl), 6.35 and 6.19 (2 bs, 1H, NH Amide), 5.61 (bs, 1H, NH Fmoc), 4.69 and 4.76 (2bs, 2H, NH Boc), 4.15-4.27 (m, $5 \mathrm{H}, \mathrm{CH} \alpha \mathrm{Tbt}, \mathrm{CH}_{2} \mathrm{Fmoc}, \mathrm{CH}_{2} \mathrm{Ph}$ ), 4.08 (t, $J=76.8,1 \mathrm{H}, \mathrm{CH}$ Fmoc), 3.24-3.39 (m, 3H, $\mathrm{CH}_{2} \beta_{1}$ Tbt, $\mathrm{CH}_{2} \beta \varepsilon$ $\beta^{2,2} h$ bis-Orn), 2.84-2.94 (m, 4H, $\mathrm{CH}_{2} \delta \beta^{2,2} h$ bis-Orn), 2.67-2.74 (m, 1H, $\left.\mathrm{CH}_{2} \beta_{2} \mathrm{Tbt}\right), 1.30-1.34$ (m, $53 \mathrm{H}, \mathrm{C}\left(\mathrm{CH}_{3}\right)_{3}$ indole, $\mathrm{C}\left(\mathrm{CH}_{3}\right)_{3}$ Boc, $\mathrm{CH}_{2} \beta \beta^{2,2} h$ bis-Orn and $\mathrm{CH}_{2} \gamma \beta^{2,2} h$ bis-Orn ${ }^{13} \mathrm{C}$ NMR $(75 \mathrm{MHz}$, $\left.\mathrm{CD}_{3} \mathrm{OD}\right) \delta 175.1$ and 172.4 (C, $\mathrm{C}=\mathrm{O}$ amide), 156.2 (C, $\mathrm{C}=\mathrm{O}$ carbamate), 143.9, 143.6, 142.8, 142.6, 141.3, 141.2, 138.3, 132.1, 130.2, 129.8 (10C, C Ar), 128.7, 127.7, 127.4, 127.1, 125.3, 125.2, 120, 116.8, 112.1 (9CH, $\mathrm{CH}$ Ar), 104.5 (C, $\mathrm{C}$ indolyl), $79.1\left(\mathrm{C}, \mathrm{C}\left(\mathrm{CH}_{3}\right)_{3}\right), 67.2\left(\mathrm{CH}_{2}, \mathrm{CH}_{2} \mathrm{Fmoc}\right), 56.7(\mathrm{CH}, \mathrm{CH} \alpha \mathrm{T} \beta \tau), 49.2(\mathrm{C}, \mathrm{C} \alpha$ $\beta^{2,2} h$ bis-Orn), 47.1 ( $\mathrm{CH}, \mathrm{CH}$ F $\left.\mu \mathrm{ox}\right), 43.6\left(\mathrm{CH}_{2}, \mathrm{CH}_{2} \mathrm{Ph}\right), 42.9\left(\mathrm{CH}_{2}, \mathrm{CH}_{2} \beta \mathrm{Tbt}\right), 40.7\left(2 \mathrm{CH}_{2}, \mathrm{CH}_{2} \delta \beta^{2,2} h\right.$ bis-Orn), 34.9, 34.7, 33.1 ( $3 \mathrm{CH}_{2}, \mathrm{CH}_{2} \beta \alpha v \delta \mathrm{CH}_{2} \beta^{\prime} \beta^{2,2} h$ bis-Orn), 32.2, 30.9, 30.8, $30.7\left(4 \mathrm{CH}_{3}, \mathrm{C}\left(\mathrm{CH}_{3}\right)_{3}\right)$, $24.2,24.3\left(2 \mathrm{CH}_{2}, \mathrm{CH}_{2} \gamma\right)$.

H-Tbt- $\beta^{2,2}$ h bis-Arg-NHBn 21: Compound 30 (64 mg, $\left.0.06 \mathrm{mmol}\right)$ was dissolved in DCM ( 0.4 M) and an equivalent volume of TFA containing 5\% of TIS. The mixture was stirred at $\mathrm{rt}$ for $2 \mathrm{~h}$ then evaporated to dryness. The crude compound was dissolved in $4 \mathrm{~mL}$ of THF. 1,3-Di-Boc-2(trifluoromethylsulfonyl)guanidine $(117 \mathrm{mg}, 0.3 \mathrm{mmol})$ and $\mathrm{NEt}_{3}(80 \mu \mathrm{L}, 0.6 \mathrm{mmol})$ were added and the reaction mixture was stirred at $\mathrm{rt}$ for $48 \mathrm{~h}$. After evaporation of THF, the crude mixture was dissolved in a $20 \%$ solution of piperidine in DCM and allowed to react for $2 \mathrm{~h}$ before evaporation to dryness. A solution of TFA/TIS (95:5) in DCM was added and the mixture was stirred at $\mathrm{rt}$ for $1.5 \mathrm{~h}$. After evaporation, the crude product was purified by preparative RP-HPLC using a gradient of $40 \%$ to $100 \%$ $\mathrm{MeCN}$ in $30 \mathrm{~min}$. After lyophilisation, compound 21 was obtained as white powder with purity $>99 \%$ (20 mg, 45\% yield); ${ }^{1} \mathrm{H}$ NMR (300 MHz, $\left.\mathrm{CD}_{3} \mathrm{OD}\right) \delta 7.32$ (s, $1 \mathrm{H}, \mathrm{CH}$ indole), 7.25-7.32 (m, 5H, CH arom), $7.17\left(\mathrm{~s}, 1 \mathrm{H}, \mathrm{CH}\right.$ indole), 4.28 (s, 2H, CH $\left.\mathrm{CH}_{2} \mathrm{Ph}\right), 4.06$ (dd, $\left.J=9.4 \mathrm{~Hz}, 6.1 \mathrm{~Hz}, 1 \mathrm{H}, \mathrm{CH} \alpha \mathrm{Tbt}\right), 3.44-3.56(\mathrm{~m}$, $3 \mathrm{H}, \mathrm{CH}_{2} \beta \varepsilon_{1} \beta^{2,2} h$ bis-Arg and $\left.\mathrm{CH}_{2} \beta \mathrm{Tbt}\right), 3.11-3.17$ (m, $4 \mathrm{H}, \mathrm{CH}_{2} \delta \beta^{2,2} h$ bis-Arg), $2.39(\mathrm{~d}, J=14 \mathrm{~Hz}$, $1 \mathrm{H}, \mathrm{CH}_{2} \beta \varepsilon_{2} \beta^{2,2} h$ bis-Arg), $1.22-1.54\left(\mathrm{~m}, 35 \mathrm{H}, \mathrm{C}\left(\mathrm{CH}_{3}\right)_{3}, \mathrm{CH}_{2} \beta \beta^{2,2} h\right.$ bis-Arg and $\mathrm{CH}_{2} \gamma \beta^{2,2} h$ bis-Arg); MALDI-TOF: calcd for $\mathrm{C}_{41} \mathrm{H}_{66} \mathrm{~N}_{10} \mathrm{O}_{2} 730.5$, found $731.6[\mathrm{M}+\mathrm{H}]^{+}$; HPLC (Water/ACN $(0.1 \%$ TFA); $40 \%$ to $100 \% \mathrm{ACN}$ in $30 \mathrm{~min}$ : $\operatorname{tr}=13.57 \mathrm{~min}$ (Figure 23 ).

\subsubsection{Synthesis of Tbt- $\beta^{2,2} \mathrm{~h}$ bis-Arg- $\mathrm{NH}\left(\mathrm{CH}_{2}\right)_{13} \mathrm{CH}_{3} 22$ (Scheme 16)}

$\beta^{2,2}$-h-bis-Orn (Boc) ${ }_{2} \mathrm{NH}\left(\mathrm{CH}_{2}\right)_{13} \mathrm{CH}_{3}$ 31: Fmoc $\beta^{2,2} h$ bis-Orn(Boc) $)_{2} \mathrm{OH} 2(300 \mathrm{mg}, 0.48 \mathrm{mmol})$ was dissolved in DCM (25 mL). DCC (109 mg, $0.53 \mathrm{mmol})$, HOBt (72 mg, $0.53 \mathrm{mmol})$, DMAP (5 mg, $0.05 \mathrm{mmol})$, and tetradecyl amine $(113 \mathrm{mg}, 0.53 \mathrm{mmol})$ were added. The reaction mixture was stirred at for $4 \mathrm{~h}$. The solution was washed with brine, dried over $\mathrm{MgSO}_{4}$, filtered, and concentrated in vacuo. The crude compound was purified by flash chromatography (Cy/AcOEt 100:0 to 50:50) to afford a colorless oil (390 mg, 99\% yield); $\mathbf{R}_{\mathbf{f}}(\mathrm{Cy} / \mathrm{AcOEt}, 1: 1)=0.76 ;{ }^{1} \mathrm{H}$ NMR $\left(300 \mathrm{MHz}, \mathrm{CDCl}_{3}\right) \delta$ $7.67(\mathrm{~d}, J=7.3 \mathrm{~Hz}, 2 \mathrm{H}, \mathrm{CH} \mathrm{Ar}), 7.51(\mathrm{~d}, J=7.3 \mathrm{~Hz}, 2 \mathrm{H}, \mathrm{CH} \mathrm{Ar}), 7.31(\mathrm{t}, J=7.3 \mathrm{~Hz}, 2 \mathrm{H}, \mathrm{CH} \mathrm{Ar}), 7.22$ (t, $J=7.3 \mathrm{~Hz}, 2 \mathrm{H}, \mathrm{CH}$ Ar), 6.05 (bs, 1H, NH amide), 5.65 and 5.47 (2bs, 1H, NH Fmoc), 4.80 (bs, 2H, $\mathrm{NH}$ Boc), 4.30 (d, J = 6.2 Hz, 2H, CH Fmoc), 4.11 (t, $J=6.9 \mathrm{~Hz}, 1 \mathrm{H}, \mathrm{CH}$ Fmoc), 3.28 (d, J = 6.1 Hz, 
$1 \mathrm{H}, \mathrm{CH}_{2} \beta \varepsilon \beta^{2,2} h$ bis-Orn), 3.13 (m, 2H, $\left.\mathrm{CH}_{2} \mathrm{C}_{13} \mathrm{H}_{27}\right), 3\left(\mathrm{~m}, 4 \mathrm{H}, \mathrm{CH}_{2} \delta \beta^{2,2} h\right.$ bis-Orn), $1.41(\mathrm{~m}, 4 \mathrm{H}$, $\mathrm{CH}_{2} \gamma \beta^{2,2} h$ bis-Orn), 1.17-1.35 (m, $46 \mathrm{H}, \mathrm{C}\left(\mathrm{CH}_{3}\right)_{3}$ Boc, $\left(\mathrm{CH}_{2}\right)_{12} \mathrm{CH}_{3}$ and $\mathrm{CH}_{2} \beta \beta^{2,2} h$ bis-Orn), $0.8(\mathrm{t}$, $\left.3 \mathrm{H},\left(\mathrm{CH}_{2}\right){ }_{12} \mathrm{CH}_{3}\right) ;{ }^{13} \mathrm{C} \mathrm{NMR}\left(75 \mathrm{MHz}, \mathrm{CD}_{3} \mathrm{OD}\right) \delta 175.2(\mathrm{C}, \mathrm{C}=\mathrm{O}$ amide) 157.3 and $156.3(2 \mathrm{C}, \mathrm{C}=\mathrm{O}$ carbamate), 143.9 and 141.3 (C, $\mathrm{C}$ arom Fmoc), 127.7, 127.1, 125.1, 120 (5CH, $\mathrm{CH}$ arom Fmoc), 79.1 (C, $\left.\mathrm{C}\left(\mathrm{CH}_{3}\right)_{3}\right), 66.9\left(\mathrm{CH}_{2}, \mathrm{CH}_{2}\right.$ Fmoc), 49.6 (C, $\mathrm{C} \alpha \beta^{2,2} h$ bis-Orn), $47.2\left(\mathrm{C}, \mathrm{CH}\right.$ Fmoc), $44.6\left(\mathrm{CH}_{2}, \mathrm{CH}_{2} \beta \varepsilon\right.$ $\beta^{2,2} h$ bis-Orn), $40.7\left(\mathrm{CH}_{2}, \mathrm{CH}_{2} \mathrm{C}_{13} \mathrm{H}_{27}\right), 39.8\left(\mathrm{CH}_{2}, \mathrm{CH}_{2} \delta \beta^{2,2} h\right.$ bis-Orn), $33.9\left(\mathrm{CH}_{2}, \mathrm{CH}_{2} \mathrm{C}_{12} \mathrm{H}_{25}\right)$, $31.9\left(\mathrm{CH}_{2}, \mathrm{CH}_{2} \beta \beta^{2,2} h\right.$ bis-Orn), $30.8\left(\mathrm{CH}_{2}, \mathrm{CH}_{2} \mathrm{C}_{11} \mathrm{H}_{23}\right), 29.72,29.68,29.62,29.59,29.39,29.33\left(\mathrm{CH}_{2}\right.$, $\left.\mathrm{CH}_{2} \mathrm{C}_{7} \mathrm{H}_{17}\right), 28.4\left(\mathrm{CH}_{3}, \mathrm{C}\left(\mathrm{CH}_{3}\right)_{3}\right), 27.1,27.0,24.2\left(\mathrm{CH}_{2},\left(\mathrm{CH}_{2}\right)_{3} \mathrm{CH}_{3}\right), 22.7\left(\mathrm{CH}_{2}, \mathrm{CH}_{2} \gamma \beta^{2,2} h\right.$ bis-Orn $)$, $14.2\left(\mathrm{CH}_{3},\left(\mathrm{CH}_{2}\right)_{13} \mathrm{CH}_{3}\right)$; HRMS-ESI+: calcd for $\mathrm{C}_{48} \mathrm{H}_{76} \mathrm{~N}_{4} \mathrm{O}_{7} 820.5714$, found 843.5606 [M + Na] ${ }^{+}$. The obtained Fmoc $\beta^{2,2}$-h-bis-Orn(Boc) ${ }_{22} \mathrm{NH}\left(\mathrm{CH}_{2}\right)_{13} \mathrm{CH}_{3}(130 \mathrm{mg}, 0.12 \mathrm{mmol})$ was dissolved in THF $(2 \mathrm{~mL})$. Octanethiol $(210 \mu \mathrm{L}, 1.2 \mathrm{mmol})$ and DBU $(0.5 \mu \mathrm{L}, 0.0036 \mathrm{mmol})$ were added. The reaction mixture was stirred for $20 \mathrm{~min}$ then concentrated in vacuo. The crude compound was purified by flash chromatography (DCM/MeOH/NEt ${ }_{3}$ 100:0:0.1 to 80:20:0.1) to afford a colorless oil (58 $\mathrm{mg}, 81 \%$ yield); ${ }^{1} \mathrm{H}$ NMR $\left(300 \mathrm{MHz}, \mathrm{CD}_{3} \mathrm{OD}\right) \delta 3.21\left(\mathrm{t}, J=7.2 \mathrm{~Hz}, 2 \mathrm{H}, \mathrm{CH}_{2} \mathrm{C}_{12} \mathrm{H}_{27}\right), 33.04\left(\mathrm{t}, J=6.9 \mathrm{~Hz}, 4 \mathrm{H}, \mathrm{CH}_{2} \delta\right.$ $\beta^{2,2} h$ bis-Orn), $\delta 2.78$ (s, 2H, $\mathrm{CH}_{2} \beta^{\prime} \beta^{2,2} h$ bis-Orn), 1.32-1.58 (m, 48H, C( $\left.\mathrm{CH}_{3}\right)_{3}$ Boc, $\mathrm{CH}_{2}\left(\mathrm{CH}_{2}\right)_{11} \mathrm{CH}_{3}$, $\mathrm{CH}_{2} \beta \beta^{2,2} h$ bis-Orn and $\mathrm{CH}_{2} \gamma \beta^{2,2} h$ bis-Orn), $0.93\left(\mathrm{t}, 3 \mathrm{H}, J=6.6 \mathrm{~Hz},\left(\mathrm{CH}_{2}\right)_{13} \mathrm{CH}_{3}\right) ;{ }^{13} \mathrm{C}$ NMR (75 $\left.\mathrm{MHz}, \mathrm{CD}_{3} \mathrm{OD}\right) \delta 178.2\left(\mathrm{C}, \mathrm{C}=\mathrm{O}\right.$ amide), $159.4\left(\mathrm{C}, \mathrm{C}=\mathrm{O}\right.$ carbamate), $79.8\left(\mathrm{C}, \mathrm{C}\left(\mathrm{CH}_{3}\right)_{3}\right), 50.2(\mathrm{C}, \mathrm{C} \alpha), 45.8$ $\left(\mathrm{CH}_{2}, \mathrm{CH}_{2} \beta^{\prime}\right), 41.7\left(\mathrm{CH}_{2}, \mathrm{CH}_{2} \delta\right), 40.4\left(\mathrm{CH}_{2}, \mathrm{CH}_{2}\left(\mathrm{CH}_{2}\right)_{12} \mathrm{CH}_{3}\right), 33.1,31.6,30.8,30.5\left(4 \mathrm{CH}_{2}\right), 28.8,\left(6 \mathrm{CH}_{3}\right.$, $\left.\mathrm{C}\left(\mathrm{CH}_{3}\right)_{3}\right), 28.2,25.3,23.7\left(\mathrm{CH}_{2}\right), 14.5\left(\mathrm{CH}_{3}, \mathrm{CH}_{2} \mathrm{CH}_{3}\right)$; HRMS-ESI+: calcd for $\mathrm{C}_{33} \mathrm{H}_{66} \mathrm{~N}_{4} \mathrm{O}_{5} 598.5033$, found $599.5112[\mathrm{M}+\mathrm{H}]^{+}$.

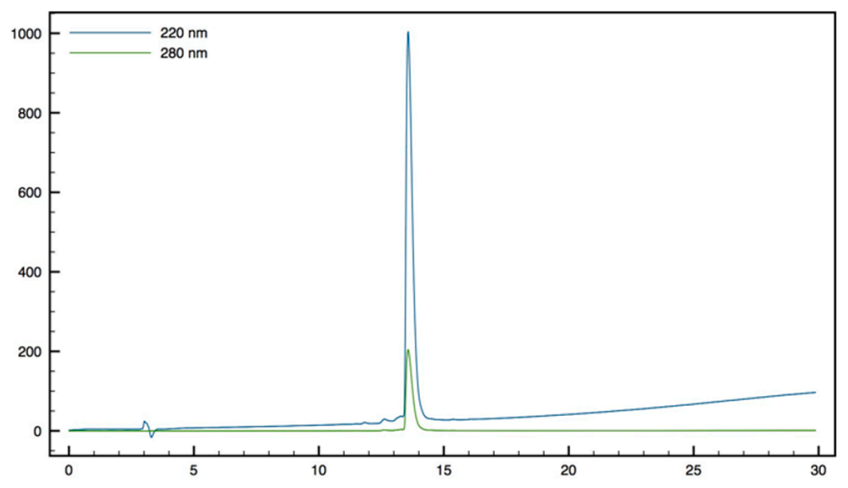

Figure 23. HPLC profile of $H-T b t-\beta^{2,2} h$ bis-Arg-NHBn 21.
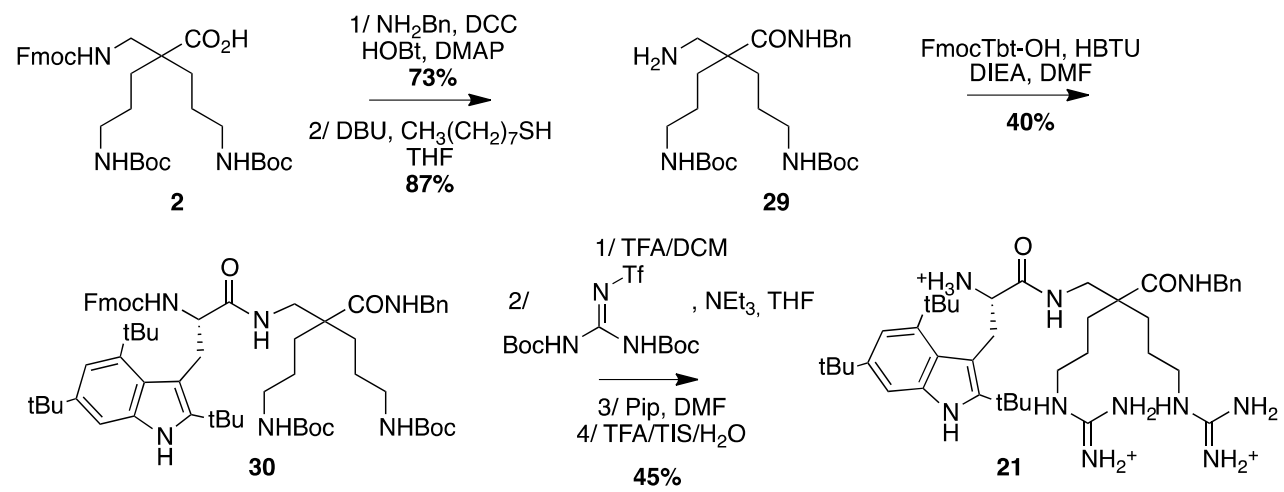

Scheme 15. Synthesis of Tbt- $\beta^{2,2}$ h bis-Arg-NHBn 21.

Fmoc-Tbt- $\beta^{2,2}$-h-bis-Orn $(\mathrm{Boc})_{2} \mathrm{NH}\left(\mathrm{CH}_{2}\right)_{13} \mathrm{CH}_{3}$ 32: Fmoc-Tbt-OH (54 mg, $0.09 \mathrm{mmol}$ ) was dissolved in DMF ( $5 \mathrm{~mL})$. HBTU ( $34 \mathrm{mg}, 0.09 \mathrm{mmol})$ and DIEA $(20 \mu \mathrm{L}, 0.09 \mathrm{mmol})$ were added and the mixture was stirred for $5 \mathrm{~min}$ before addition of $\beta^{2,2}$ - $h$-bis-Orn $(\mathrm{Boc})_{2} \mathrm{NH}\left(\mathrm{CH}_{2}\right)_{13} \mathrm{CH}_{3} 31$ (55 mg, $\left.0.09 \mathrm{mmol}\right)$. The reaction mixture was stirred at room temperature for $4 \mathrm{~h}$, then diluted with $\mathrm{Et}_{2} \mathrm{O}$ and washed with an aqueous saturated solution of $\mathrm{NH}_{4} \mathrm{Cl}$. The organic layer was dried over $\mathrm{MgSO}_{4}$, filtered, 
and evaporated to dryness. The crude compound was purified by flash chromatography (Cy/AcOEt, 100:0 to 50:50) to afford the pure protected dipeptide as a white powder $\left(70 \mathrm{mg}, 66 \%\right.$ yield). ${ }^{1} \mathrm{H} \mathrm{NMR}$ $\left(300 \mathrm{MHz}, \mathrm{CDCl}_{3}\right) \delta 7.99$ (s, 1H, NH indole), 7.23 (d, J = 7.5, 2H, CH Ar Fmoc), 7.50 (d, J = 7.2, 2H, CH Ar Fmoc), 7.43 (s, 1H, CH Ar indole), $7.38(\mathrm{t}, J=7.5,2 \mathrm{H}, \mathrm{CH}$ Ar Fmoc), 7.24 (t, $J=7.5,2 \mathrm{H}, \mathrm{CH}$ Ar Fmoc), 7.17 (s, 1H, CH indole), 6.23 (bs, 1H, NH amide), 5.92 and 5.66 (2bs, 1H, NH Fmoc), 4.78 and 4.86 (2bs, 2H, NH Boc), 4.25-4.37 (m, 3H, CH $\alpha$ Tbt and $\mathrm{CH}_{2}$ Fmoc), 4.13-4.17 (m, 1H, CH Fmoc), 3.33-3.44 (m, $3 \mathrm{H}, \mathrm{CH}_{2} \beta \varepsilon \beta^{2,2} h$ bis-Orn and $\left.\mathrm{CH}_{2} \beta_{1} \mathrm{Tbt}\right), 3.02\left(\mathrm{~m}, 6 \mathrm{H}, \mathrm{CH}_{2} \delta \beta^{2,2} h\right.$ bis-Orn and $\left.\mathrm{CH}_{2}\left(\mathrm{CH}_{2}\right)_{12} \mathrm{CH}_{3}\right)$, 2.75-2.80 (m, 1H, $\left.\mathrm{CH}_{2} \beta_{2} \mathrm{~T} \beta \tau\right), 1.30-1.47\left(\mathrm{~m}, 77 \mathrm{H}, 3 \mathrm{C}\left(\mathrm{CH}_{3}\right)_{3}\right.$ indole, $\mathrm{CH}_{2}\left(\mathrm{CH}_{2}\right)_{12} \mathrm{CH}_{3}, 2 \mathrm{C}\left(\mathrm{CH}_{3}\right)_{3} \mathrm{Boc}$, $2 \mathrm{CH}_{2} \beta \beta^{2,2} h$ bis-Orn and $2 \mathrm{CH}_{2} \gamma \beta^{2,2} h$ bis-Orn), $0.86\left(\mathrm{t}, J=6.9,3 \mathrm{H},\left(\mathrm{CH}_{2}\right){ }_{13} \mathrm{CH}_{3}\right){ }^{13} \mathrm{C} \mathrm{NMR}(75 \mathrm{MHz}$, $\left.\mathrm{CDCl}_{3}\right) \delta 174.8$ and 172.3 (C, $\mathrm{C}=\mathrm{O}$ amide), 156.1 and 156.2 (C, $\mathrm{C}=\mathrm{O}$ carbamate), 143.9, 143.6, 142.8, 142.6, 141.3, 141.2, 132.1, 130.2, 129.8 (9C, C Ar), 127.7, 127.1, 125.3, 125.2, 120, 116.8, 112.1 (7CH, CH $\mathrm{Ar}), 104.5$ (C, $\mathrm{C}$ indolyl), $79.1\left(\mathrm{C}, \mathrm{C}\left(\mathrm{CH}_{3}\right)_{3}\right), 67.2\left(\mathrm{CH}_{2}, \mathrm{CH}_{2} \mathrm{Fmoc}\right), 56.7(\mathrm{CH}, \mathrm{CH} \alpha \mathrm{T} \beta \tau), 49.2(\mathrm{C}, \mathrm{C} \alpha$ $\beta^{2,2} h$ bis-Orn), 47.1 (CH, CH F $\mu$ ox), $43\left(\mathrm{CH}_{2}, \mathrm{CH}_{2} \beta \mathrm{Tbt}\right), 40.7\left(\mathrm{CH}_{2}, \mathrm{CH}_{2} \mathrm{C}_{13} \mathrm{H}_{29}, 39.7\left(2 \mathrm{CH}_{2}, \mathrm{CH}_{2} \delta\right.\right.$ $\beta^{2,2} h$ bis-Orn), $34.9\left(\mathrm{CH}_{2}, \mathrm{CH}_{2} \mathrm{C}_{12} \mathrm{H}_{27}\right), 34.8\left(\mathrm{CH}_{2}, \mathrm{CH}_{2} \mathrm{C}_{11} \mathrm{H}_{25}\right), 33.1\left(\mathrm{CH}_{2}, \mathrm{CH}_{2} \mathrm{C}_{10} \mathrm{H}_{23}\right), 32.1\left(\mathrm{CH}_{3}\right.$, $\left.\mathrm{C}\left(\mathrm{CH}_{3}\right)_{3}\right), 32\left(\mathrm{CH}_{2}, \mathrm{CH}_{2} \mathrm{C}_{9} \mathrm{H}_{21}\right), 30.6$ and $30.9\left(2 \mathrm{CH}_{3}, \mathrm{C}\left(\mathrm{CH}_{3}\right)_{3}\right), 29.8,29.7,29.6,29.5,29.4,29.3\left(7 \mathrm{CH}_{2}\right.$, $\left.\left(\mathrm{CH}_{2}\right)_{8} \mathrm{CH}_{3}\right), 28.5\left(2 \mathrm{CH}_{3}, \mathrm{C}\left(\mathrm{CH}_{3}\right)_{3} \mathrm{Boc}\right), 27$ and $26.9\left(2 \mathrm{CH}_{2}, \mathrm{CH}_{2} \beta \beta^{2,2} h\right.$ bis-Orn $), 24.2\left(\mathrm{CH}_{2}, \mathrm{CH}_{2} \beta \varepsilon\right.$ $\beta^{2,2} h$ bis-Orn), $22.7\left(2 \mathrm{CH}_{2}, \mathrm{CH}_{2} \gamma\right), 14.2\left(\mathrm{CH}_{3},\left(\mathrm{CH}_{2}\right)_{13} \mathrm{CH}_{3}\right)$.

$\mathrm{H}$-Tbt- $\beta^{2,2} \mathrm{~h}$ bis- $\mathrm{Arg}-\mathrm{NH}\left(\mathrm{CH}_{2}\right)_{13} \mathrm{CH}_{3}$ 22: Compound 32 (52 mg, $\left.0.045 \mathrm{mmol}\right)$ was dissolved in DCM $(3 \mathrm{~mL})$ and a mixture of TFA/TIS/ $\mathrm{H}_{2} \mathrm{O}(3 \mathrm{~mL} / 150 \mu \mathrm{L} / 150 \mu \mathrm{L})$ as added. The solution was stirred at $\mathrm{rt}$ for $4 \mathrm{~h}$ then evaporated to dryness. The crude compound was dissolved in $4 \mathrm{~mL}$ of THF. 1,3-Di-Boc-2-(trifluoromethylsulfonyl)guanidine ( $53 \mathrm{mg}, 0.135 \mathrm{mmol}$ ) and $\mathrm{NEt}_{3}(40 \mu \mathrm{L}, 0.27 \mathrm{mmol}$ ) were added and the reaction mixture was stirred at rt overnight. After evaporation of THF, the crude mixture was dissolved in a 20\% solution of piperidine in DCM and allowed to react for $2 \mathrm{~h}$ before evaporation to dryness. A solution of TFA/TIS/ $\mathrm{H}_{2} \mathrm{O}$ (95:2.5:2.5) in DCM was added and the mixture was stirred at $\mathrm{rt}$ for $3 \mathrm{~h}$. After evaporation, the crude product was purified by preparative RP-HPLC using a gradient of $40 \%$ to $90 \% \mathrm{MeCN}$ in $30 \mathrm{~min}$. After lyophilisation, compound 22 was obtained as white powder with purity $>99 \%(12 \mathrm{mg}, 40 \%) ;{ }^{1} \mathrm{H}$ NMR $\left(300 \mathrm{MHz}, \mathrm{CD}_{3} \mathrm{OD}\right) \delta 8.33(\mathrm{~s}, 1 \mathrm{H}, \mathrm{NH}$ indole), $7.60(\mathrm{t}, J=5.6 \mathrm{~Hz}, 1 \mathrm{H}, \mathrm{NH}$ amide), $7.30(\mathrm{~d}, J=1.5 \mathrm{~Hz}, 1 \mathrm{H}, \mathrm{CH}$ indole), $7.15(\mathrm{~d}, J=1.5 \mathrm{~Hz}$, $1 \mathrm{H}, \mathrm{CH}$ indole), $4.06(\mathrm{dd}, J=10.1 \mathrm{~Hz}, 5.6 \mathrm{~Hz}, \mathrm{CH} \alpha \mathrm{Tbt}), 3.34-3.55\left(\mathrm{~m}, 3 \mathrm{H}, \mathrm{CH}_{2} \beta \varepsilon_{1} \beta^{2,2} h\right.$ bis-Arg and $\mathrm{CH}_{2} \beta \mathrm{Tbt}$ ), 3.11-3.17 (m, 2H, $\left.\mathrm{CH}_{2} \mathrm{C}_{13} \mathrm{H}_{29}\right), 3.01-3.09$ (m, $4 \mathrm{H}, \mathrm{CH}_{2} \delta \beta^{2,2} h$ bis-Arg), 2.37 (d, J = 14.1 Hz, $1 \mathrm{H}, \mathrm{CH}_{2} \beta \varepsilon_{2} \beta^{2,2} h$ bis-Arg), $1.68-1.84\left(\mathrm{~m}, 2 \mathrm{H}, \mathrm{CH}_{2} \mathrm{C}_{12} \mathrm{H}_{27}\right), 1.16-1.62\left(\mathrm{~m}, 57 \mathrm{H}, 3 \mathrm{C}\left(\mathrm{CH}_{3}\right)_{3},\left(\mathrm{CH}_{2}\right)_{11} \mathrm{CH}_{3}\right.$, $\mathrm{CH}_{2} \beta \beta^{2,2} h$ bis-Arg and $\mathrm{CH}_{2} \gamma \beta^{2,2} h$ bis-Arg), $0.90\left(\mathrm{t}, J=6.7,3 \mathrm{H},\left(\mathrm{CH}_{2}\right)_{13} \mathrm{CH}_{3}\right)$; MALDI-TOF: calcd for $\mathrm{C}_{48} \mathrm{H}_{88} \mathrm{~N}_{10} \mathrm{O}_{2}$ 836.7, found $837.6[\mathrm{M}+\mathrm{H}]^{+}$, $859.6[\mathrm{M}+\mathrm{Na}]^{+}$; HPLC (Water/ACN $(0.1 \%$ TFA); $50 \%$ to $100 \% \mathrm{ACN}$ in $10 \mathrm{~min}: \mathrm{tr}=8.09 \mathrm{~min}$ (Figure 24).

\subsection{Antimicrobial Assays}

\subsubsection{Bacterial Strains and Media}

Three Gram-negative strains (Escherichia coli ATCC25922, Acinetobacter baumannii ATCC19606, and Pseudomonas aeruginosa ATCC29853) and three Gram-positive strains (Staphylococcus aureus ATCC25923, Staphylococcus aureus SA-1199B, and Enterrococcus faecalis ATCC29212) were used in this study. Staphylococcus aureus SA-1199B is resistant to fluoroquinolones due notably to the overexpression of the membrane-associated NorA efflux pump [36].

All these strains were grown in Mueller-Hinton Broth media (MH, BioRad 69444, Mitry Mory, France) overnight at $37^{\circ} \mathrm{C}$ without shaking, before being diluted in $1 \%$ Bacto Peptone water (Conda 1616.00, batch $\mathrm{n}^{\circ}$ 30927). Counting was realized on MH agar plates (MH, BioRad 64884, Mitry Mory, France). Colony forming unit (CFU) counting, used to check the bacterial density at $\mathrm{T} 0$ in the antibacterial activity test, was carried out by counting colonies present in $2 \times 10 \mu \mathrm{L}$ of serial log dilutions of bacteria inoculum spotted on $\mathrm{MH}$ agar plates. Plates were examined for growth after one night at $37^{\circ} \mathrm{C}$. 


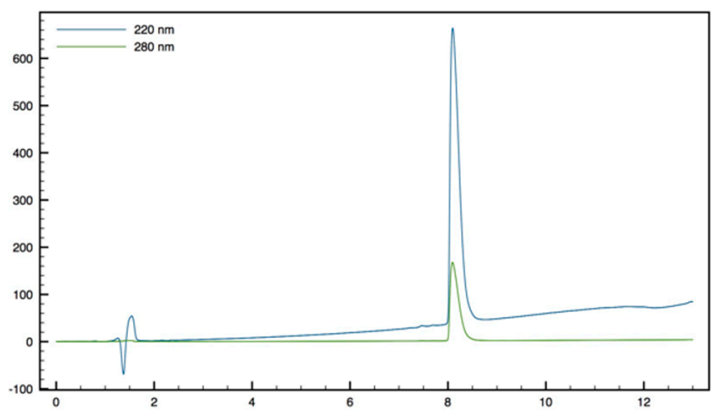

Figure 24. $\mathrm{H}-\mathrm{Tbt}-\beta^{2,2} \mathrm{~h}$ bis-Arg- $\mathrm{NH}\left(\mathrm{CH}_{2}\right)_{13} \mathrm{CH}_{3} 22$.
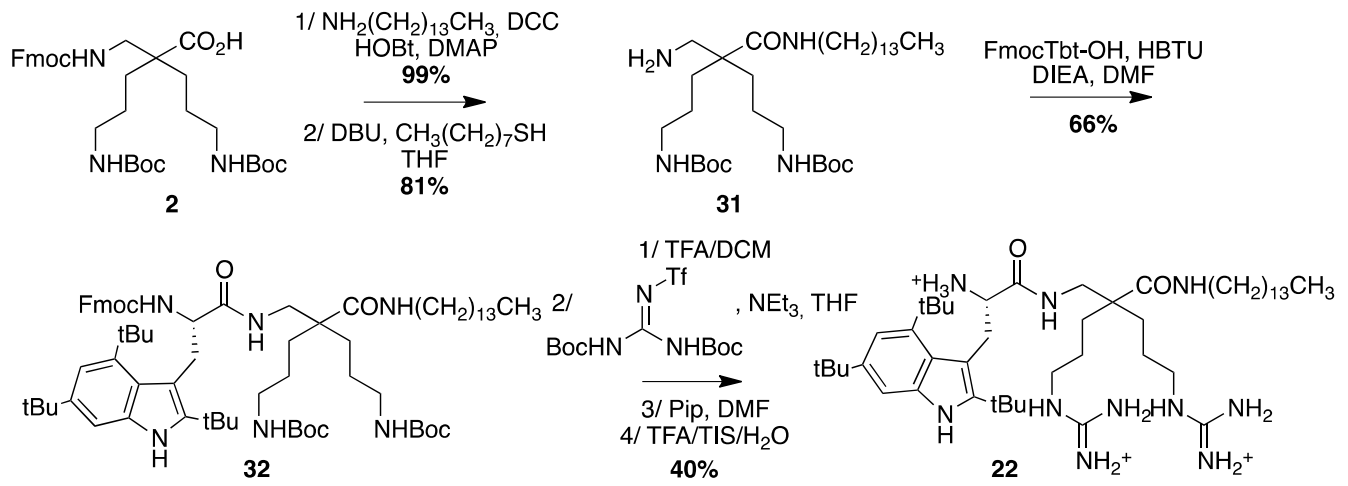

$40 \%$

$\mathrm{H}_{3} 22$.

\subsubsection{Antibacterial Activity}

The antibacterial activity was evaluated in $1 \%$ Bacto Peptone. First, the peptides (solubilized in $\mathrm{H}_{2} \mathrm{O}$ or in DMSO according to their own solubility), were dispensed in a 96-wells microplate by 2-fold serial dilutions in 1\% Bacto Peptone water using a handling robot (Biomek 2000, Beckman, Fullerton, CA, USA). The final volume in each well was $100 \mu \mathrm{L}$. Then, $100 \mu \mathrm{L}$ of an overnight grown bacterial culture diluted in $1 \%$ Bacto Peptone water was added in order to reach a bacterial concentration comprised between $10^{5}$ and $10^{6} \mathrm{CFU} / \mathrm{mL}$. The final range of peptide concentrations were $64,32,16$, $8,4,2,1,0.5,0.25,0.125$, and $0.06 \mu \mathrm{g} / \mathrm{mL}$, and the highest final concentration of DMSO or $\mathrm{H}_{2} \mathrm{O}$ was less than $1.3 \%$ in all experiments. Growth at $37^{\circ} \mathrm{C}$ without shaking was assayed using a microplate reader (DTX880, Beckman) by monitoring the absorption at $620 \mathrm{~nm}$, at $0,1,4,7$, and $24 \mathrm{~h}$. A solution of 2.6\% DMSO was used as negative control, and peptide A was used as positive control. For each experiment, MICs of reference antibiotics were also measured and compared to the reported one in order to validate the assay. The minimal inhibitory concentrations (MIC) of the different peptides were defined as the lowest concentration of compound that completely inhibits cell growth during $24 \mathrm{~h}$ incubation. All peptides were tested at least twice in parallel.

\subsection{Hemolytic Activities}

Red blood cells (RBCs) were isolated from rat blood and re-suspended in PBS (4\% v/v). RBC suspensions $(100 \mu \mathrm{L})$ were introduced into a 96-microwell plate and either $1 \mu \mathrm{L}$ (final concentration of $10 \mu \mathrm{M}$ ) or $5 \mu \mathrm{L}$ (final concentration of $50 \mu \mathrm{M})^{*}$ of peptides solutions in PBS $(1 \mathrm{mM}$ ) were added to the wells. PBS was used as negative control while a solution of $1 \%$ triton $\times 100$ in PBS was used as positive control. The plate was incubated for $1 \mathrm{~h}$ at $37^{\circ} \mathrm{C}$. After the incubation, the plate was centrifuged at $1500 \mathrm{rpm}$ for $5 \mathrm{~min}$. The absorbance of the supernatant $550 \mathrm{~nm}$ was measured and percentage of hemolysis was determined as $(\mathrm{A}-\mathrm{APBS}) /($ Atriton $-\mathrm{A} 0) \times 100$, where $\mathrm{A}$ is the absorbance of the tested well, APBS the absorbance of the negative control, and Atriton the absorbance of the positive control. 


\subsection{Cytotoxicity on Human SH-SYS5 Cells}

The cytotoxicity of the compounds was evaluated on SH-SYS5 neuroblastoma adherent cells (Figure 7). The SH-SYS5 cells were seeded (40,000 cells per well) in 96-well microplates the day before, then incubated at $37^{\circ} \mathrm{C}$, with $0,1,10,50$, or $100 \mu \mathrm{M}$ compounds in RPMI for $2 \mathrm{~h}$. The cell-counting kit solution was used as indicated by the supplier (Dojindo Laboratories). Absorbance at $450 \mathrm{~nm}$ (and reference at $620 \mathrm{~nm}$ ) is directly related to the number of living cells. Experiments were done in triplicates and repeated two-times independently. Results are normalized to the control cells, in the absence of any compound.

\subsection{In Vivo Experiments}

Mice were bred and maintained at the mouse facilities of the Bichat Medical School campus. All experiments were performed in accordance with the French Council of Animal Care guidelines and national ethical guidelines of INSERM Animal Care Committee (Animal Use Protocol number 75-1596).

\subsection{Cecal Ligation and Puncture (CLP)}

B16 mice (only male 12 weeks old) were anesthetized and the cecum exposed by a $1 \mathrm{~cm}$ midline incision on the abdomen. The distal half of the cecum was ligated with a 5-0 silk suture and punctured with a 21-gauge needle. The cecum was replaced, and $1 \mathrm{ml}$ of sterile saline injected into the peritoneal cavity. The incision was closed using surgical sutures. Mice were monitored every $8 \mathrm{~h}$ for the first 3 days and then every $12 \mathrm{~h}$ until death or day 7, when they were euthanized. For the peptide 11 treatment, $1 \mathrm{ug} / \mathrm{g}$ of mice (on average $20 \mathrm{~g}$ ) was injected (intraperitoneal injection) during the surgical suture at the end of the CLP procedure.

\subsection{Peptide Hydrophobicity}

Analytical HPLC on C18 column (Higgins RS 1046 D183, 100*4.6 mm) using as eluent a 5\% to $100 \%$ gradient of MeCN containing $0.1 \%$ TFA in water containing $0.1 \%$ TFA, in 30 min, and UV detection was done at 220 and $280 \mathrm{~nm}$.

\subsection{Stability of Peptide in Human Serum}

To a mixture of $250 \mu \mathrm{L}$ of human serum and $750 \mu \mathrm{L}$ of RPMI 1640 were added $20 \mu \mathrm{L}$ of the peptide solution at $10 \mathrm{mg} / \mathrm{mL}$. The mixture was incubated at $37^{\circ} \mathrm{C}$. Aliquots of $100 \mu \mathrm{L}$ were removed from the medium at different time, mixed with $100 \mu \mathrm{L}$ of ethanol and $5 \mu \mathrm{L}$ of $1 \mathrm{M} \mathrm{NaOH}$, and incubated at $4{ }^{\circ} \mathrm{C}$ for at least $15 \mathrm{~min}$ to precipitate all the serum proteins. After centrifugation at $12,000 \mathrm{rpm}$ for $2 \mathrm{~min}, 50 \mu \mathrm{L}$ of the supernatant were injected in HPLC with a a linear gradient from $5 \%$ to $50 \%$ $\operatorname{ACN}[0.1 \%(v / v)$ TFA in acetonitrile] in aqueous $0.1 \%(v / v)$ TFA. The relative concentrations of the remaining soluble peptides were analyzed by the integration of the absorbance at $220 \mathrm{~nm}$ as a function of retention time.

To ensure the serum activity, the peptide 4NGG [37] is used as positive control (Figure 25):

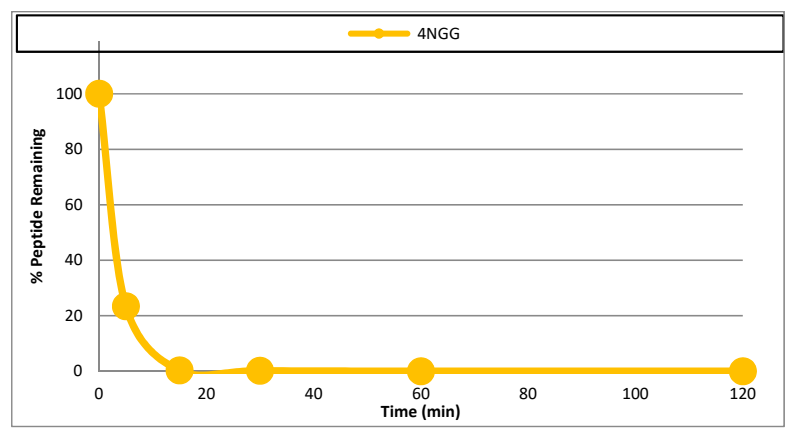

Figure 25. Serum activity evaluated with the 4NGG peptide degraded in $15 \mathrm{~min}$. 


\section{Patents}

The patent application WO2014191392 A1 (PCT/EP2014/060917) included results from this paper. The authors declare that no other competing interest exist.

Supplementary Materials: The following are available online. ${ }^{1} \mathrm{H}$ and ${ }^{13} \mathrm{C}$ NMR Spectra of all compounds.

Author Contributions: H.B. performed amino acids, peptides syntheses and metabolic stability assay under the supervision of R.M. and P.K. A.H., C.G.-E. performed the antimicrobial assays under the supervision of C.J. C.B. and H.B. performed the cytotoxicity assays under the supervision of S.S. E.P. performed the in vivo assays under the supervision of P.L. F.B. and C.L. performed the study of Interaction with membrane model. P.K. and R.M. wrote the manuscript with the assistance of the others authors. P.K. designed the AMPs and led the project. All authors have given approval to the final version of the manuscript.

Funding: H.B. was recipient of a MERS fellowship from the french Ministère de l'Enseignement Supérieure et de la Recherche. P.K. is grateful to SATT-Lutech and DGRTT (Sorbonne-Université) for financial and logistic supports in patent filing.

Conflicts of Interest: The authors declare no conflict of interest.

\section{References}

1. Jones, D. The antibacterial lead discovery challenge. Nat. Rev. Drug Discov. 2010, 9, 751-752.

2. Bax, B.D.; Chan, P.F.; Eggleston, D.S.; Fosberry, A.; Gentry, D.R.; Gorrec, F.; Giordano, I.; Hann, M.M.; Hennessy, A.; Hibbs, M.; et al. Type IIA topoisomerase inhibition by a new class of antibacterial agents. Nature 2010, 466, 935-940. [CrossRef] [PubMed]

3. Fjell, C.D.; Hiss, J.A.; Hancock, R.E.W.; Schneider, G. Designing antimicrobial peptides: Form follows function. Nat. Rev. Drug Discov. 2011, 1, 37-51.

4. Uggerhøj, L.E.; Poulsen, T.J.; Munk, J.K.; Fredborg, M.; Sondergaard, T.E.; Frimodt-Moller, N.; Hansen, P.R.; Wimmer, R. Rational design of alpha-helical antimicrobial peptides: Do's and don'ts. ChemBioChem 2015, 16, 242-253. [CrossRef] [PubMed]

5. Shai, Y. Mode of action of membrane active antimicrobial peptides. Biopolymers 2002, 66, 236-248. [CrossRef] [PubMed]

6. Tew, G.N.; Scott, R.W.; Klein, M.L.; DeGrado, W.F. De Novo Design of Antimicrobial Polymers, Foldamers, and Small Molecules: From Discovery to Practical Applications. Acc. Chem. Res. 2010, 43, 30-39. [CrossRef]

7. Ramesh, S.; Govender, T.; Kruger, H.G.; de la Torre, B.G.; Albericio, F. Short AntiMicrobial Peptides (SAMPs) as a class of extraordinary promising therapeutic agents. J. Pept. Sci. 2016, 22, 438-451. [CrossRef]

8. Teng, P.; Nimmagadda, A.; Su, M.; Hong, Y.; Shen, N.; Li, C.; Tsai, L.-Y.; Cao, J.; Li, Q.; Cai, J. Novel bis-cyclic guanidines as potent membrane-active antibacterial agents with therapeutic potential. Chem Commun. 2017, 53, 11948-11951. [CrossRef]

9. Niu, Y.; Wang, M.; Yafei Cao, Y.; Nimmagadda, A.; Hu, J.; Wu, Y.; Cai, J.; Ye, X.-S. Rational Design of Dimeric Lysine N-Alkylamide as Potent and Broad Spectrum Antibacterial Agents. J. Med. Chem. 2018, 61, 2865-2874. [CrossRef]

10. Aussedat, B.; Dupont, E.; Sagan, S.; Joliot, A.; Lavielle, S.; Chassaing, G.; Burlina, F. Modifications in the chemical structure of Trojan carriers: Impact on cargo delivery. Chem. Commun. 2008, 1398-1400. [CrossRef]

11. Seebach, D.; Abele, S.; Sifferlen, T.; Hänggi, M.; Gruner, S.; Seiler, P. Disubstituted $\beta^{2,2}$ and $\beta^{3,3}$ amino Acids. A Turn Motif for $\beta$-peptides. Helv. Chim. Acta 1998, 81, 2218-2243. [CrossRef]

12. Yu, J.-S.; Noda, H.; Shibasaki, M. Quaternary $\beta^{2,2}$-Amino Acids: Catalytic Asymmetric Synthesis and Incorporation into Peptides by Fmoc-Based Solid-Phase Peptide Synthesis. Angew. Chem. Int. Ed. 2018, 57, 818-822. [CrossRef] [PubMed]

13. Basuroy, K.; Rajagopal, A.; Raghothama, S.; Shamala, N.; Balaram, P. $\beta$-Turn analogues in model $\alpha \beta$-hybrid peptides: Structural characterization of peptides containing $\beta(2,2)$ Ac6c and $\beta(3,3)$ Ac6c residues. Chem. Asian J. 2012, 7, 1671-1678. [CrossRef] [PubMed]

14. García-González, I.; Mata, L.; Corzana, F.; Jiménez-Osés, G.; Avenoza, A.; Busto, J.H.; Peregrina, J.M. Synthesis and conformational analysis of hybrid $\alpha / \beta$-dipeptides incorporating S-glycosyl- $\beta(2,2)$-amino acids. Chemistry 2015, 21, 1156-1168. [CrossRef] 
15. Hansen, T.; Ausbacher, D.; Flaten, G.E.; Havelkova, M.; Strøm, M.B. Synthesis of cationic antimicrobial $\beta(2,2)$-amino acid derivatives with potential for oral administration. J. Med. Chem. 2012, 54, 858-868. [CrossRef]

16. Tørfoss, V.; Ausbacher, D.; de A. Cavalcanti-Jacobsen, C.; Hansen, T.; Brandsdal, B.-O.; Havelkova, M.; Strøm, M.B. Synthesis of anticancer heptapeptides containing a unique lipophilic $\beta(2,2)$-amino acid building block. J. Pept. Sci. 2012, 18, 170-176. [CrossRef]

17. Hansen, T.; Ausbacher, D.; Zachariassen, Z.G.; Anderssen, T.; Havelkova, M.; Strøm, M.B. Anticancer activity of small amphipathic $\beta^{2}{ }^{2}$-amino acid derivatives. Eur. J. Med. Chem. 2012, 58, 22-29. [CrossRef] [PubMed]

18. Saidi, M.R.; Azizi, N.; Akbari, E.; Ebrahimi, F. LiCO4/Et3N: Highly efficient and active catalyst for selective Michael addition of active methylene compounds under solvent-free condition. J. Mol. Catal. A Chem. 2008, 292, 44-48. [CrossRef]

19. Strøm, M.B.; Rekdal, Ø.; Svendsen, J.S. Antimicrobial activity of short arginine- and tryptophan-rich peptides. J. Pept. Sci. 2002, 8, 431-437. [CrossRef] [PubMed]

20. Strøm, M.B.; Haug, B.E.; Skar, M.L.; Stensen, W.; Stiberg, T.; Svendsen, J.S. The pharmacophore of short cationic antibacterial peptides. J. Med. Chem. 2003, 46, 1567-1570. [CrossRef] [PubMed]

21. Haug, B.E.; Stensen, W.; Stiberg, T.; Svendsen, J.S. Bulky nonproteinogenic amino acids permit the design of very small and effective cationic antibacterial peptides. J. Med. Chem. 2004, 47, 4159-4162. [CrossRef] [PubMed]

22. Haug, B.E.; Stensen, W.; Kalaaji, M.; Rekdal, Ø.; Svendsen, J.S. Synthetic antimicrobial peptidomimetics with therapeutic potential. J. Med. Chem. 2008, 51, 4306-4314. [CrossRef] [PubMed]

23. Isaksson, J.; Brandsdal, B.O.; Engqvist, M.; Flaten, G.E.; Svendsen, J.S.M.; Stensen, W. A synthetic antimicrobial peptidomimetic (LTX109): Stereochemical impact on membrane disruption. J. Med. Chem. 2011, 54, 5786-5795. [CrossRef] [PubMed]

24. Sharma, R.K.; Reddy, R.P.; Tegge, W.; Jain, R. Discovery of Trp-His and His-Arg analogues as new structural classes of short antimicrobial peptides. J. Med. Chem. 2009, 52, 7421-7431. [CrossRef] [PubMed]

25. Hansen, T.; Alst, T.; Havelkova, M.; Strøm, M.B. Antimicrobial activity of small beta-peptidomimetics based on the pharmacophore model of short cationic antimicrobial peptides. J. Med. Chem. 2010, 53, 595-606. [CrossRef] [PubMed]

26. Bremner, J.B.; Keller, P.A.; Pyne, S.G.; Boyle, T.P.; Brkic, Z.; David, D.M.; Garas, A.; Morgan, J.; Robertson, M.; Somphol, K.; et al. Binaphthyl-based dicationic peptoids with therapeutic potential. Angew. Chem. Int. Ed. 2010, 49, 537-540. [CrossRef] [PubMed]

27. Rekdal, Ø.; Haug, B.E.; Kalaaji, M.; Hunter, H.N.; Lindin, I.; Israelsson, I.; Solstad, T.; Yang, N.; Brandl, M.; Mantzilas, D.; Vogel, H.J. Relative spatial positions of tryptophan and cationic residues in helical membrane-active peptides determine their cytotoxicity. J. Biol. Chem. 2012, 287, 233-244. [CrossRef] [PubMed]

28. Thennarasu, S.; Lee, D.-K.; Tan, A.; Prasad Kari, U.; Ramamoorthy, A. Antimicrobial activity and membrane selective interactions of a synthetic lipopeptide MSI-843. Biochim. Biophys. Acta 2005, 1711, 49-58. [CrossRef] [PubMed]

29. Das, S.; Ben Haj Salah, K.; Wenger, E.; Martinez, J.; Kotarba, J.; Andreu, V.; Ruiz, N.; Savini, F.; Stella, L.; Didierjean, C.; et al. Enhancing the Antimicrobial Activity of Alamethicin F50/5 by Incorporating N-terminal Hydrophobic Triazole Substituents. Chemistry 2017, 23, 17964-17972. [CrossRef] [PubMed]

30. Ladokhin, A.S.; Jayasinghe, S.; White, S.H. How to measure and analyze tryptophan fluorescence in membranes properly, and why bother? Anal. Biochem. 2000, 285, 235-245. [CrossRef] [PubMed]

31. Killian, J.A.; Keller, R.C.A.; Struyve, M.; De Kroon, A.; Tommassen, J.; De Kruijff, B. Tryptophan fluorescence study on the interaction of the signal peptide of the Escherichia coli outer membrane protein PhoE with model membranes. Biochemistry 1990, 29, 8131-8137. [CrossRef] [PubMed]

32. Pinheiro da Silva, F.; Aloulou, M.; Skurnik, D.; Benhamou, M.; Andremont, A.; Velasco, I.T.; Chiamolera, M.; Verbeek, J.S.; Launay, P.; Monteiro, R.C. CD16 promotes Escherichia coli sepsis through an FcR gamma inhibitory pathway that prevents phagocytosis and facilitates inflammation. Nat. Med. 2007, 13, 1368-1374. [CrossRef] [PubMed]

33. Svenson, J.; Karstad, R.; Flaten, G.E.; Brandsdal, B.-O.; Brandl, M.; Svendsen, J.S. Altered activity and physicochemical properties of short cationic antimicrobial peptides by incorporation of arginine analogues. Mol. Pharm. 2009, 6, 996-1005. [CrossRef] [PubMed] 
34. Bisello, A.; Sala, S.; Tonello, A.; Signor, G.; Melotto, E.; Mammi, S.; Peggion, E. Conformation and interactions of all-D-, retro-all-D- and retro-bombolitin III analogues in aqueous solution and in the presence of detergent micelles. Int. J. Biol. Macromol. 1995, 17, 273-282. [CrossRef]

35. Basuroy, K.; Karuppiah, V.; Shamala, N.; Balaram, P. The Structural Characterization of Folded Peptides Containing the Conformationally Constrained $\beta$-Amino Acid Residue $\beta^{2,2} \mathrm{Ac}_{6}$ c. Helv. Chim. 2012, 95, 2589-2603. [CrossRef]

36. Sabatini, S.; Gosetto, F.; Manfroni, G.; Tabarrini, O.; Kaatz, G.W.; Patel, D.; Cecchetti, V. Evolution from a natural flavones nucleus to obtain 2-(4-Propoxyphenyl)quinoline derivatives as potent inhibitors of the S. aureus NorA efflux pump. J. Med. Chem. 2011, 54, 5722-5736. [CrossRef] [PubMed]

37. Denèfle, T.; Boullet, H.; Herbi, L.; Newton, C.; Martinez-Torres, A.C.; Guez, A.; Pramil, E.; Quiney, C.; Pourcelot, M.; Levasseur, M.D.; et al. Thrombospondin-1 Mimetic Agonist Peptides Induce Selective Death in Tumor Cells: Design, Synthesis, and Structure-Activity Relationship Studies. J. Med. Chem. 2016, 59, 8412-8421. [CrossRef] [PubMed]

Sample Availability: Sample of the compound $\mathbf{1 1}$ is available from the authors.

(C) 2019 by the authors. Licensee MDPI, Basel, Switzerland. This article is an open access article distributed under the terms and conditions of the Creative Commons Attribution (CC BY) license (http://creativecommons.org/licenses/by/4.0/). 